The Federal Reserve BanK of Kansas City Research Working Papers

Productivity, Congested Commuting, and Metro Size

Jordan Rappaport

January 2016

RWP 16-03

http://dx.doi.org/10.18651/RWP2016-03 


\title{
Productivity, Congested Commuting, and Metro Size*
}

\author{
Jordan Rappaport \\ Federal Reserve Bank of Kansas City
}

January 2016

\begin{abstract}
The monocentric city model is generalized to a fully structural form with leisure in utility, congested commuting, and the equalizing of utility and perimeter land price across metros. Exogenous and agglomerative differences in total factor productivity (TFP) drive differences in metro population, radius, land use, commute time, and home prices. Quantitative results approximate observed correspondences among these outcomes across U.S. metros. Traffic congestion proves the critical force constraining population. Self-driving cars significantly increase the sensitivity of metro population to productivity. Population becomes less responsive to increases in productivity as metros become larger. Correspondingly, the productivity "cost" of metro population - the TFP required to support a given population - increases convexly with size. Benchmark estimates suggest that agglomerative productivity suffices to support increases in population from low levels, allowing chance to play a significant role in determining which locations with sufficient exogenous TFP develop into small metros. But agglomerative productivity falls considerably short of supporting increases in population from high levels, suggesting that large metros arise from strong "fundamentals" such as high exogenous TFP.
\end{abstract}

JEL classifications: R12, R41, J22

Keywords: City Size, Commuting, Congestion, Land Use, Time Use, Self-Driving Cars

\section{Introduction}

The size of U.S. metros varies widely. The New York City metro in 2000 had population 17.6 million and land area 3,400 square miles. Portland, by population the 25th largest metro in 2000, had population 1.6 million and land area 540 square miles. Trenton, the 100th largest metro, had population 340 thousand and land area 168 square miles. Among the 100 largest metros, populationweighted mean density ranged from 1,700 to 34,000 per square mile. Among commuters driving to the central business district (CBD) in these metros, the 98th percentile straight-line distance from

${ }^{*}$ The views expressed herein are those of the author and do not necessarily reflect the views of the Federal Reserve Bank of Kansas City or the Federal Reserve System. Thank you to David Albuoy, Edward Coulson, Gilles Duranton, Cecile Gaubert, Steve Gibbons, Jeffrey Lin, Roberto Pinheiro, and Kenneth Small for advice and feedback. Maeve Maloney and Daniel Molling provided excellent research assistance. Available for free download at https://dx.doi.org/10.18651/RWP2016-03. 
residence to workplace ranged from 10 to 53 miles. Among the same group, the 95 th percentile commute time ranged from 23 to 90 minutes.

From the perspective of economic theory, these differences can arise from only three sources: variation in metros' productivity, variation in metros' consumption amenities, and variation in topographic constraints such as mountains and water. In this context, productivity should be broadly interpreted as anything that makes firms willing to pay higher prices for identical inputs and so encompasses characteristics such as business taxes, regulation, and zoning (Rosen, 1979; Roback 1982). Consumption amenities should be analogously interpreted as anything that makes residents willing to accept a lower numeraire wage and pay higher prices for identical housing and other non-traded goods and so encompasses taxes that fall on individuals.

This paper focuses on the case when variations in metro total factor productivity (TFP), either exogenous or agglomerative, drive differences in metro size while abstracting from variations in consumption amenities other than traffic congestion. To do so, I generalize the standard monocentric city (Alonso, 1964; Mills, 1967; Muth, 1969) to a fully structural form with leisure as a source of utility and commuting that is subject to congestion. I then embed this model of internal metro structure in a system-of-cities framework. Perfect mobility equalizes utility within and across metros. The value of land for non-metro use equalizes its perimeter price across metros.

Plausible variations in metros' TFP imply quantitative correspondences among metros' population, radius, commute time, and a number of other outcomes that approximate those within and across U.S. metros except for the very largest ones. Parameterizations and assumptions that decrease the explicit or implicit demand for land, such as higher elasticities to substitute away from land in housing production and from housing in utility, increase the responsiveness of metro population to productivity. Similarly, parameterizations and assumptions that implicitly increase the supply of land that is accessible for metro use, such as more highway provision, increase the responsiveness of population to productivity. Traffic congestion proves the most important force quantitatively constraining metro size. Self-driving cars, by increasing the leisure content of commute time and decreasing demand for parking, significantly boost the size of metros with high productivity and significantly depress the size of metros with low productivity.

Unless commuting remains uncongested, population becomes considerably less responsive to differences in productivity as metros become larger. This concave correspondence of population with respect to productivity implies that the "cost" of metro population - the TFP required to support a given level - increases convexly with population. Correspondingly, the elasticity of required TFP with respect to population increases with population.

Under the baseline parameterization, the required elasticity to support increases in the population of small monocentric metros lies below typical estimates of agglomerative elasticity, the TFP benefit of metro population. This suggests that chance, such as the chronological order of settlement, plays a significant role in determining which locations with sufficient exogenous TFP develop into small metros and which remain agricultural or unsettled. For example, Bleakley and Lin (2010) 
document that locations along early nineteenth-century portages between navigable rivers remain a statistically-significant, quantitatively-meaningful determinant of variations in population density almost two centuries after such proximity is likely to have conferred a productivity advantage.

In contrast, the productivity required to support a large monocentric metro considerably exceeds what can be attained from agglomeration. This suggests that strong "fundamentals," such as high exogenous TFP, play a significant role in supporting large size. For example, Rappaport and Sachs (2003) argue that a coastal location continued to significantly boost productivity during the late twentieth century in the U.S., even after extensively controlling for historical channels that might account for this. More generally, the implausibly high productivity required to support monocentric metros with the population of the very largest U.S. ones suggests that monocentricity must give way to polycentricity for a metro to grow very large.

The remainder of the paper is structured as follows: Section 2 presents the empirical motivation. Sections 3 and 4 lay out and parameterize the model. Section 5 presents baseline quantitative results. Section 6 describes alternative scenarios, which build intuition and give insight into the determinants of metro size. Section 7 describes the increasing marginal productivity cost of metro population and the resulting equilibrium, where realized TFP equals required TFP.

\section{Empirical Motivation}

The Office of Management and Budget, using data from the 2000 decennial census, delineated 922 Core Based Statistical Areas (CBSA) in 2003. Of these, 362 had a population of at least 50 thousand and so were labeled "metropolitan." (The remainder were labeled "micropolitan.") The CBSA delineations were constrained to be combinations of whole counties and so ended up including significant land area that was essentially agricultural or undeveloped. A modified version of the CBSA delineations, which includes only census tracts with a population density of at least 500 persons per square mile or an employment density of at least 1000 workers per square mile, typically captures more than four fifths of CBSAs' population while excluding more than four fifths of their land area (Rappaport, 2014).

Table 1 shows a partial ranking of the 210 resulting metropolitan areas with a population of at least 100 thousand. As will be described below, the highlighted metros-Denver, Portland, Omaha, and Des Moines - roughly conform to the monocentric stylization and so are used to calibrate the quantitative model.

The metro population density variables are constructed by weighting the "raw" density of each census tract by its population and so describe the distribution of density as experienced by residents (Glaeser and Kahn, 2004; Rappaport, 2008a). The commute distance and time variables are constructed based on driving flows during the morning rush hour to a workplace within the central business district (CBD). ${ }^{1}$ The CBD is delineated as the union of census tracts with an employment

\footnotetext{
${ }^{1}$ The Census Transportation Planning Package 2000 reports tract-to-tract commuting flows and a number of
} 


\begin{tabular}{|c|c|c|c|c|c|c|c|c|c|c|c|c|}
\hline \multirow[t]{3}{*}{ Rank } & \multirow[t]{3}{*}{ Metro } & \multirow[t]{3}{*}{ Population } & \multirow{3}{*}{$\begin{array}{l}\text { Land } \\
\text { Area } \\
\text { (sq.mi) }\end{array}$} & \multicolumn{3}{|c|}{$\begin{array}{l}\text { Pop Density } \\
\text { (pers/sq.mi) }\end{array}$} & \multicolumn{3}{|c|}{$\begin{array}{c}\text { Commute Distance } \\
\text { to } \mathrm{CBD} \text { (miles) }\end{array}$} & \multicolumn{3}{|c|}{$\begin{array}{l}\text { Commute Time } \\
\text { to } \mathrm{CBD} \text { (minutes) }\end{array}$} \\
\hline & & & & \multirow[t]{2}{*}{ mean } & \multicolumn{2}{|c|}{ pctile } & \multirow[t]{2}{*}{ mean } & \multicolumn{2}{|c|}{ pctile } & \multirow[t]{2}{*}{ mean } & \multicolumn{2}{|c|}{ pctile } \\
\hline & & & & & 90 & 98 & & 90 & 98 & & 90 & 95 \\
\hline & VERY LARGE & & & & & & & & & & & \\
\hline 1 & New York City & $17,621,000$ & 3,420 & 33,900 & 95,000 & 158,300 & 11.1 & 23.3 & 37.2 & 41 & 75 & 90 \\
\hline 2 & Los Angeles & $12,181,000$ & 1,890 & 12,400 & 23,600 & 39,500 & 9.7 & 19.2 & 27.5 & 30 & 50 & 60 \\
\hline \multirow[t]{2}{*}{3} & Chicago & $8,557,000$ & 2,530 & 10,300 & 26,300 & 42,500 & 12.0 & 24.9 & 33.0 & 37 & 60 & 73 \\
\hline & LARGE & & & & & & & & & & & \\
\hline 4 & Philadelphia & $5,157,000$ & 1,880 & 8,800 & 23,500 & 34,900 & 8.7 & 16.2 & 23.0 & 32 & 50 & 59 \\
\hline $\begin{array}{l}5 \\
:\end{array}$ & Miami & $4,862,000$ & 1,200 & 7,000 & 12,500 & 23,300 & 10.0 & 17.2 & 24.6 & 33 & 52 & 59 \\
\hline 11 & Boston & $3,957,000$ & 1,820 & 8,351 & 21,707 & 41,414 & 8.4 & 18.6 & 28.5 & 32 & 54 & 61 \\
\hline \multirow[t]{2}{*}{12} & Atlanta & $3,405,000$ & 2,160 & 2,586 & 4,729 & 8,762 & 11.8 & 22.4 & 27.4 & 33 & 53 & 60 \\
\hline & $\underline{\text { MEDIUM }}$ & & & & & & & & & & & \\
\hline 13 & Phoenix & $2,942,000$ & 930 & 5,400 & 9,300 & 12,900 & 9.7 & 16.2 & 21.3 & 29 & 45 & 51 \\
\hline $\begin{array}{c}14 \\
:\end{array}$ & Seattle & $2,760,000$ & 1,060 & 4,900 & 8,600 & 15,800 & 9.1 & 18.4 & 26.9 & 26 & 43 & 50 \\
\hline 21 & Denver & $1,965,000$ & 600 & 5,400 & 9,100 & 15,900 & 6.7 & 12.5 & 15.1 & 25 & 40 & 45 \\
\hline $\begin{array}{c}25 \\
:\end{array}$ & Portland & $1,606,000$ & 540 & 4,700 & 7,800 & 11,500 & 6.9 & 12.3 & 15.0 & 24 & 38 & 44 \\
\hline 36 & New Orleans & $1,164,000$ & 390 & 6,700 & 13,000 & 19,400 & 6.7 & 11.0 & 30.3 & 26 & 43 & 52 \\
\hline \multirow[t]{2}{*}{37} & Indianapolis & $1,150,000$ & 550 & 3,200 & 5,700 & 8,600 & 8.1 & 13.6 & 18.0 & 25 & 35 & 38 \\
\hline & SMALL & & & & & & & & & & & \\
\hline 38 & Buffalo & 997,000 & 430 & 5,300 & 11,500 & 16,100 & 6.7 & 11.7 & 14.9 & 22 & 31 & 34 \\
\hline $\begin{array}{c}39 \\
:\end{array}$ & Charlotte & 970,000 & 710 & 2,100 & 4,000 & 6,800 & 8.0 & 14.4 & 20.2 & 27 & 40 & 43 \\
\hline 57 & Omaha & 606,000 & 230 & 4,100 & 6,600 & 8,900 & 6.0 & 11.0 & 13.1 & 19 & 28 & 30 \\
\hline 93 & Des Moines & 344,000 & 160 & 3,400 & 6,200 & 7,700 & 5.2 & 9.0 & 15.6 & 18 & 24 & 30 \\
\hline 119 & Port St Lucie FL & 264,000 & 190 & 1,900 & 3,100 & 4,900 & - & - & - & - & - & - \\
\hline \multirow[t]{2}{*}{120} & Winston NC & 252,000 & 210 & 1,700 & 3,000 & 4,400 & 4.8 & 8.2 & 10.2 & 17 & 22 & 26 \\
\hline & VERY SMALL & & & & & & & & & & & \\
\hline 121 & Rockford IL & 248,000 & 120 & 3,300 & 6,500 & 6,900 & 4.0 & 6.5 & 12.8 & 17 & 26 & 33 \\
\hline 122 & Visalia CA & 244,000 & 100 & 4,000 & 6,800 & 9,500 & 4.1 & 9.2 & 21.4 & 14 & 21 & 25 \\
\hline $\begin{array}{c}123 \\
:\end{array}$ & Boulder CO & 242,000 & 120 & 4,200 & 9,100 & 13,400 & 5.4 & 12.5 & 14.7 & 17 & 28 & 31 \\
\hline 208 & Abilene TX & 102,000 & 48 & 2,795 & 4,126 & 5,773 & - . & - & - & - & - & - \\
\hline 209 & Springfield OH & 102,000 & 62 & 2,975 & 5,277 & 8,493 & 2.5 & 4.0 & 11.9 & 14 & 19 & 22 \\
\hline 210 & Tuscaloosa AL & 100,000 & 72 & 2,300 & 4,200 & 7,600 & - & - & - & - & - & - \\
\hline Botto & m 10 (mean) & 104,000 & 45 & 1,462 & 2,591 & 3,470 & 2.5 & 3.8 & 5.6 & 13 & 18 & 20 \\
\hline \multicolumn{13}{|c|}{ Ratio to Bottom 10: } \\
\hline \multicolumn{2}{|l|}{ NYC } & 169 & 75 & 23 & 37 & 46 & 4.5 & 6.1 & 6.6 & 3.2 & 4.3 & 4.5 \\
\hline \multicolumn{2}{|c|}{ Max Excluding VL\&L } & 28 & 24 & 8 & 13 & 18 & 4.2 & 4.8 & 9.5 & 2.3 & 2.6 & 2.6 \\
\hline
\end{tabular}

Table 1: U.S. Metros in 2000. Metros are constructed as the combination of CBSA tracts with population density of at least 500 per square mile or employment density of at least 1000 per square mile. Means and percentiles are population weighted. Commute distances and times are based on driving flows during the morning rush hour to a tract-of-work that is part of the CBD. Missing values reflect unavailable data. The four highlighted metros serve as benchmarks for the quantitative model. 
density of at least 8,000 workers per square mile and that are within 5 miles of the Google Maps centroid of the metro's principle city (Rappaport, 2014). Holian and Kahn (2012) show that the Google Maps centroids typically correspond closely to subjective judgments of "downtown."

The bottom rows summarize several of the many dimensions along which metro size varies. Excluding the "very large" and "large" metros (the twelve with population more than 3 million), population varies by a multiplicative factor of 28 and land area, by a multiplicative factor of 24 . Mean population density and the density of the most crowded residential tracts respectively vary by factors of 8 and 18. The distance and drive time of longer commutes to the CBD respectively vary by factors of 10 and 3. Plausible differences in metro TFP allow the quantitative model to approximate this variation across "medium," "small," and "very small" U.S. metros as well as the additional variation from including the large metros.

In contrast, the model falls short of approximating the additional variation from including the very large U.S. metros. For the population of a monocentric metro to exceed about 5 million requires implausibly high $\mathrm{TFP}$ in order to compensate for heavily congested commuting. This inability makes sense as Denver, population 2 million, was the largest metro that roughly conformed to the monocentric stylization in 2000 .

Several criteria are used to identify the highlighted metros and a number others as roughly monocentric (Rappaport, 2014). In each metro, the CBD is required to account for at least a moderate share of total employment and a moderately high share of employment in agglomerative occupations. Each metro can have no more than two employment sub-centers (in addition to the CBD), as identified by McMillen and Smith (2003). And each must have experienced moderate positive population growth from 1970 to 2000, both for the entire metro as well as for the principle city portion of it. This excludes metro areas whose housing stock and infrastructure are especially likely to reflect historical rather than contemporary residence and employment patterns. Table 2 gives some summary statistics for the four highlighted metros used to calibrate the model as well as for three other medium metros that meet these criteria - Sacramento, Columbus, and Indianapolis.

Calibrating a monocentric city model requires recognizing that actual metros, to the extent that they are circular, typically span considerably less than $360^{\circ}$ (Rappaport, 2014). I calculate an angle of occupancy, $\theta$, for each of the seven metros that reconciles its land area with a proxy for its empirical radius such that, $\theta / 360^{\circ}=$ area $/ \pi r^{2}$. The radius proxy is constructed as the 98 th percentile distance commute of people who drive by car to work in the CBD plus an inferred radius of the CBD based on its share of metro land area. ${ }^{2}$ The implied angles vary considerably, only a small portion of which can be accounted for by the topographic constraints identified in Saiz (2010). Understanding why this is so is left for future research.

For quantitative purposes, it is necessary to normalize metros' empirical population to a com-

related decennial census variables retabulated by place of work.

${ }^{2}$ For Des Moines I use the $97 \mathrm{th}$ percentile commute distance, 10.3 miles, because of the especially large gap between it and the 98th percentile distance, 15.6 miles. 


\begin{tabular}{|c|c|c|c|c|c|c|c|}
\hline & Denver & Portland & $\begin{array}{l}\text { Sacra- } \\
\text { mento }\end{array}$ & $\begin{array}{r}\text { Colum- } \\
\text { bus }\end{array}$ & $\begin{array}{l}\text { Indian- } \\
\text { apolis }\end{array}$ & Omaha & $\begin{array}{c}\text { Des } \\
\text { Moines }\end{array}$ \\
\hline population & $1,970,000$ & $1,610,000$ & $1,560,000$ & $1,260,000$ & $1,150,000$ & 610,000 & 340,000 \\
\hline land area & 600 sqmi & $540 \mathrm{sqmi}$ & $530 \mathrm{sqmi}$ & $560 \mathrm{sqmi}$ & $550 \mathrm{sqmi}$ & $230 \mathrm{sqmi}$ & $160 \mathrm{sqmi}$ \\
\hline CBD land area & $16.3 \mathrm{sqmi}$ & 13.8 sqmi & $10.0 \mathrm{sqmi}$ & $14.2 \mathrm{sqmi}$ & $5.2 \mathrm{sqmi}$ & $3.7 \mathrm{sqmi}$ & $3.6 \mathrm{sqmi}$ \\
\hline$\underline{\text { radius }}$ & $\underline{18.1 \mathrm{mi}}$ & $\underline{17.8 \mathrm{mi}}$ & $\underline{25 \mathrm{mi}}$ & $\underline{17.8 \mathrm{mi}}$ & $\underline{19.9 \mathrm{mi}}$ & $\underline{15.0 \mathrm{mi}}$ & $\underline{13.0 \mathrm{mi}}$ \\
\hline 98th pctile commute & $15.1 \mathrm{mi}$ & $15.0 \mathrm{mi}$ & $21.5 \mathrm{mi}$ & $15.0 \mathrm{mi}$ & $18.0 \mathrm{mi}$ & $13.1 \mathrm{mi}$ & $10.3 \mathrm{mi}^{*}$ \\
\hline $\mathrm{CBD}$ radius & $3.0 \mathrm{mi}$ & $2.8 \mathrm{mi}$ & $3.4 \mathrm{mi}$ & $2.8 \mathrm{mi}$ & $1.9 \mathrm{mi}$ & $1.9 \mathrm{mi}$ & $2.7 \mathrm{mi}$ \\
\hline span of occupancy & $211^{\circ}$ & $195^{\circ}$ & $97^{\circ}$ & $204^{\circ}$ & $159^{\circ}$ & $117^{\circ}$ & $111^{\circ}$ \\
\hline $180^{\circ}$ population & $1,670,000$ & $1,480,000$ & $2,890,000$ & $1,110,000$ & $1,310,000$ & 930,000 & 560,000 \\
\hline quantitative equiv pop & $1,580,000$ & $1,410,000$ & $2,660,000$ & $1,060,000$ & $1,370,000$ & $1,000,000$ & 530,000 \\
\hline
\end{tabular}

Table 2: Benchmark Monocentric Metros. (Values are for 2000) The CBD radius is inferred from its land area relative to that of the metro. The $180^{\circ}$ population proportionally scales actual metro population to a semicircular span of occupancy. The quantitative equivalent additionally normalizes population to the assumed 2.4 mile CBD radius in the quantitative model. *Des Moines' population is normalized using the 97th percentile distance rather than the 98th because of the large discrete jump (5.3 miles) between the two.

mon span of occupancy. As the monocentric model is typically implemented linearly, without any circumferential component such as arterial commutes, it cannot match empirical outcomes arising from differences in span. Table 2 includes the population level of each metro normalized to span a semicircle as well as further normalized to have a CBD radius of 2.4 miles. The normalized radius, which is within the range of observed values of the seven metros, implies that population exactly equals 1 million for a quantitative "anchor" metro calibrated to match Omaha.

\section{Model}

The model integrates several literatures. The monocentric city framework (Alonso, 1964; Mills, 1967; Muth, 1969) serves as its core. The time-use and transportation literatures (e.g., Becker, 1965; Small, Winston, and Yan, 2005; Small and Verhoef, 2007) serve to micro-found the opportunity cost of commuting. The transportation literature additionally serves to endogenize commuting congestion. The resulting model of a single monocentric city is embedded in a system of metros, across which perfect mobility equalizes utility and the return to capital (Rosen, 1979; Roback 1982). Land's value in non-metro use similarly equalizes the perimeter price of metro land. Quantitative results within and across metros approximately match a wide range of observed outcomes, sharply contrasting with previous wide misses when approximating a single metro (e.g., Muth, 1975; Arnott and MacKinnon, 1977; Sullivan, 1983, 1986). 


\subsection{Setup}

The setup is static and so should be interpreted as a long-run steady state. A system of monocentric metros is composed of a "closed" anchor metro, $m=A$, with exogenous population and radius and an indefinite number of "open" metros, $m \in\{B, C, D, \ldots\}$, with endogenous population and radius. The anchor metro establishes a reservation utility that must be attained by residents in all other metros and a reservation price of land that must be at least matched at the perimeter of all other metros. It also serves as the main basis for calibrating the model. Remaining metros differ in their total factor productivity, both exogenous and agglomerative. ${ }^{3}$

Each metro consists of a central business district with fixed radius, $\widehat{d}_{0}$, and an endogenous number of concentric rings, indexed by $j \in\left\{1,2, \ldots, J_{m}\right\}$, surrounding it. ${ }^{4}$ Each ring, except for the outermost one, has predetermined width, $\widehat{\widetilde{d}}_{j}$. Workers drive to a place-of-work on the border of the CBD, where they combine with capital and land inputs to produce a numeraire good. Capital combines with the land in each residential ring to produce housing services. In order to better match observed land use, metros may exogenously span less than a full circle, $\widehat{\theta}_{m} \leq 360^{\circ}$. Figure 1 illustrates for a generic metro (with metro subscript suppressed).

\subsection{Production}

Numeraire production, which takes place exclusively in the CBD (ring 0), is Cobb Douglas in land, capital, and aggregate labor hours. Each factor is paid its marginal product,

$$
\begin{aligned}
& X_{m}=A_{X, m} L_{m, 0}^{\alpha_{L}} K_{m, 0}^{\alpha_{K}} N_{m}^{1-\alpha_{L}-\alpha_{K}} \\
& r_{m, 0}^{L}=\frac{\partial X_{m}}{\partial L_{m, 0}} \quad r_{m, 0}^{K}=\frac{\partial X_{m}}{\partial K_{m, 0}} \quad w_{m}=\frac{\partial X_{m}}{\partial N_{m}}
\end{aligned}
$$

Capital in the CBD is determined residually by achieving an exogenously-specified required rent, $r_{m, 0}^{K}=\widehat{r}^{K}$. Aggregate labor hours are the sum of labor hours supplied by residents in each residential ring, $j$,

$$
N_{m}=\sum_{j=1}^{J_{m}} P O P_{m, j} \cdot n_{m, j}
$$

Housing in each residential ring is produced with constant elasticity of substitution between land and capital, with each factor being paid its marginal revenue product

$$
H_{m, j}=A_{H, m}\left(\eta_{L} \frac{\sigma_{m, j}-1}{\sigma_{L}}+\left(1-\eta_{L}\right) K_{m, j}^{\frac{\sigma_{L}-1}{\sigma_{L}}}\right)^{\frac{\sigma_{L}}{\sigma_{L}-1}}
$$

\footnotetext{
${ }^{3}$ Larson and Yezer (2015) independently develop a similar quantitative system of monocentric metros. The present setup adds internal metro structure to the quantitative systems in Rappaport (2008a, 2008b). A companion paper, Rappaport (2014), focuses on the internal structure of the closed, anchor metro. Metros described as "open" more typically use exogenously-specified utility and perimeter land price. But utility is ordinal and quantitative prices are measured in ambiguous numeraire units. For this reason, openness based on matching exogenous utility and perimeter land price better corresponds to a solution strategy than to model structure.

${ }^{4}$ Modeling urban land use as discrete is standard in rich quantitative specifications of the Alonso-Muth-Mills framework (e.g., Muth, 1975; Arnott and MacKinnon, 1977; Sullivan, 1983, 1986).
} 


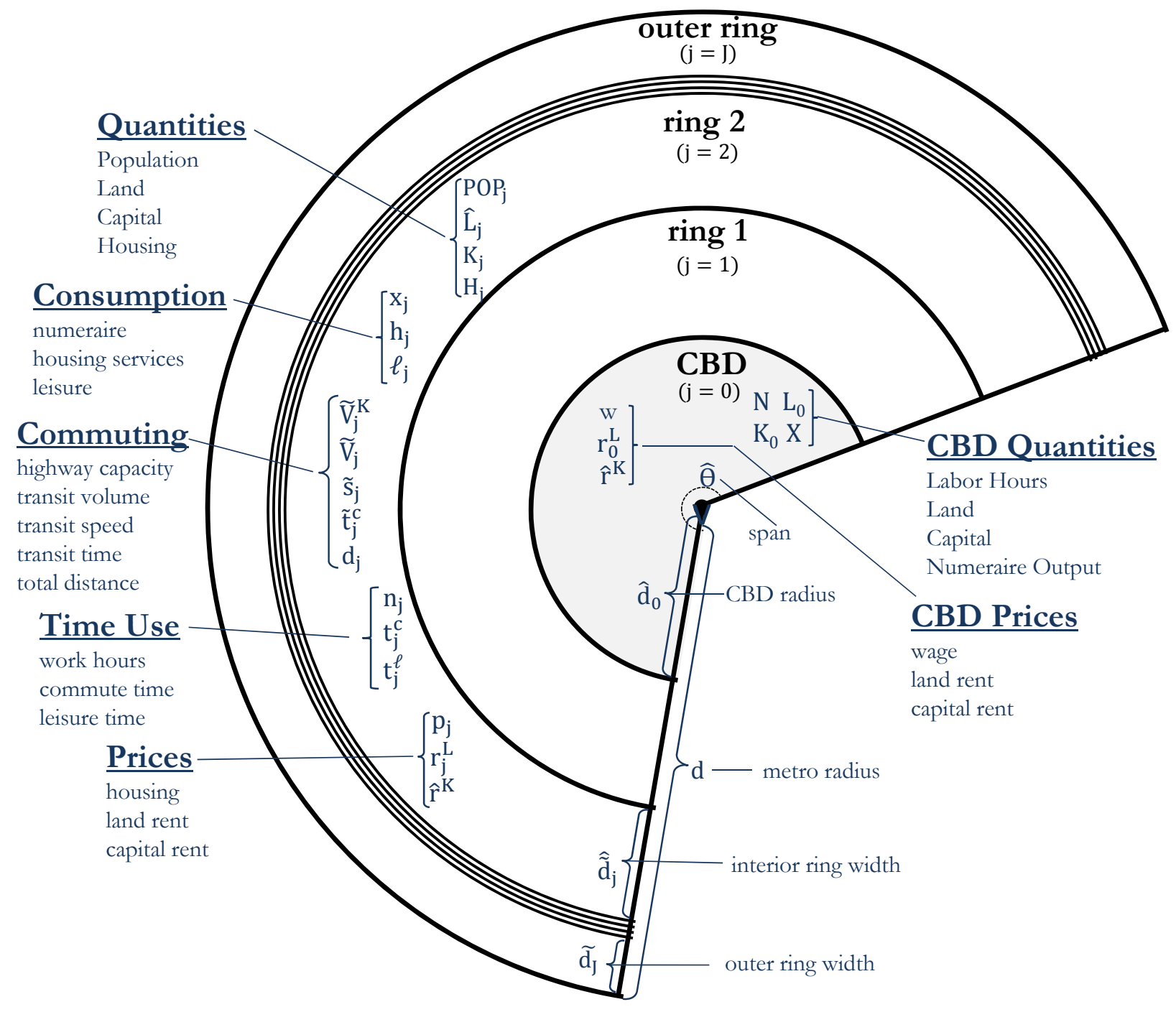

Figure 1: Internal Metro Structure. Residents of metro $m$ live in rings $j \in\left\{1,2, \ldots, J_{m}\right\}$ and commute to work radially from the outer border of their ring to the border of the CBD. Decorative hats denote a variable that is exogenous. Decorative tildes denote a variable that applies to commuters passing through a ring. The number of rings and the width of the outermost one are determined endogenously. The widths of interior rings are exogenous. 


$$
r_{m, j}^{L}=p_{m, j} \cdot \frac{\partial H_{m, j}}{\partial L_{m, j}} \quad r_{m, j}^{K}=p_{m, j} \cdot \frac{\partial H_{m, j}}{\partial K_{m, j}}
$$

The capital input can be interpreted as structure. As in the CBD, the quantity of capital in each ring is residually determined such that $r_{m, j}^{K}=\widehat{r}^{K}$.

For both types of production, factor payments to land and capital are paid to absentee owners. As described in Section 6, alternatively rebating non-labor factor income significantly dampens the responsiveness of metro population to TFP.

\subsection{Individuals}

Individuals derive utility from housing, numeraire, and leisure with nested constant elasticity of substitution,

$$
\begin{aligned}
& U_{m, j}^{h x}=\left(\eta_{h}\left(h_{m, j}\right)^{\frac{\sigma_{h}-1}{\sigma_{h}}}+\left(1-\eta_{h}\right)\left(x_{m, j}\right)^{\frac{\sigma_{h}-1}{\sigma_{h}}}\right)^{\frac{\sigma_{h}}{\sigma_{h}-1}} \\
& U_{m, j}=\left(\eta_{\ell}\left(\ell_{m, j}\right)^{\frac{\sigma_{\ell}-1}{\sigma_{\ell}}}+\left(1-\eta_{\ell}\right)\left(U_{m, j}^{h x}\right)^{\frac{\sigma_{\ell}-1}{\sigma_{\ell}}}\right)^{\frac{\sigma_{\ell}}{\sigma_{\ell}-1}}
\end{aligned}
$$

This reduces to a standard non-nested form when the two elasticities of substitution, $\sigma_{h}$ and $\sigma_{\ell}$, equal each other. It further simplifies to Cobb Douglas when they both equal 1.

Including leisure in utility allows for the elastic supply of labor hours and micro-founds the negative effect of commute time on wellbeing. Most monocentric city models instead assume that labor is supplied inelastically and that commute time decreases disposable income at some fraction of the wage rate. The latter discount is motivated by surveys finding that workers' marginal willingness to pay (MWTP) to shorten their commute time is below their after-tax wage rate. A natural interpretation is that individuals derive some leisure content from commuting, for example listening to the radio or talking on their cell phone. I make this interpretation explicit by letting leisure sum together time explicitly devoted to it and leisure accumulated while commuting. An advantage of this approach is that MWTP can be modeled as increasing as commute congestion worsens: leisure content is surely lower, perhaps even negative, when stuck in traffic. ${ }^{5}$

$$
\ell_{m, j}=t_{m, j}^{\ell}+\ell_{m, j}^{c}
$$

Let disposable income, $y_{m, j}^{d}$, be total wage income less numeraire commute costs; let $d_{m, j}$ denote the distance of each one-way commute; and let $\delta$ denote the per mile numeraire cost of commuting. Then,

$$
y_{m, j}^{d}=w_{m} \cdot n_{m, j}-\delta \cdot d_{m, j} \cdot \text { trips }
$$

\footnotetext{
${ }^{5}$ The only monocentric city models of which I am aware that explicitly include leisure in utility are Arnott and MacKinnon (1977), Fujita (1989), and Duranton and Puga (2015). In a macro context, McGrattan, Rogerson, and Wright (1997) combine a consumption hybrid and leisure in the outer nesting of a CES utility function. Their innermost nesting, market consumption and home production, seems especially relevant to a monocentric city setup that models the utility of households rather than individuals. More typically, macro models assume a reduced-form specification in which utility includes a separable component that decreases with hours worked.
} 
Individuals face the numeraire budget constraint that their consumption expenditure not exceed their disposable income. Similarly, they face the time constraint that the sum of their weekly work hours, commute hours, and leisure-time hours not exceed total weekly hours less some minimum time for necessities such as sleeping and eating. The excluded minimum time, $\widehat{t}^{z}$, can be interpreted as a Stone-Geary minimum level of leisure.

$$
\begin{gathered}
x_{m, j}+p_{m, j} \cdot h_{m, j} \leq y_{m, j}^{d} \\
n_{m, j}+t_{m, j}^{c} \cdot \operatorname{trips}+t_{m, j}^{\ell} \leq 24 \cdot 7-\widehat{t}^{z}
\end{gathered}
$$

Individuals choose the consumption bundle, $\left\{x_{m, j}^{*}, h_{m, j}^{*}, \ell_{m, j}^{*}\right\}$, that equates the marginal utility relative to price for each of numeraire, housing, and leisure consumption,

$$
\partial U_{m, j} / \partial x_{m, j}=\frac{\left(\partial U_{m, j} / \partial h_{m, j}\right)}{p_{m, j}}=\frac{\left(\partial U_{m, j} / \partial \ell_{m, j}\right)}{w_{m}}
$$

\subsection{Commuting}

Individuals drive directly from the outer perimeter of their residential ring to the outer perimeter of the CBD. Commute distance is simply the sum of the ring widths through which a commuter must pass, $d_{m, j}=\sum_{i=1}^{j} \widetilde{d}_{m, i}$.

Traffic slows drive speed. Let $\widetilde{V}_{m, j}^{K}$ denote highway capacity through a residential ring and $\widetilde{V}_{m, j}$ denote the volume of commuters driving through the ring,

$$
\widetilde{V}_{m, j}=\sum_{i=j}^{J_{m}} P O P_{m, i}
$$

Feasible speed decreases from a "free-flow" upper-bound, $\widehat{s}^{f}$, as volume increases relative to capacity according to a standard formula (Small and Verhoef, 2007),

$$
\frac{1}{\widetilde{\widetilde{s}}_{m, j}}=\frac{1}{\widehat{s}^{f}} \cdot\left(1+a \cdot\left(\frac{\widetilde{V}_{m, j}}{\widetilde{V}_{m, j}^{K}}\right)^{b}\right) \quad a, b>0
$$

Speed is additionally constrained by lower and upper bounds, $s^{\min }$ and $s^{\max }$. The former might be interpreted as capturing unmodeled alternative modes of transport likely to be available in the large metros where it binds. The latter gives the calibration an extra degree of freedom, which considerably improves its fit to observed commute times.

$$
\widetilde{s}_{m, j}=\max \left(\min \left(\widetilde{\widetilde{s}}_{m, j}, s^{\max }\right), s^{\min }\right)
$$

Highway capacity is modeled as depending on commute volume according to,

$$
\widetilde{V}_{m, j}^{K}=\widehat{V} \cdot\left(\frac{\widetilde{V}_{m, j}}{\widehat{V}}\right)^{\sigma_{V}} \quad 0 \leq \sigma_{V} \leq 1
$$


The term $\widehat{V}$ is the flow at which road capacity equals commute volume. Higher values of $\widehat{V}$ imply a larger volume of commuters can be accommodated before congestion sets in. The term $\sigma_{V}$ is the elasticity of highway capacity with respect to volume. Parameterizing $\sigma_{V}$ to equal 1 implies that speed is constant. Parameterizing it to equal 0 implies that highway capacity is constant. Speed falls off more rapidly with metro population as $\sigma_{V}$ decreases.

The time to commute through a ring, $\widetilde{t}_{m, j}^{c}$, is just the width of the ring divided by the speed through it. Total commute time sums a fixed time component with the cumulative time to pass through each required residential ring.

$$
t_{m, j}^{c}=\widehat{t}^{c}+\sum_{i=1}^{j} \widetilde{t}_{m, i}^{c}
$$

Anecdotes suggest that people dislike traffic congestion. To capture this, I allow the leisure content of commuting to increase with speed. Total leisure from commuting sums together the leisure derived while passing through each ring.

$$
\ell_{m, j}^{c}=\sum_{i=1}^{j} \lambda\left(\widetilde{s}_{m, i}\right) \cdot \widetilde{t}_{m, i}^{c} \quad \lambda^{\prime}(s) \geq 0
$$

\subsection{Model Closure}

The model is first solved for the anchor metro, $A$, which has exogenous radius and total population. The exogenous radius implies that the number of interior rings, which have pre-determined width, and the width of the outermost ring are exogenous as well. The exogenous population implies an adding-up condition over the population in each ring,

$$
\sum_{j=1}^{\widehat{J}_{A}} P O P_{A, j}=\widehat{P O P}_{A}
$$

Equilibrium in the anchor metro requires that utility must be equal across rings. This can be written as requiring utility in the second through outermost ring of the anchor metro to equal utility in its innermost ring.

$$
U_{A, j}=U_{A, 1} \quad \forall\{j\} \in\left\{2,3, \ldots, J_{A}\right\}
$$

In addition, the land and housing markets in each ring must clear. Land market clearing, in the sense of matching demand to its fixed supply in each ring, follows from the constant-returnsto-scale production of housing, (3), together with paying land its marginal revenue product, (4). For housing services, clearing requires that,

$$
H_{m, j}=P O P_{m, j} \cdot h_{m, j}
$$

If all structural parameters were known, the anchor-metro equilibrium could be solved as an exactly-identified system of $4 \cdot J_{A}$ equations and unknowns. Optimal housing consumption and 
leisure values, $\left\{h_{A, j}^{*}\right\}$ and $\left\{\ell_{A, j}^{*}\right\}$, correspond to (10) and account for $2 \cdot J_{A}$ equations. The price of housing that equates supply and demand in each ring, $\left\{p_{A, j}\right\}$, corresponds to (18) and accounts for $J_{A}$ equations. The population in each ring that satisfies utility equalization, $\left\{P O P_{A, j}\right\}$, corresponds to (17a) and accounts for $J_{A}-1$ equations. Lastly, population adding up, (16), which determines the shared level of utility, accounts for 1 equation. Optimal numeraire consumption, $\left\{x_{A, j}^{*}\right\}$, is then implied residually. In practice, I solve the anchor system together with 4 additional equations to calibrate the weighting parameters, $\left\{\eta_{L}, \eta_{h}, \eta_{\ell}\right\}$ and the per mile numeraire cost of commuting, $\delta$.

The solution to the system of equations for the anchor metro gives the cardinal level of utility there, $U_{A}$, and the numeraire price of land in its outermost ring, $r_{A, J_{A}}^{L}$. These must be matched in each open metro. The sequential nature of the solution lets the anchor values be interpreted as pre-determined when solving for open metros.

$$
\begin{array}{cc}
U_{m, j}=\widehat{U}=U_{A} & \forall\{m\} \in\{B, C, D, \ldots\} \\
r_{m, J_{m}}^{L}=\widehat{r}_{J}^{L}=r_{A, J_{A}}^{L} & \forall\{m\} \in\{B, C, D, \ldots\}
\end{array}
$$

The system of equations for each open metro encompasses $4 \cdot J_{m}+1$ equations and unknowns. Compared to the anchor-metro system, open-metro utility equalization swaps in (17b) for (17a) $\left(J_{m}\right.$ equations rather than $J_{A}-1$ equations). The population adding up constraint is dropped (0 rather than 1 equation). The number of residential rings and the width of the outermost one, $\widetilde{d}_{m, J_{M}}$, is pinned down by the required perimeter land price equalization, (19) (1 additional equation). The determination of optimal housing and leisure and the price of housing services remain unchanged (3. $J_{m}$ equations).

The number of rings of each open metro, $J_{m}$, is determined iteratively. I first solve for an open metro with candidate $I$ residential rings, all of which have a default width including the outermost one. To do so, I use the open system of equations excluding the land-price matching one. If the price of land in the outermost ring exceeds the price of land in the outermost ring of the anchor

metro, $r_{m, I}^{L}>r_{A, J_{A}}^{L}$, I solve for a candidate metro with $I+1$ residential rings. If $r_{m, I}^{L}<r_{A, J_{A}}^{L}$, I set $J_{m}=I$ and re-solve, letting the width of the outermost ring solve the perimeter matching requirement.

\section{Parameterization}

The model requires assigning values to a large number of structural parameters. The population and radius of the anchor metro are set to match normalized equivalents for Omaha. Several key parameters are set to estimates from existing literature. Others are calibrated by requiring a moment of the anchor metro to exactly match a moment in aggregate U.S. data. Lastly, the parameters governing highway provision are jointly calibrated to the correspondences between commute time 
and commute distance in Omaha, Des Moines, Portland, and Denver. Section 6 describes the sensitivity of outcomes to key parameter choices.

\subsection{Population and Geography}

Baseline parameter values other than those for commuting are shown in Table 3. Values of the weighting parameters in housing production and utility- $\eta_{L}, \eta_{h}$, and $\eta_{\ell}$-lack inherent interpretation and so are not reported.

The anchor metro is normalized to span $180^{\circ}$, which is within the range of the seven metros described in Table 2. Its outer commute is set to 13.1 miles, the 98th percentile commute distance of Omaha residents who drive to work in Omaha's CBD. The anchor metro's CBD radius is set to 2.4 miles, the distance that normalizes Omaha's population to 1 million. Quantitative results are nearly identical with a fixed CBD radius of 1 mile.

The width of the innermost ring is set to 0.1 miles. This short distance implies a similar commute time regardless of congestion. Widths of subsequent interior rings taper up, partly offsetting the lessening time to pass through each due to increasing speed. The width of the outermost ring, whatever its number, is endogenously determined so that perimeter land price matching holds. Results are largely insensitive to alternative assumed interior widths.

\subsection{Production}

Cobb Douglas production of numeraire requires parameterizing the factor income shares accruing to land, capital, and labor $-\alpha_{L}, \alpha_{K}$, and $1-\alpha_{L}-\alpha_{K}$. The land share is set to 1.6 percent, corresponding to a weighted average of intermediate-input shares across a large number of industries (Jorgenson, Ho, and Stiroh, 2005). ${ }^{6}$ Ciccone (2002) suggests using a nearly identical value to approximate the land share of manufacturing. One third of remaining factor income is assumed to accrue to capital; two thirds is assumed to accrue to labor (Gollin, 2002).

Production of housing services requires calibrating the elasticity of substitution between land and structure, $\sigma_{L}$, and the relative weight on land, $\eta_{L}$. The former is set to 0.90 , consistent with a number of estimates that it lies between 0.5 and 1 (Jackson, Johnson, and Kaserman, 1984; Thorsnes, 1997). Recent research suggests that $\sigma_{L}$ lies at the upper end of this range (Ahlfeldt and McMillen, 2014; Combes, Gobillion, and Duranton, 2016). These estimates are based on prices and attributes of single-family units and lots, many of which are likely to be subject to land use restrictions. As discussed in Section 6, the elasticity of substitution between land and structure using multifamily construction technology is likely to be considerably higher. The weight on land is calibrated such that the population-weighted mean share of housing factor income accruing to land in the anchor metro, $\bar{\mu}_{A}^{L}$, equals 0.35, consistent with Davis and Heathcote (2007). ${ }^{7}$

\footnotetext{
${ }^{6}$ The industry-specific intermediate input estimates, which are not included in the publication, were kindly provided by the authors.

${ }^{7}$ Davis and Heathcote find that between 1975 and 2004, land accounted for an average of 47 percent of the sales
} 


\begin{tabular}{|c|c|c|c|}
\hline Description & Notation & Value/Target & Rationale \\
\hline \multicolumn{4}{|l|}{ Population \& Geography } \\
\hline population (anchor metro) & $P O P_{A}$ & 1 million & $\begin{array}{l}\text { Omaha normalized to } 180^{\circ} \text { and } 2.4 \\
\text { mi CBD radius }\end{array}$ \\
\hline outermost commute (anchor metro) & $d_{A, J}$ & $13.1 \mathrm{mi}$ & Omaha 98th pctile drive to CBD \\
\hline $\mathrm{CBD}$ radius & $\widehat{d}_{0}$ & $2.4 \mathrm{mi}$ & very small loss of generality \\
\hline span of settlement & $\theta$ & $180^{\circ}$ & normalization \\
\hline rings (anchor metro) & $J_{A}$ & 10 & very small loss of generality \\
\hline \multirow{2}{*}{ ring widths except outermost } & $\left\{\tilde{d}_{1}, \ldots, \tilde{d}_{4}\right\}$ & $\{0.1 \mathrm{mi}, 0.4,0.7,1.1\}$ & very small loss of generality \\
\hline & $\left\{\tilde{d}_{5}, \ldots\right\}$ & $\{1.6,1.6,1.6,2,2,2, \ldots\}$ & \\
\hline \multicolumn{4}{|l|}{ Numeraire Production } \\
\hline land factor share & $\alpha_{L}$ & 0.016 & Jorgenson et al. (2005) \\
\hline capital factor share & $\alpha_{K}$ & 0.328 & Jorgenson et al. (2005) \\
\hline required capital rent & $\widehat{r}^{K}$ & 0.05 & no loss of generality \\
\hline \multicolumn{4}{|l|}{ Housing Production } \\
\hline CES, $L$ and $K$ & $\sigma_{L}$ & 0.90 & $\begin{array}{l}\text { Ahlfeldt and McMillen (2014); } \\
\text { Combes, Duranton, and Gobillon } \\
(2016)\end{array}$ \\
\hline weight on land & $\eta_{L}$ & - & $\begin{array}{l}\text { calibrated s.t. mean land factor } \\
\text { share in anchor metro is } 0.35 \\
\text { (Davis and Heathcote, 2007) }\end{array}$ \\
\hline \multicolumn{4}{|l|}{ Utility } \\
\hline $\mathrm{CES}, h$ and $x$ & $\sigma_{h}$ & 0.67 & Albuoy, Ehrlich, and Liu (2014) \\
\hline weight on housing & $\eta_{h}$ & - & $\begin{array}{l}\text { calibrated s.t. mean house expend } \\
\text { share in anchor metro is } 0.17 \\
\text { (housing expend share of market } \\
\text { PCE, avg 1990-2000, U.S. NIPA) }\end{array}$ \\
\hline CES, $h-x$ and $\ell$ & $\sigma_{\ell}$ & 0.34 & $\begin{array}{l}\text { calibrated s.t. Frisch elasticity in } \\
\text { anchor metro inner ring is } 0.20 \\
\text { (Reichling and Whalen, 2012); de- } \\
\text { pends on } \widehat{t}^{z}\end{array}$ \\
\hline weight on leisure & $\eta_{\ell}$ & - & $\begin{array}{l}\text { calibrated s.t. residents in inner } \\
\text { ring of anchor metro choose to } \\
\text { work } 40 \text { hours per week }\end{array}$ \\
\hline weekly time for necessities & $\widehat{t}^{z}$ & $70 \mathrm{hrs}$ & $\begin{array}{l}\text { very small loss of generality with } \\
\text { contingent calibration of } \sigma_{\ell} \text { and } \\
\text { baseline assumption that individ- } \\
\text { uals freely choose their work hours }\end{array}$ \\
\hline
\end{tabular}

Table 3: Non-Commuting Parameterization. Calibrated values of weighting parameters depend closely on model-specific assumptions and lack inherent interpretation. For this reason, they are not reported. 


\section{$4.3 \quad$ Utility}

The utility specification, (5a) and (5b), requires setting values for four key parameters: two elasticities of substitution - which together describe the curvature of the tradeoffs among numeraire, housing, and leisure - and two weights, which pin down the housing expenditure share and leisure time in the anchor metro. The calibrated values for the leisure elasticity and weight depend on the number of hours reserved for necessities.

The elasticity of substitution between housing and the numeraire good, $\sigma_{h}$, is set to 0.67 . This is the preferred value of Albuoy, Ehrlich, and Liu (2014), who report estimates that range from 0.42 to 0.76. Estimates using microdata are typically lower. For example, Li et al. (2015), using simulated method of moments applied to a structural model of life-cycle housing consumption, estimate $\sigma_{h}$ to be 0.32 .

The weight on housing, $\eta_{h}$, is calibrated such that the population-weighted mean consumption expenditure share on housing in the anchor metro, $\bar{\mu}_{A}^{h}$, equals 0.17 . This matches the U.S. aggregate ratio of the sum of nominal rent and owners' equivalent rent relative to nominal market personal consumption expenditures during the 1990s and early 2000s. ${ }^{8}$ As is intuitive, increasing housing's expenditure share and decreasing its substitutability with numeraire each dampen the responsiveness of metro population to TFP.

The calibration of leisure in utility depends closely on the assumed number of weekly hours required for sleep and other necessities, $\widehat{t}^{z}$. This makes sense as $\widehat{t}^{z}$ can be interpreted as a required minimum level of leisure and so affects curvature. I arbitrarily set it to 70 hours, leaving 98 hours to be split among work time, commute time, and leisure time. ${ }^{9}$

The elasticity of substitution between leisure and the numeraire-housing hybrid, $\sigma_{\ell}$, is calibrated such that the compensated elasticity of work hours with respect to wages, the "Frisch elasticity," in the innermost ring of the anchor metro is 0.20 , the central value from a comprehensive survey of estimates by Reichling and Whalen (2012). With $\widehat{t}^{z}$ set to 70, doing so implies setting $\sigma_{\ell}$ to $0.34 .^{10}$

The weight on leisure, $\eta_{\ell}$, is calibrated such that individuals in the innermost ring of the anchor metro choose to work 40 hours per week, $n_{A, 1}=40$, consistent with average market work hours for

value of the aggregate U.S. housing stock. Adjusting for the fact that structures depreciate but land does not brings the land share down to approximately 35 percent.

${ }^{8}$ I exclude commuting expenses from the calculation of the housing expenditure share, $\mu_{m, j} \equiv\left(p_{m, j} \cdot h_{m, j}\right) /\left(x_{m, j}+\right.$ $\left.p_{m, j} \cdot h_{m, j}\right)$. Davis and Ortalo-Magné (2011) report an average housing expenditure share for renter households in 2000 of 0.24 . Their estimate exceeds the present baseline in part because it includes spending on utilities. In addition, demand for housing is thought to have an income elasticity less than one (e.g., Albouy, Ehrlich, and Liu, 2014). Renter households typically have lower income than do homeowner households and so are likely to have a higher housing expenditure share.

${ }^{9}$ There is considerable ambiguity about which uses of time should be interpreted as leisure (Aguiar and Hurst, 2007).

${ }^{10}$ I calibrate $\sigma_{\ell}$ by trial and error. Separately, the Frisch elasticity used here describes the intensive margin of work hours supplied contingent on supplying positive hours. Macro models are more typically calibrated to a reduced-form Frisch elasticity that describes aggregate hours supplied and so includes the extensive margin of participation. The latter, extensive elasticity is typically estimated to be about 2 . 


\begin{tabular}{|c|c|c|c|}
\hline Description & Notation & Value/Target & Rationale \\
\hline \multicolumn{4}{|l|}{ Commuting General } \\
\hline weekly 1 -way commutes & trips & 10 & \\
\hline per mile cost & $\delta$ & - & $\begin{array}{l}\text { calibrated s.t. mean cost to income } \\
\text { in anchor metro is } 0.05 \text { (Albouy } \\
\text { and Lue, 2014) }\end{array}$ \\
\hline leisure content & $\lambda(s)$ & $\begin{array}{l}0.50 @ \geq 50 \mathrm{mph} \text { declines } \\
\text { linearly to } 0 @ \leq 10 \mathrm{mph}\end{array}$ & $\begin{array}{l}\text { Small, Winston, and Yan (2005); } \\
\text { Rizzi, Limonado, and Steimetz } \\
(2012)\end{array}$ \\
\hline \multicolumn{4}{|l|}{ Speed } \\
\hline fixed time & $\widehat{t}^{c}$ & $8 \min$ & calibrated \\
\hline free-flow speed & $\widehat{s}^{f}$ & $70 \mathrm{mph}$ & calibrated \\
\hline maximum speed & $\widehat{s}^{\max }$ & $50 \mathrm{mph}$ & calibrated \\
\hline minimum speed & $\widehat{s}^{\min }$ & $10 \mathrm{mph}$ & arbitrary \\
\hline elasticity, highway capacity to volume & $\sigma_{V}$ & 0.92 & calibrated \\
\hline benchmark highway capacity & $\widehat{V}$ & 77 ths & calibrated \\
\hline speed vs volume technical parameters & $a, b$ & $0.2,10$ & Small and Verhoef (2007) \\
\hline
\end{tabular}

Table 4: Commuting Calibration. Speed parameters are jointly calibrated to fit estimated kernels of time versus distance for commuters who drive to work in the CBDs of Omaha, Des Moines, Portland, and Denver. The calibrated per mile numeraire driving cost has no inherent interpretation and so is not reported.

employed adult males in 1985 and 2003 (Robinson and Godbey, 1999; Aguiar and Hurst, 2007).

Under the baseline assumption that individuals can freely choose the number of hours to work, quantitative results are close to identical across a wide range of assumed values of $\widehat{t}^{z}$. The reason is that the unchanged targets for the Frisch elasticity and weekly work hours require the calibrated values of $\sigma_{\ell}$ and $\eta_{\ell}$ to "adjust" to keep the curvature of utility with respect to leisure exactly unchanged at the consumption bundle in the innermost ring of the anchor metro, $\left\{x_{A, 1}^{*}, h_{A, 1}^{*}, \ell_{A, 1}^{*}\right\}$. For example, as $\widehat{t}^{z}$ is set to values from 0 to 84 , the calibrated value of $\sigma_{\ell}$ increases from 0.26 to 0.39 . This dependence of $\sigma_{L}$ on an arbitrary assumption illustrates a pitfall of interpreting calibrated parameters as structural estimates.

Results also prove relatively insensitive to the targeted Frisch elasticity if individuals can freely choose their workhours.

\subsection{Commuting}

Baseline values of commuting parameters are reported in Table 4. Individuals make ten weekly one-way commutes. The numeraire cost per mile, $\delta$, is set such that the population-weighted mean ratio of commute costs to income in the anchor metro equals 0.05 (Albouy and Lue, 2014).

I set the leisure content of commute time to decline linearly from 0.5 at the calibrated $50 \mathrm{mph}$ 

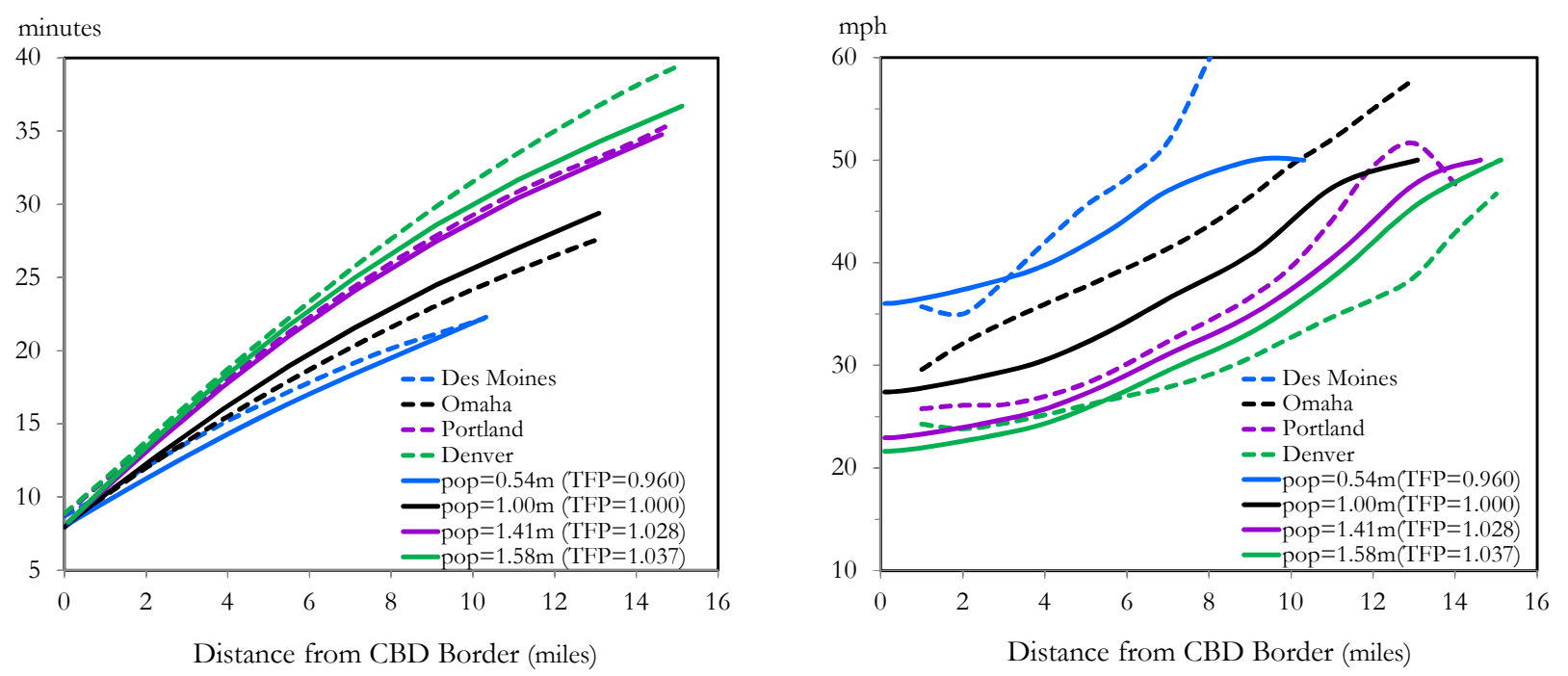

Figure 2: Commute Time and Speed Left panel shows commute time against commute distance from the CBD boundary. The relative TFP levels of the four quantitative metros are chosen to match the normalized population of Des Moines, Omaha, Portland, and Denver. Dashed lines show fitted empirical splines constructed as a worker-weighted regression of drive time on straight-line distance from tract-ofresidence to a tract-of-work in the CBD. Right panel shows the implied driving speed.

speed limit to 0 at an assumed minimum speed of $10 \mathrm{mph}$. A leisure content of 0.5 conforms with numerous estimates based on stated MWTP to shorten commute time (Small and Verhoef, 2007). Zero leisure content is consistent with revealed preference estimates (Small, Winston, and Yan, 2005) along with studies of subjective well being (Krueger et al., 2009). The intuitive decline in leisure content as congestion worsens is consistent with evidence reported in Wardman and Ibáñez (2012) and Rizzi, Limonado, and Steimetz (2012).

I set the parameters governing commute speed to approximate fitted kernels of mean commute time versus straight-line distance of workers who drive during the morning commute to the CBDs of Omaha, Des Moines, Portland, and Denver (Figure 2, left panel). The kernel estimates (dashed lines) are weighted by tract-to-tract flows and so implicitly account for the co-location of residences, workplaces, and highways. As is intuitive, the relationship is concave reflecting faster driving as distance from the CBD increases. The speeds implied by the fitted kernel are shown in the right panel.

The quantitative correspondences of commute time and distance (solid lines) characterize metros with relative TFP that corresponds to the normalized populations of Des Moines, Omaha, Portland, and Denver. TFP for producing housing services, $A_{H, m}$, is assumed to be the same in all metros. TFP for producing numeraire, $A_{X, m}$, is normalized to 1 in the anchor metro, which has population of 1 million. A metro with population equal to the normalized equivalent of Des Moines (530 thousand) requires normalized TFP equal to 0.960. In other words, a metro with numeraire TFP 4 percent below that of the anchor metro will have a population of 530 thousand. Metros 
with population equal to the normalized values of Portland (1.41 million) and Denver (1.58 million) require respective TFP of 1.028 and 1.037 .

The quantitative commute times tightly match their respective empirical kernels. This is especially true for Des Moines and Portland, with quantitative commute times that stay within 1 minute of fitted values. The Omaha quantitative commute eventually lags its empirical kernel by almost 2 minutes. The Denver quantitative commute eventually leads its empirical kernel by almost 3 minutes. These tight fits were achieved, by trial and error, with an elasticity of highway capacity with respect to volume, $\sigma_{V}$, equal to 0.92 and a benchmark capacity of 77 thousand. Lowering the elasticity increases the curvature of commute times. Increasing the benchmark capacity rotates the commute time locus clockwise. ${ }^{11}$

Quantitative outermost commute distances also tightly match their empirical counterparts. By construction, the anchor metro has a 13.1 mile outermost commute, the same as the 98th percentile distance of commuters who drive to the CBD of Omaha. The quantitative outermost commutes for the three remaining metros are determined by the required equalization of perimeter land prices. The match is within a tenth of a mile of the 98th percentile commute of Denver and the 97th percentile commute of Des Moines and falls short of the 98th percentile commute of Portland by two fifths of a mile. ${ }^{12}$

\section{Baseline Quantitative Results}

The quantitative model approximately matches land use-population density gradients and the distance distribution of CBD commuters - of the four metros to which commute speed is calibrated. It also approximately matches the correspondences among population, density, commute times, and commute distances across U.S. metros except for the very largest ones. These approximations of observed outcomes help validate the model's empirical relevance, suggesting that it can give insight into many of the factors determining metro size. ${ }^{13}$

The implausibly high TFP required to support monocentric metros with population of the very largest U.S. metros also helps validate the model's empirical relevance. Results that suggested otherwise - that plausible TFP and wages could motivate several million identical workers to endure long, hyper-congested commutes to a single business district rather than take otherwise identical jobs in less crowded metros - would be worrisome. After all, the largest metro that roughly

\footnotetext{
${ }^{11}$ The estimated kernels imply speeds near the CBD of at least $20 \mathrm{mph}$ and so the baseline $10 \mathrm{mph}$ floor on commute speed is arbitrary. Including it accentuates the effects of alternative scenarios when TFP is very high.

${ }^{12}$ As described in Section 2, I use the 97th percentile commute distance for Des Moines because of the especially large gap between it and the 98th percentile distance.

${ }^{13}$ The approximation of observed outcomes is surprising given the model's many first-order abstractions. Partly it reflects unmodeled forces that "offset" each other. For example, door-to-door radial commutes to a workplace on the perimeter of the CBD help offset the lack of alternative modes of transport, the absence of required space to park cars, and missing non-centralized employment. In addition, the approximations partly reflect empirical estimates that embed unmodeled forces. For example, the external estimates of the elasticity of substitution between land and structure in the provision of housing services are based on single-family units, many of which are subject to land use regulation.
} 

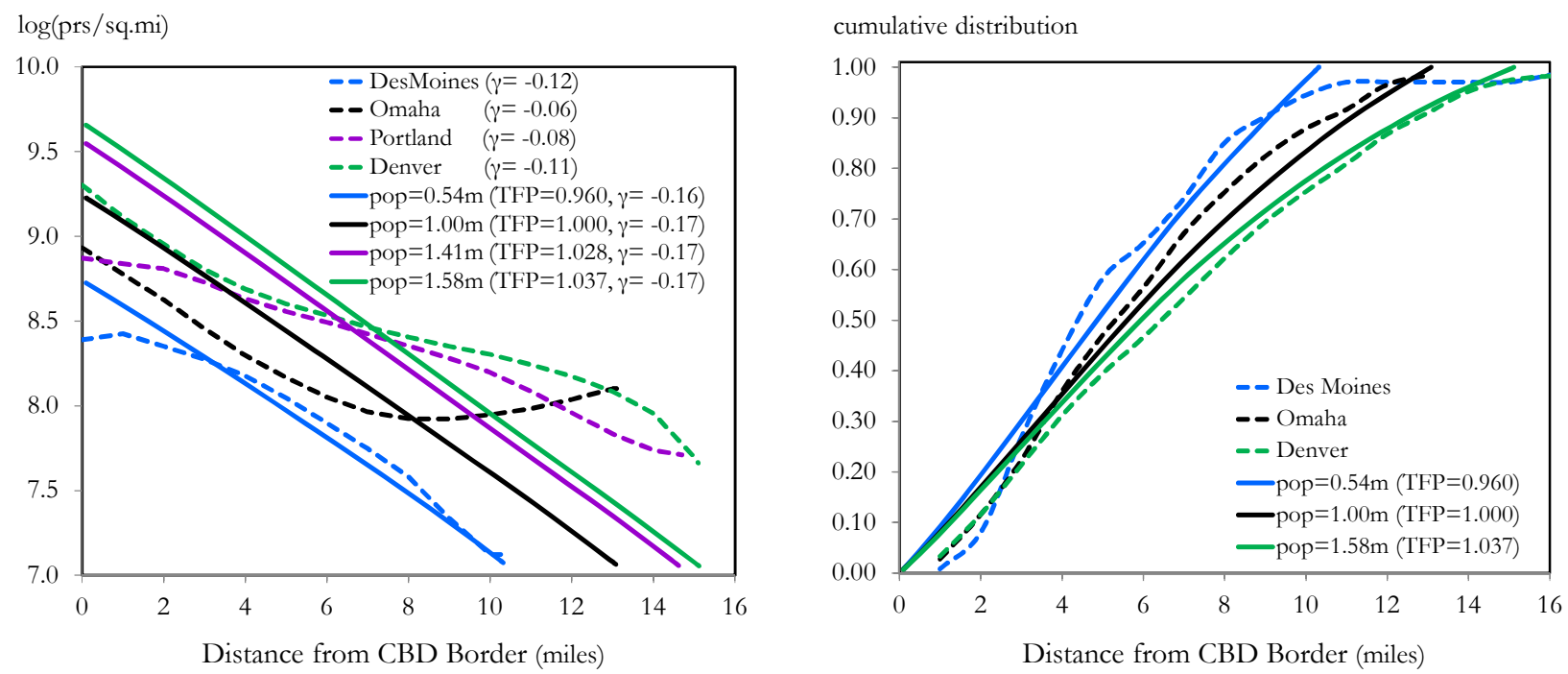

Figure 3: Population Density Gradient and Cumulative Population Distribution. Left panel shows population density against commute distance. The relative TFP levels of the four quantitative metros are chosen to match the normalized population of Des Moines, Omaha, Portland, and Denver. Summary gradient in parentheses, $\gamma$, denotes the slope coefficient from a population-weighted regression of $\log$ density on distance. Dashed lines show corresponding empirical density gradients with distance measured as a straight line from the census tract of residence to the CBD centroid. Right panel shows the quantitative cumulative distribution of population (solid lines) and the empirical cumulative distribution of workers who commute to the CBD by car (dashed lines). Portland is excluded for legibility.

conformed to the monocentric stylization in 2000, Denver, had a population of only 2 million.

\subsection{Metro Land Use}

Population density gradients for metros with population corresponding to Des Moines, Omaha, Portland, Denver are shown in Figure 3 (left panel, solid lines). These are the "same" metros used to calibrate commute speed in the sense that they are generated by the same relative TFP for producing numeriare. As is intuitive, the density gradients shift upward with metro population. Consistent with empirical estimates, they decline at an almost perfectly exponential rate (Anas, Arnott, and Small, 2000; Glaeser and Kahn, 2001). Under the baseline parameterization, they have nearly identical slope, $\gamma$ (listed in parentheses).

Dashed lines show corresponding empirical gradients, based on population-weighted kernel regressions of log tract population density on distance to the CBD centroid. Quantitative population density in the innermost ring of each of the four metros exceeds the maximum of the corresponding kernel by about half a log point. The quantitative gradient for Des Moines closely matches its empirical counterpart beginning about 2 miles away from the CBD. The quantitative gradients for Omaha and Denver match the slope of their counterparts at shorter distances but then turn flatter. The quantitative gradient for Portland is steeper at all distances. The sharper falloff in the quantitative gradients partly reflects the abstractions from land use regulation and decentralized 
employment.

The high quantitative population densities near the CBDs compare more favorably with the right tails of the empirical distributions. For each of the four metros, the 99th percentile quantitative density - which falls in the innermost ring - lies comfortably below the 99th percentile empirical density, with ratios ranging from 0.76 for Des Moines up to 0.96 for Portland. At the 98th percentile - which falls in the second ring - quantitative density remains well below empirical density in Des Moines and Denver and is respectively just 3 and 9 percent above empirical density in Omaha and Portland.

The right panel of Figure 3 shows the quantitative cumulative distribution of population with respect to the distance they live from the CBD (solid lines) and the empirical cumulative distribution of workers who commute by car to the CBD with respect to the straight-line distance between their residence and workplace (dashed lines). The key difference from the density gradients is that these empirical distributions describe only people who work in the CBD.

The quantitative cumulative distributions match the empirical cumulative distributions relatively tightly. To be sure, at near distances the quantitative ones rise significantly more steeply. But beginning about 3 miles from the CBD, the empirical ones catch up and thereafter the corresponding distributions remain quite close. The same holds for Portland, which is excluded from the figure to improve legibility. For Denver, which has the tightest match, the quantitative CDF remains within 4 percentage points of the empirical one from mile 3 through the quantitative perimeter.

Rappaport (2014) more extensively describes land use, commuting, house and land prices, and other outcomes in the anchor metro.

\subsection{Productivity and Metro Size}

The remainder of this section describes the cross-sectional correspondences among TFP, population, population density, and a number of other metro outcomes that arise as numeraire TFP varies from moderately below its anchor level to moderately above it. The correspondences prove mostly intuitive and hold regardless of whether the source of the variation is exogenous or arises from the agglomerative effect of population on productivity.

Figure 4 shows the concave correspondence of population with respect to numeraire TFP. As land area is normalized to a semicircle, metro population at any given TFP can theoretically range from significantly lower to twice as high depending on a metro's span of occupancy. The anchor metro, with normalized unitary TFP and population 1 million, is denoted by the black dot. As TFP falls to 0.95 and then further to 0.90 , population falls to 440 thousand and then to 130 thousand. As TFP rises to 1.05 and then further to 1.10 and 1.15 , population rises to 1.8 million and then to 2.8 million and 4.0 million.

To give some empirical perspective, Albouy (2015) estimates that traded-good productivity among the 210 metros ranked in Table 1 ranged from 20 percentage points below the U.S. national 


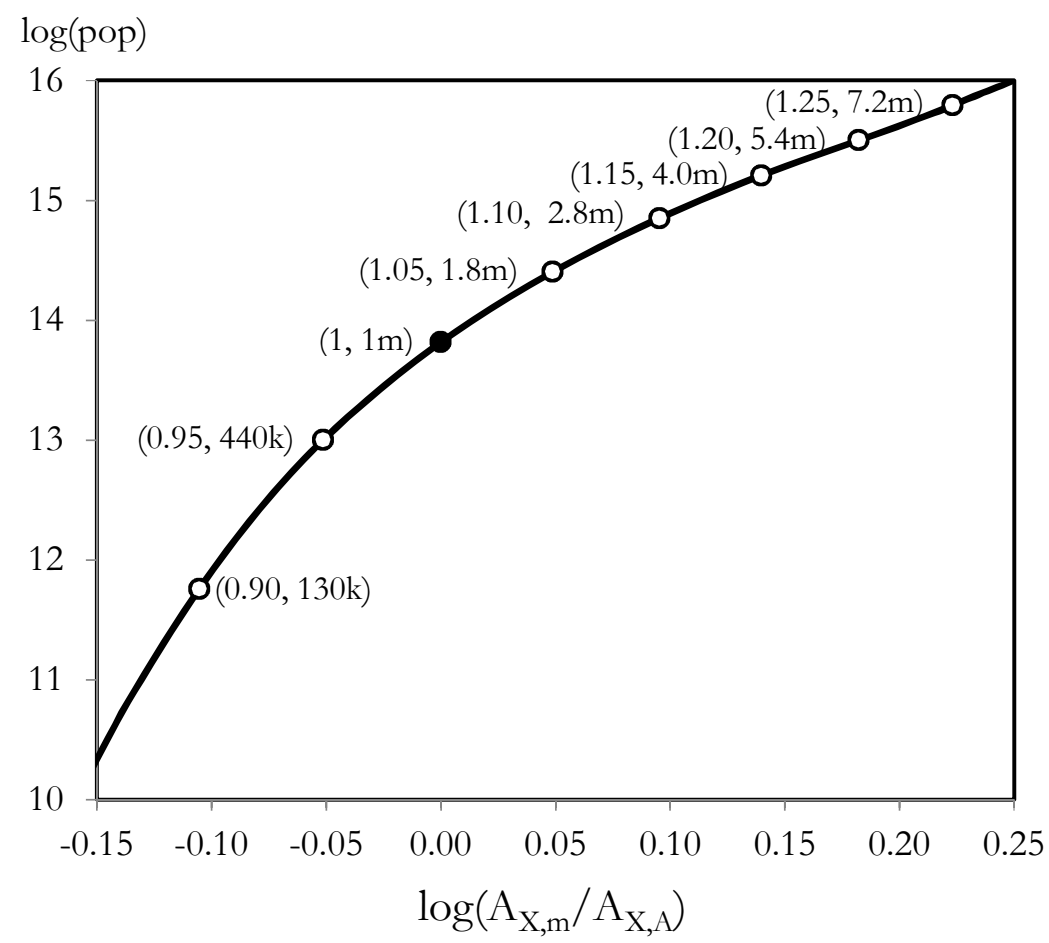

Figure 4: Total Factor Productivity and Population. Figure shows the non-causal correspondence of population with respect to relative TFP in the numeraire sector. Numbers in parentheses are the relative levels of TFP and population.

average to 23 percentage points above it in the New York City metro area and to 34 percentage points above it in the combined San Francisco/San Jose metro area. These estimates are not able to control for unobserved worker heterogeneity, which is likely to account for about half of the variation (Combes and Gobillion, 2015). Hence productivity across U.S. metros in 2000 probably spanned about 30 percentage points (i.e., from least productive to most productive relative to the national average). Aligning Albouy's normalization with the present one suggests that TFP relative to the quantitative anchor, $A_{X, m} / A_{X, A}$, across the 210 metros ranged from about 0.90 to about 1.20 .

Supporting monocentric metros with population of the very largest U.S. metros would require TFP significantly above this upper bound. For example, the Chicago metro would require a relative TFP of 1.25. The Los Angeles and New York City metros would respectively require relative TFP of 1.33 and $1.37 .{ }^{14}$ Wide error bands accompany these exact values, both quantitative and estimated,

\footnotetext{
${ }^{14}$ Albouy estimates (traded-good) TFP in Des Moines and Omaha respectively to be 4 and 8 percentage points below the national average and TFP in Portland and Denver respectively to be 4 and 3 percentage points above the national average. The 42 percentage point difference between Omaha and San Francisco, allowing for unobserved heterogeneity to account for half the variation, implies an upper bound of 1.21 on relative TFP. The differences from the other three metros to San Francisco imply upper bound relative TFP several percentage points lower. Using New York City rather than San Francisco as the most productive metro shifts the upper bounds down by 5 percentage points. The TFP to support Chicago, Los Angeles, and New York City corresponds to that required to support the population of each normalized to span $180^{\circ}$, using their maximal feasible span as a proxy for their actual span. For
} 
and so they should be interpreted with caution. But the key takeaway, that supporting very large monocentric metros requires very high levels of TFP, is likely to be robust.

The concavity of population with respect to TFP arises from the asymptotic curvature of production and utility as land and housing become scarce and so is extremely robust. Metro population density proves similarly concave with respect to TFP in a framework with exogenous land area and no internal structure, including no commuting (Rappaport, 2008a).

Corresponding to the concavity, population becomes increasingly unresponsive to proportional changes in TFP as these increase. The (non-causal) elasticity of population with respect to TFP under the baseline, measured by the slope of the correspondence, decreases from 26 when $\log$ population is 12 (population 160 thousand) to 8 when log population is 15 (population 3.3 million) to a minimum of 6.5 when the assumed $10 \mathrm{mph}$ floor on speed first binds. Without the floor, the population elasticity declines considerably further as population rises.

Increases in population are partly accommodated by concave increases in metro land area (Figure 5, left panel, black line). Land area increases almost one-to-one with increases in population from low levels. But from high population levels, land area increases considerably less than proportionally. Correspondingly, weighted population density remains relatively unchanged as population increases from low levels but then increases proportionately with population from intermediate and high levels (left panel, green line).

The decrease in the responsiveness of land area to population partly reflects geometry, as each additional mile of commute distance adds proportionately less land, and partly reflects worsening traffic congestion, which channels population to increase via infill. Reflecting this infill, mean commute distance remains approximately flat as population increases above its anchor level (right panel, black line). This flatness also characterizes the mean distance of driving commutes to the CBDs of the medium and large metros reported in Table 1.

The worsening congestion is illustrated in Figure 6. Highway provision suffices to keep outermost commute speed equal to its assumed maximum, $50 \mathrm{mph}$, regardless of metro size (left panel, blue line). Commute speed through the innermost residential ring falls increasingly below $50 \mathrm{mph}$ as log population increasingly exceeds 12 (population 160 thousand), hitting $27 \mathrm{mph}$ at the anchor metro population and $14 \mathrm{mph}$ at log population 15 (population 3.3 million)(green line). Mean speed, calculated as aggregate miles driven by aggregate driving time, falls from $50 \mathrm{mph}$ to $33 \mathrm{mph}$ to $14 \mathrm{mph}$ over this population range (black line).

Worsening congestion and the changing distance of commutes together cause mean commute time to increases from 10 minutes to 20 minutes to 33 minutes as log population increases from 12 to its anchor level to 15 (right panel, black line). Outermost commute time increases from 10 minutes to 30 minutes to 54 minutes over the same population range (blue line). These times

example, Saiz estimates that topographical constraints prevent development of 40 percent of the surface area within 50 miles of municipal Chicago. In a circular context, this implies Chicago has a maximum span of $216^{\circ}$ and so its population is normalized down by a multiplicative factor, $\frac{180}{216}$. 

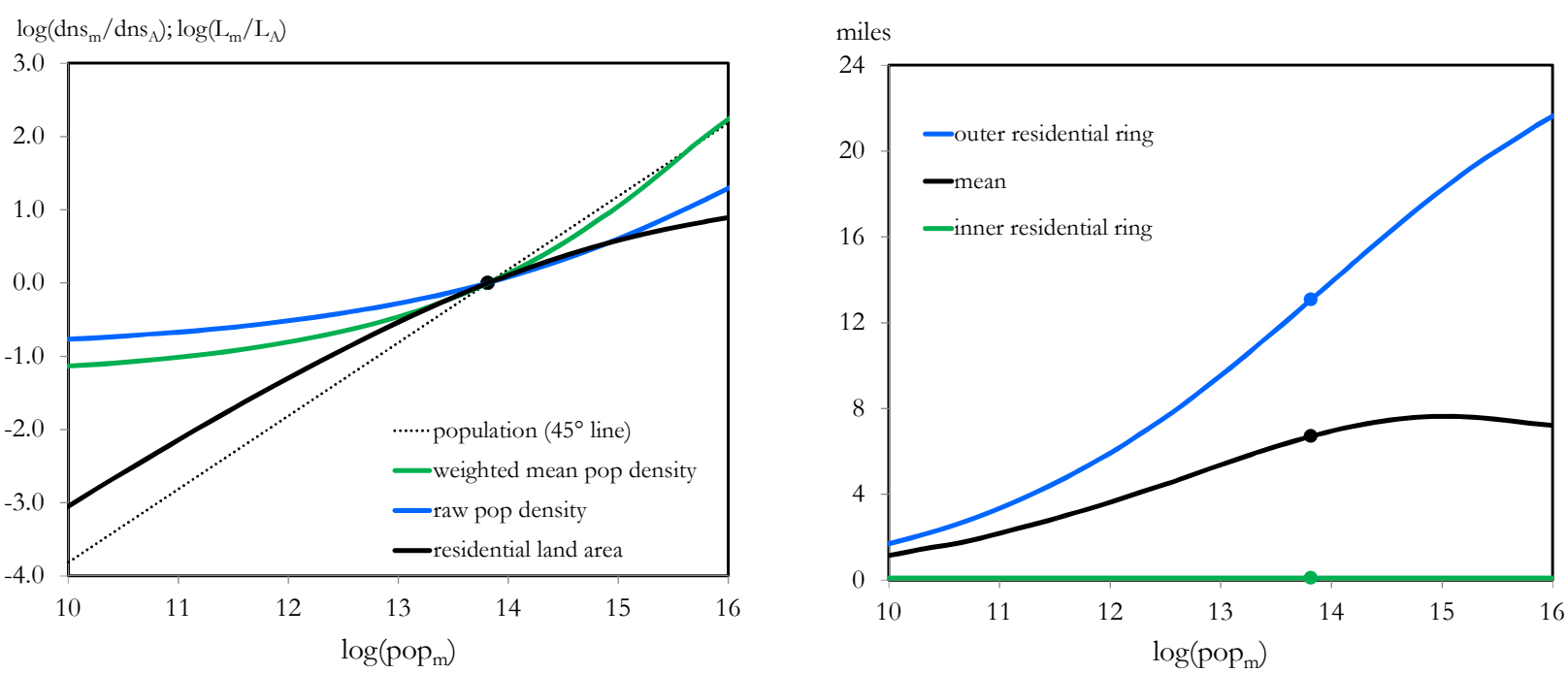

Figure 5: Distance, Density, and Land Area. Left panel shows correspondences of land area, raw population density, and mean population density with metro population. Right panel shows correspondences of inner, mean, and outermost commute distance with metro population. Metro radiuses equal the outermost distance plus 2.4 miles. Markers indicate outcomes in the anchor metro.
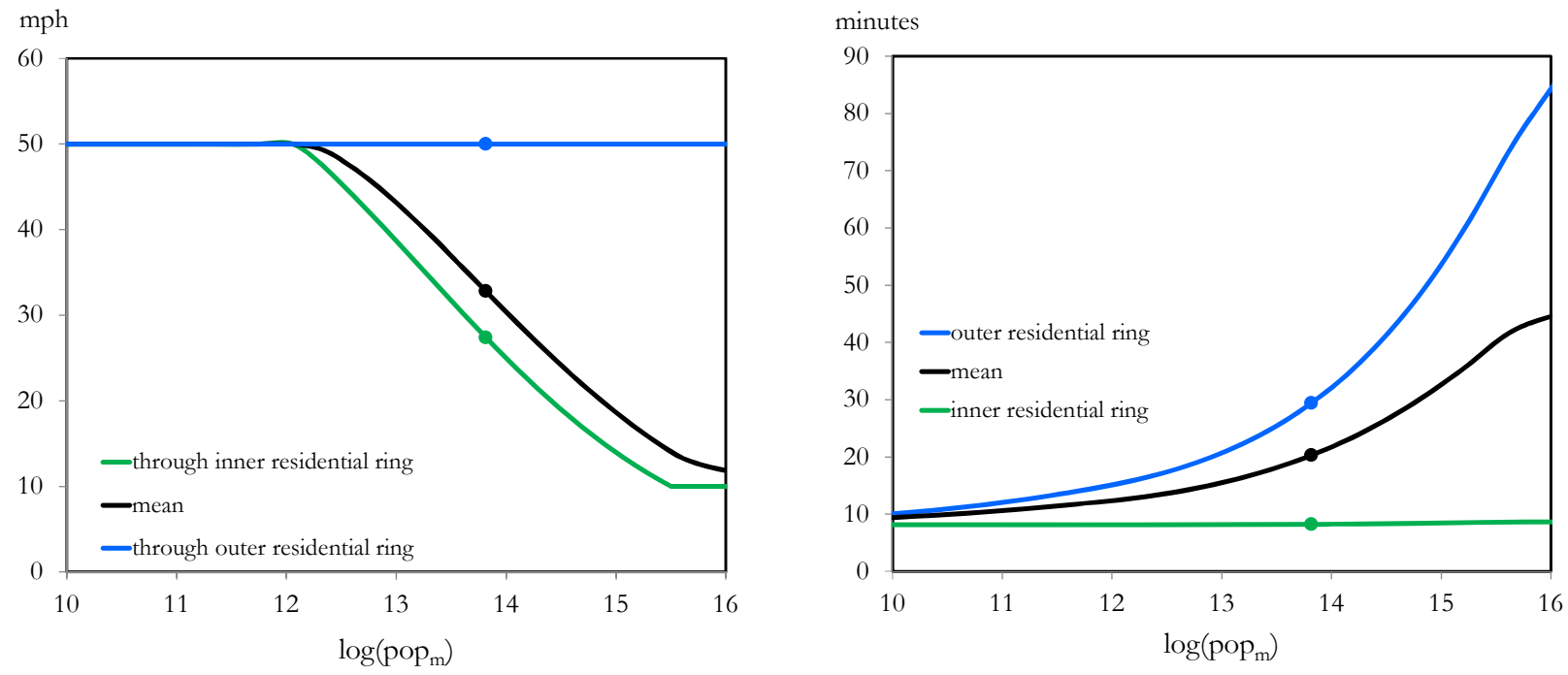

Figure 6: Commute Time and Speed. Left panel shows correspondences of commute speed with metro population. Mean speed is constructed as aggregate commute distance divided by aggregate commute time. Right panel shows correspondences of one-way commute time with metro population. Markers indicate outcomes in the anchor metro.

closely match the range of times reported across the small, medium, and large metros in Table 1.

Unsurprisingly, the price of land varies considerably across metros (Figure 7, left panel). By construction, land price in the outermost residential ring is equal regardless of size (blue line). As log population increases from 12 to 15 (population increases from 160 thousand to 3.3 million), mean land price increases from about one third to about four times its value in the anchor metro 

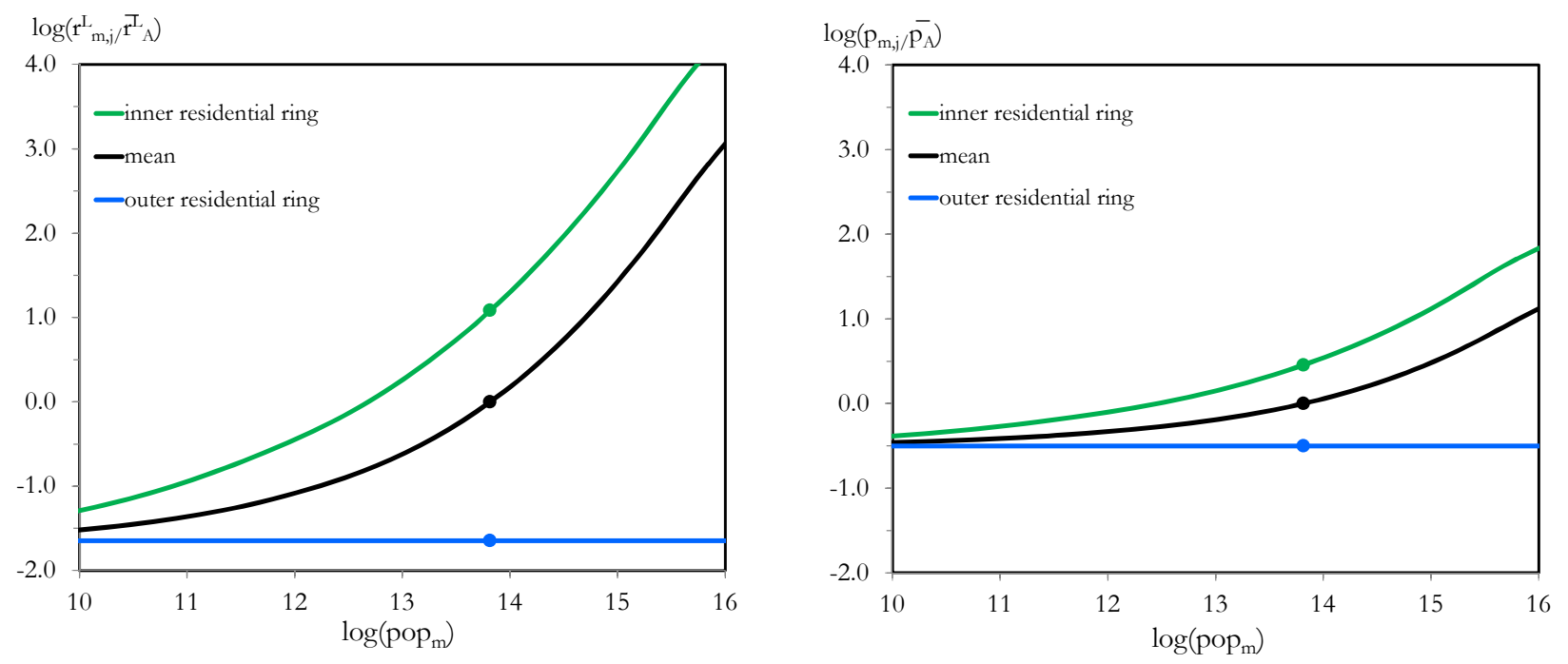

Figure 7: Land and House Prices. Left panel shows correspondences of land prices with metro population. Right panel shows correspondences of housing prices with metro population. Markers indicate outcomes in the anchor metro.

(black line). This range is consistent with Larson (2015), who estimates that the average value of land in a metro with population above 1 million is about four times that of a metro with population less than 1 million. Maximum land price, which occurs in the innermost ring, increases from about two thirds to about 15 times the mean value in the anchor metro (green line).

The price of housing services also varies considerably across metros, but by far less than does the price of land. Because both land and capital prices are the same across outer residential rings, the housing-service price must be equal as well (right panel, blue line). As log population increases from 12 to 15, the mean price of housing services increases from about 0.7 to about 1.6 its value in the anchor metro (black line). This dispersion of rental prices is similar to that reported in Davis and Ortalo-Magné (2011) for 50 medium and large U.S. metros in 2000. Over the same population range, the price of housing services in the inner residential ring rises from about 0.9 to about 3.1 times the mean price in the anchor metro (green line).

Rising prices dampen housing consumption as metros grow larger, with mean and especially inner housing consumption decreasing steeply (Figure 8, left panel, black and green lines). Normalized by mean housing consumption in the anchor metro, mean housing consumption falls from 1.16 at $\log$ population 12 (population 160 thousand) to 0.82 at log population 15 (population 3.3 million). Over the same range, innermost housing consumption falls from 1.00 to 0.52 . In contrast, housing consumption in the outermost ring increases with metro size, contributing to the compensation for longer, more congested commutes (blue line). Mechanically, this reflects higher disposable income in larger metros together with the identical outermost housing price.

The complementarity of housing and numeraire consumption, $\sigma_{h}=0.67$, tempers decreases in housing consumption, with the mean and inner housing expenditure shares increasing as metros 

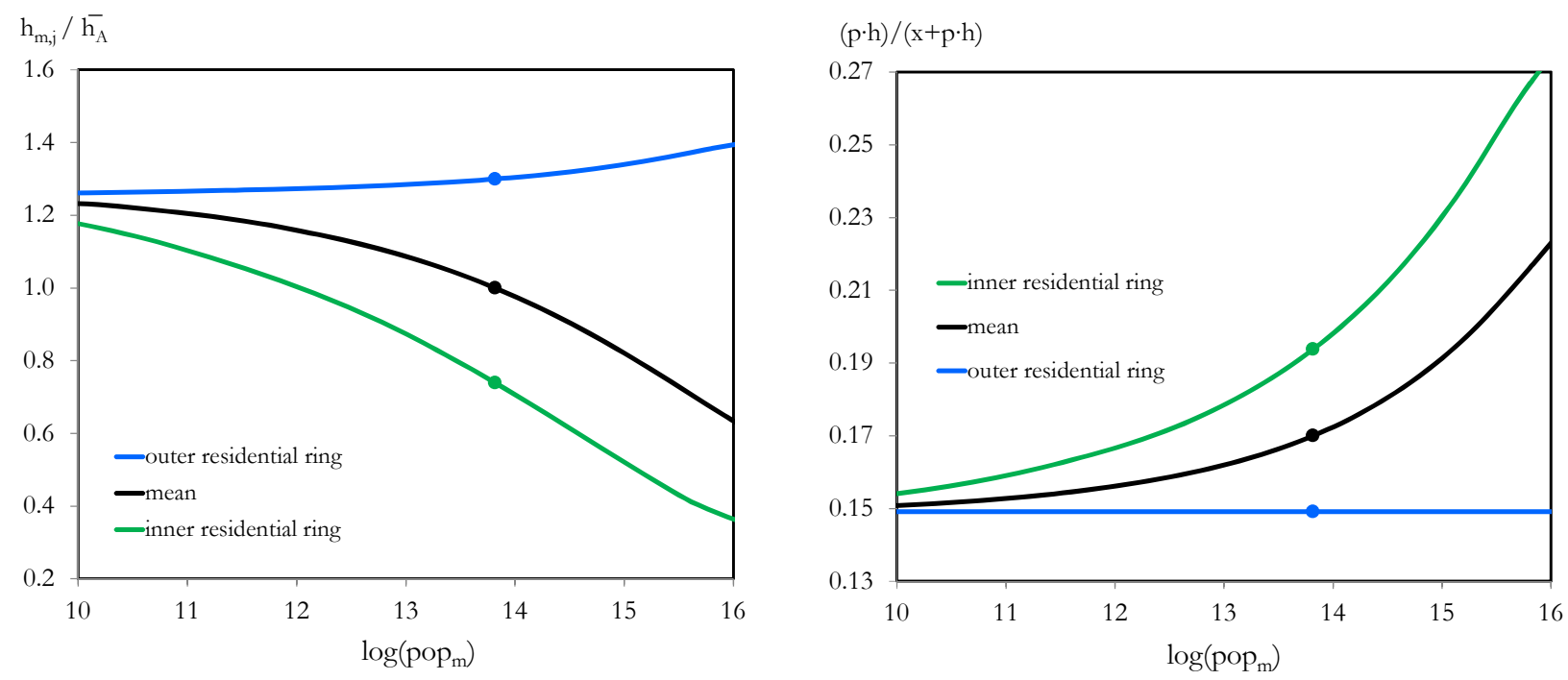

Figure 8: Housing Consumption and Expenditure Share. Left panel shows correspondences of normalized housing consumption with metro population. Right panel shows correspondences of the housing share of consumption expenditure with population. Markers indicate outcomes in the anchor metro.

grow larger (right panel, black and green lines). The model is calibrated to set the mean housing share in the anchor metro to 0.17. As log population increases from 12 to 15, the mean and inner housing expenditure shares respectively increase from 0.16 to 0.19 and from 0.17 to 0.23 . These ranges are within those reported in Davis and Ortalo-Magné (2011).

Leisure decreases only modestly with metro size (Figure 9, left panel). Measured by "hours equivalent," the sum of leisure time and leisure derived from commuting, mean leisure drops from 57 hours equivalent to 56.6 to 56.2 as log population increases from 12 to the anchor level to 15 (black line). Outermost leisure drops from 56.8 hours equivalent to 56.0 to 55.0 over the same range (blue line).

The limited reduction in leisure is made possible by individuals sharply cutting back weekly workhours (Figure 9, right panel). By construction, individuals in the inner ring of the anchor metro choose to supply 40 hours. The default inner-ring commute, 0.1 mile, is sufficiently short that individuals in the inner rings of all other metros also choose to supply very close to 40 hours (green line). For small metros, commutes from all rings remain sufficiently short and leisure content sufficiently high for hours supplied to remain close to 40. But as metros become increasingly large, residents in most rings begin to significantly cut back workhours. As log population increases from its anchor to 15 (population 3.3 million), mean work hours fall from 39.2 to 37.5 (black line); outerring work hours fall off more steeply: from 38.9 to 36.0 (blue line). Choosing to work a 36 -hour workweek is unremarkable upon reinterpreting individuals as households. But most individual fulltime workers lack such flexibility. As described in the next section, constraining individuals to supply 40 hours dampens the population response to productivity by forcing the cost of long, congested commutes to be disproportionately borne by foregoing leisure. 

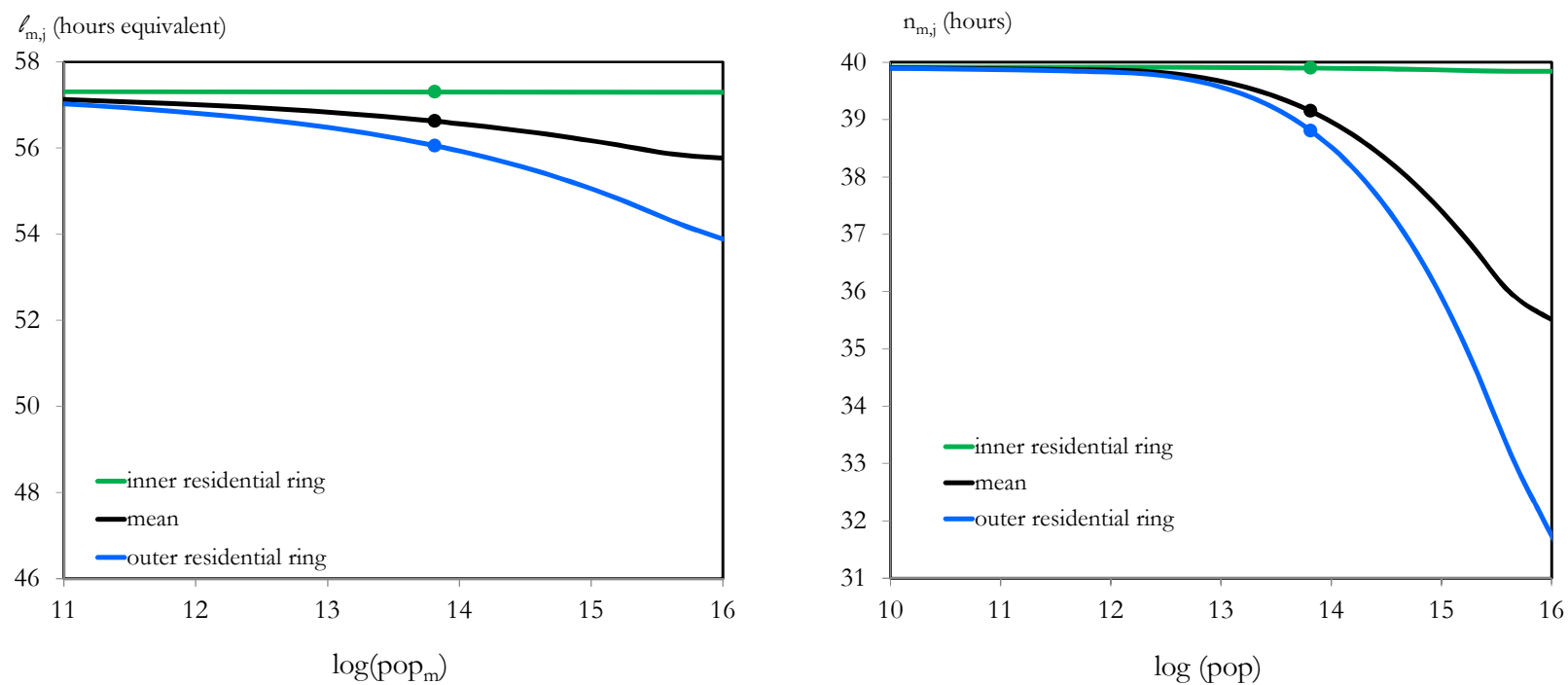

Figure 9: Leisure and Weekly Workhours. Left panel shows correspondences of leisure, the sum of leisure time and leisure from commute time, with population. Right panel shows correspondences of weekly workhours with population. Markers indicate outcomes in the anchor metro.
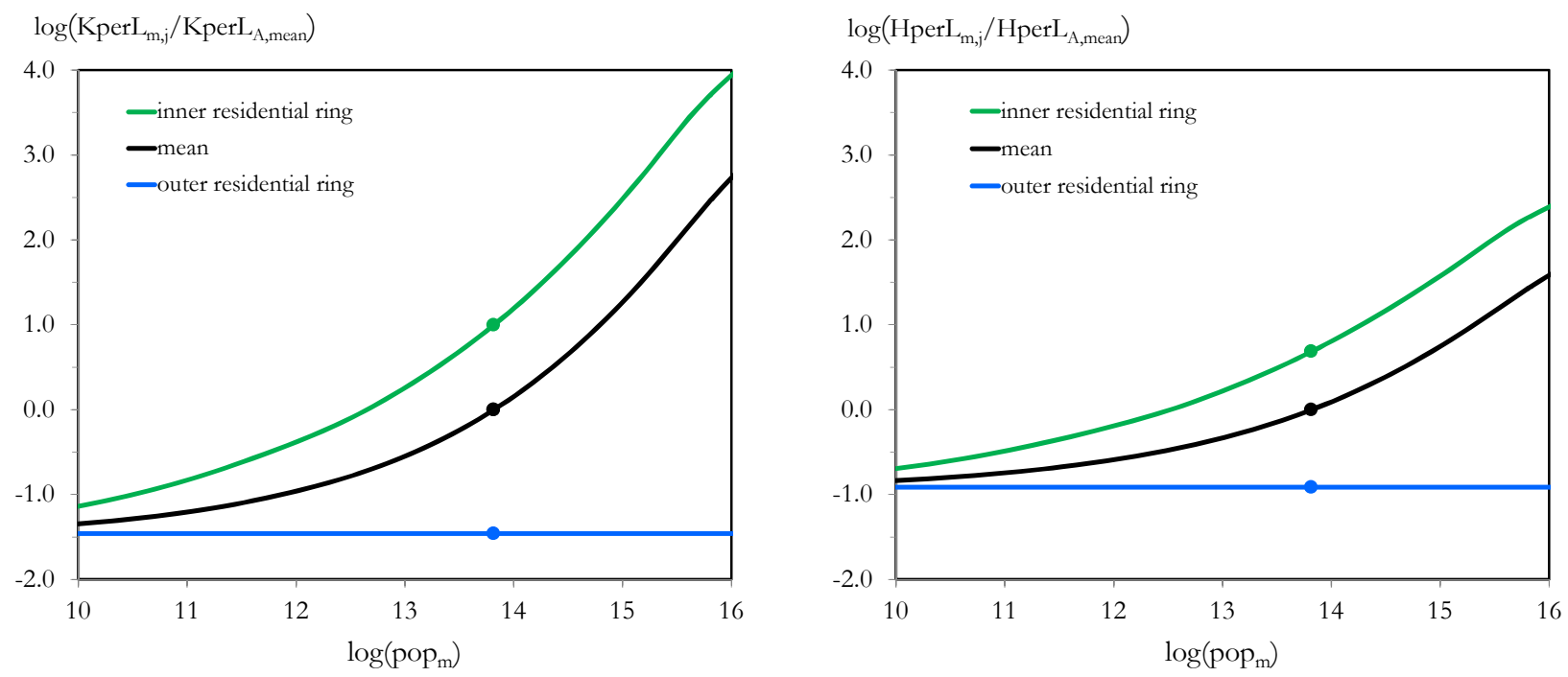

Figure 10: Housing Structure Intensity and Housing Density. Left panel shows correspondences of housing structure intensity (capital per unit land) with population. Right panel shows correspondences of housing services density (quantity per unit land) with population. Markers indicate outcomes in the anchor metro.

Rising home prices elicit vigorous construction. As log population increases from 12 to 15 , mean and inner-ring structure intensity (capital per unit land) increase by multiplicative factors of 9 and 18 (Figure 10, left panel). In consequence, supplied housing ramps up, though not quite as spectacularly. Mean and inner housing density (housing services per unit land) respectively increase by multiplicative factors of 4 and 6 (right panel). 
The implied price elasticity of housing supply ranges up from 1.24 in the inner ring of a metro with log population 15 to a mean value of 1.68 in the anchor metro to 1.92 in the outer ring of all metros. These lie in the middle of the benchmark range estimated by Saiz (2010).

Detailed tables summarizing baseline results are included as Appendix A.

\section{Alternative Scenarios}

The structural estimates and data moments used to parameterize the model are subject to considerable uncertainty. Even if the model fully captured the process generating actual metros, its baseline quantitative results would come with wide error bands. In addition - as is the case with all economic models - the present one makes a slew of first-order simplifications that are likely to significantly affect quantitative outcomes. These simplifications include no dynamics, no consumption amenities, no heterogeneity, no household structure, no alternative modes of transport, no arterial commuting, no land use by streets and highways, no local non-traded services other than housing, no employment outside the $\mathrm{CBD}$, no commute segments within the $\mathrm{CBD}$, and no parking.

In this context, quantitative correspondences may best be interpreted qualitatively. Alternative scenarios help to do so by illuminating the mechanics by which metro TFP affects metro population, radius, and other outcomes. As is intuitive, alternatives that dampen demand for land and increase its effective supply strengthen the responsiveness of population to TFP. The latter supply channel proves to be more important quantitatively.

\subsection{Alternative Parameterizations of Production, Utility, and Commuting}

A first group of alternative scenarios describe alternative parameterizations of the model. Appendix B.1 gives detailed summaries of population, density, commute time and speed, and house and land prices for a number of such alternatives. Here I highlight several examples, focusing exclusively on population and commute distance.

The quantitative correspondence of population with TFP depends importantly on parameter choices that affect demand for land. Increasing land's factor share of numeraire production, $\alpha_{L}$, land's average factor share of housing production in the anchor metro, $\bar{\mu}_{A}^{L}$, and housing's average consumption expenditure share in the anchor metro, $\bar{\mu}_{A}^{h}$, each explicitly or implicitly increase demand for land and so dampen the responsiveness of population to TFP. Increasing the elasticity of substitution between land and structure in the production of housing, $\sigma_{L}$, and between housing and numeraire in utility, $\sigma_{h}$, make it easier to explicitly or implicitly substitute away from land and so increase the responsiveness of population to TFP. The magnitude of the changes in responsiveness turn out to be asymmetric, both with respect to the direction of change in the parameterization and with respect to whether metro TFP is relatively high or low.

The baseline parameterization, $\alpha_{L}=0.016$, may misattribute factor payments to capital that pass through to land. It may also fail to capture that a significant share of CBD land enters numeraire production externally such as via its use for sidewalks, streets, and parking. Alternatively 
quadrupling $\alpha_{L}$ to 0.064 significantly dampens the responsiveness of population to TFP by increasing the incentive to keep numeraire production where CBD land is inexpensive. For example, as TFP increases from 0.90 to 1.15, population increases from 380 thousand to 2.7 million, which compares with a rise from 130 thousand to 4.0 million under the baseline. Quadrupling the land share thus triples population at the 0.90 TFP benchmark and cuts it by one third at the 1.15 TFP benchmark.

Land's share of housing factor income also powerfully affects the population correspondence at high relative TFP. For example, as $\bar{\mu}_{A}^{L}$ increases from 0.25 to its baseline (0.35) to 0.50, metro population at relative TFP 1.15 decreases from about 40 percent above baseline to about 15 percent below it. In contrast, $\bar{\mu}_{A}^{L}$ only modestly effects the population correspondence at low relative TFP, reflecting the plentifulness of residential land in small metros.

Counterintuitively, the housing production and consumption elasticities only modestly affect the responsiveness of population. As $\sigma_{L}$ increases from 0.75 to its baseline (0.90) to 1.05, metro population at relative TFP 1.15 increases from about 10 percent below to about 20 percent above baseline. As $\sigma_{h}$ increases from 0.50 to its baseline (0.67) to 0.90 , metro population at relative TFP 1.15 increases from about 5 percent below to about 15 percent above baseline. These elasticities do not exert more leverage because the corresponding weights $-\eta_{L}$ and $\eta_{h}$-are recalibrated to hit unchanged targets, partly "offsetting" the assumed changes. For example, setting $\sigma_{L}$ to 1.05 rather than 0.90 recalibrates $\eta_{L}$ to a higher value in order to hit the unchanged target land income share of housing production, $\bar{\mu}_{A}^{L}=0.35$. Under this new combination, it is easier to substitute away from land but land is also more important. ${ }^{15}$

Also counterintuitively, the elasticity of substitution with leisure, $\sigma_{\ell}$, exerts virtually no effect on the responsiveness of population so long as individuals can freely choose their workhours. Instead, individuals who face longer commutes simply adjust workhours such that their marginal valuation of leisure remains effectively pinned down by the curvature of the tradeoff between housing and numeraire.

The quantitative correspondence of population with TFP proves more sensitive to parameter choices that affect the supply of land that is accessible for metro use. For example, metro population scales up one-to-one as metro land spans a wider angle, $\theta_{m}$. More interestingly, the effective elasticity of supplied land depends on commuting technology, increasing as the numeraire and foregone leisure costs become smaller.

As a starting point for building intuition, Figure 11 shows the population and commute distance correspondences when there is no distance cost to commuting (green lines) and when there is no

\footnotetext{
${ }^{15}$ The alternative elasticities exert a significantly stronger effect at especially high relative TFP. Separately, alternative parameterizations also typically require recalibration of the benchmark level of highway capacity, $\widehat{V}$, and the numeraire per mile cost of commuting, $\delta$, so that the correspondence of commute time with respect to distance continues to approximate the kernel estimates and the mean commute cost in the anchor metro continues to equal 5 percent of income.
} 

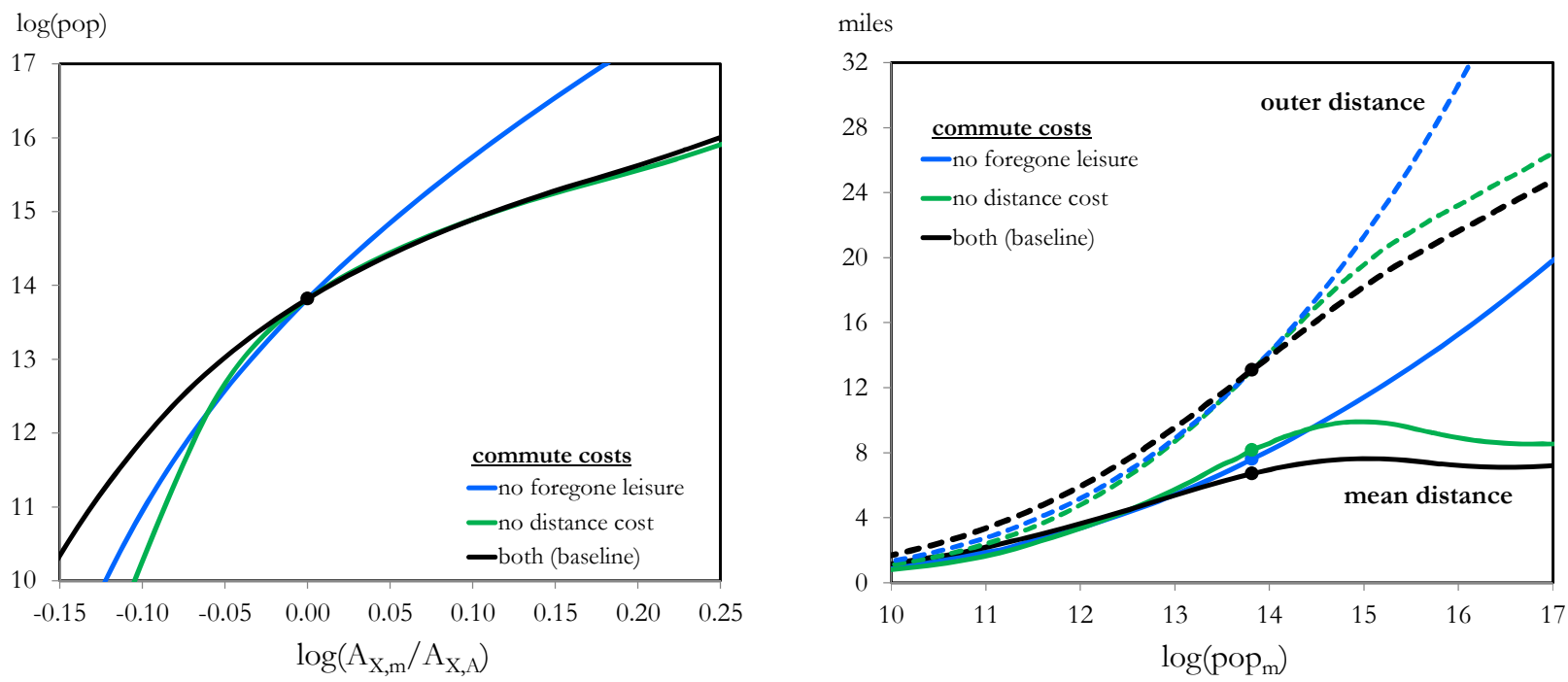

Figure 11: Distance and Foregone Leisure Costs. Left panel shows the correspondences of population with TFP when there is no foregone leisure cost to commuting (blue line) and when there is no distance cost to commuting (green line). Right panel shows associated correspondences of commute distance with population. Markers indicate outcomes for the anchor metro under each parameterization.

foregone leisure from commuting (blue lines). ${ }^{16}$ The latter illustrative scenario maps both to infinite commute speed and to commuting time having a unitary leisure component, $\lambda=1$.

The baseline distance cost proves essentially irrelevant in determining metro population at intermediate and high relative productivity (left panel). Even with no distance cost, the population correspondence almost exactly matches its baseline as TFP rises above its level in the anchor metro. But at low relative TFP, eliminating the distance cost sharply steepens the population correspondence. The asymmetry reflects that the real cost of commute distance, measured by utility rather than numeraire, decreases as productivity and hence numeraire wages increase. Eliminating the baseline distance cost does modestly increase commute distances at intermediate and high population (right panel).

The foregone leisure cost critically shapes the population correspondence at all productivity levels, with population becoming extremely responsive in its absence. For example, metro population at relative TFP 1.15 more than triples from its baseline value (from 4 million to 13 million). Unsurprisingly, eliminating the foregone leisure cost also significantly boosts commute distances. At relative TFP 1.15, mean commute distance more than doubles (from 8 to 17 miles) and outer commute distance increases by more than three quarters (from 19 to 35 miles) (right panel, blue lines).

The next two alternative scenarios assume that the leisure content of commute time, $\lambda$, re-

\footnotetext{
${ }^{16}$ In order to illustrate quantitative contributions, the scenario with no distance cost does not recalibrate highway capacity, $\widehat{V}$, to approximate the observed correspondence between commute time and distance. Similarly, the scenario with no foregone leisure does not recalibrate the per mile distance cost to match the baseline target of the mean ratio of commute costs to income in the anchor metro.
} 

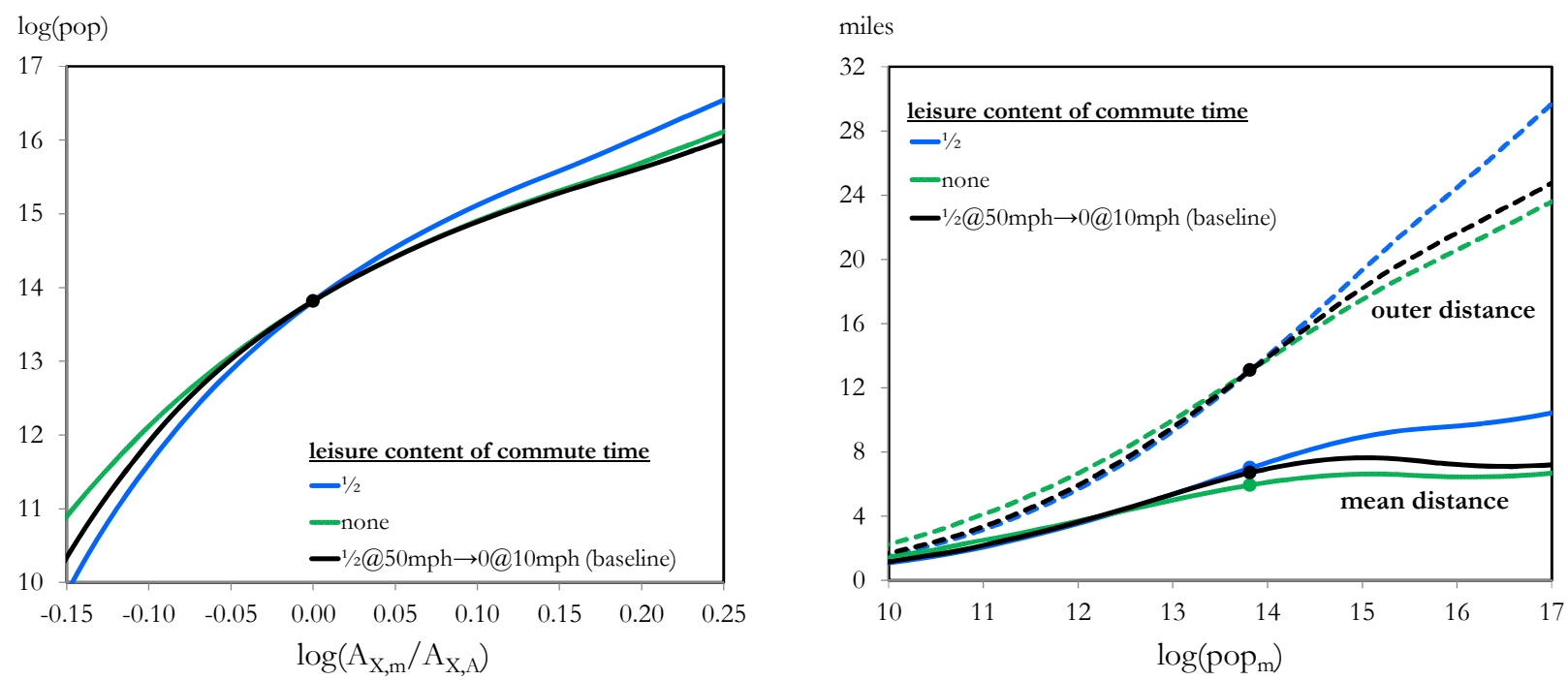

Figure 12: The Leisure Content of Commuting. Left panel shows the correspondences of population with TFP when the leisure content of commute time is constant at 0.5 (blue line) and at 0 (green line). Right panel shows associated correspondences of commute distance with population. Markers indicate outcomes for the anchor metro under each parameterization.

mains constant rather than decreasing with congestion. Holding leisure content constant at 0.5 moderately steepens the correspondence between population and TFP (Figure 12, left panel, blue line). This increased responsiveness is intuitive for large metros: the higher leisure content lessens the foregone leisure cost of commute time and so allows for longer commute distances (right panel, blue lines). For smaller metros, the higher leisure content devalues the brief commutes afforded by short distances and low congestion. In consequence, population falls off more quickly as TFP decreases from its anchor level.

Conversely, holding leisure content constant at zero rather than 0.5 increases the benefit of the fast commute speeds in small metros and so flattens the population correspondence when relative TFP is low (left panel, green line). But the population correspondence remains essentially the same as under the baseline at high relative TFP. This partly reflects that a significant share of commute time in large metros under the baseline is at slower speed and so has low leisure content. Zero leisure content does, however, modestly decrease commute distances (right panel, green lines).

A third pair of alternative commute parameterizations vary the elasticity of highway provision, $\sigma_{V}$, below and above baseline, each coupled with a recalibration of baseline capacity, $\widehat{V}$, to continue to approximate the baseline correspondence between commute time and distance. Doing so only modestly affects the population correspondence. At relative TFP 1.15, decreasing $\sigma_{V}$ to 0.90 (from its 0.92 baseline) and increasing it to 0.94 respectively pushes down and boosts population by a little more than 10 percent. For relative TFP below 1, the population correspondence is essentially unchanged. Commute distances at high relative TFP modestly decrease at the lower highway elasticity and modestly increase at the higher one. As discussed in a subsection below, changing 
the highway elasticity in a single open metro while leaving it at its baseline in the anchor metro more significantly affects the population and distance correspondences.

\subsection{Alternative Assumptions: Fixed Workhours, Capital Income, and Endoge- nous CBD Radius}

A second group of alternative scenarios describe alternative assumptions regarding the data generating process. Appendix B.2 includes detailed summaries.

Under the baseline specification, individuals living in the outer rings of large metros significantly pare back workhours to offset long commutes with low leisure content. To the extent that modeled individuals can be interpreted as households, doing so may be feasible; but for most individual workers with fulltime jobs, it probably is not.

Alternatively requiring individuals to work 40 hours per week modestly flattens the responsiveness of population and outer commute distance for large metros (Figure 13, left panel, green line; right panel, green dashed line). It also strengthens infill as population increases above its anchor level, reflected by decreasing mean commute distance (right panel, green solid line).

Fixed workhours bite more strongly as individuals become less willing to substitute away from leisure. For example, at relative TFP 1.15 and the Frisch elasticity targeted to 0.10 rather than 0.20 , population is more than 20 percent below its free-choice baseline, outer commute distance is shorter by 4.4 miles, and mean commute distance is shorter by 2.4 miles (left panel, blue line; right panel, dashed and solid blue lines). ${ }^{17}$ This sensitivity to the targeted Frisch elasticity contrasts with the almost perfect insensitivity to it when individuals can choose their workhours.

Not being able to optimally choose leisure can drive its marginal value well above the wage rate. The first order conditions (10) imply that individuals would like to choose their leisure time, and so residually their workhours, to equate the marginal value of leisure, $\frac{\partial U_{m, j}}{\partial \ell_{m, j}} / \frac{\partial U_{m, j}}{\partial x_{m, j}}$, with the metro wage rate, $w_{m}$. By construction, individuals in the inner ring of the anchor metro prefer to work the required 40 hours per week and so the ratio of their marginal valuation of leisure to their wage equals 1 . With the Frisch elasticity targeted to its baseline 0.20 , the mean and outer-ring valuation ratios in the anchor metro respectively equal 1.10 and 1.16 (Figure 14, right panel, green markers). With the Frisch elasticity instead targeted to 0.10, the mean and outer valuation ratios in the anchor metro respectively equal 1.37 and 1.72 (blue markers).

As higher relative TFP drives up metro size, the baseline ratio of the mean value of leisure to the metro wage increases significantly and the outer ratio increases steeply (right panel, solid and dashed green lines). With the lower Frisch target, the mean marginal value ratio increases steeply and the outer marginal value ratio soars (solid and dashed blue lines). These increases in marginal valuation are qualitatively consistent with the finding that individuals' MWTP to shorten their commute time increases with the distance of their commute (Small, Winston, and Yan,

\footnotetext{
${ }^{17}$ With the Frisch elasticity targeted to 0.10 , the highest log population for which I have been able to solve is 16.6 (population 16.1 million, relative TFP 1.55).
} 

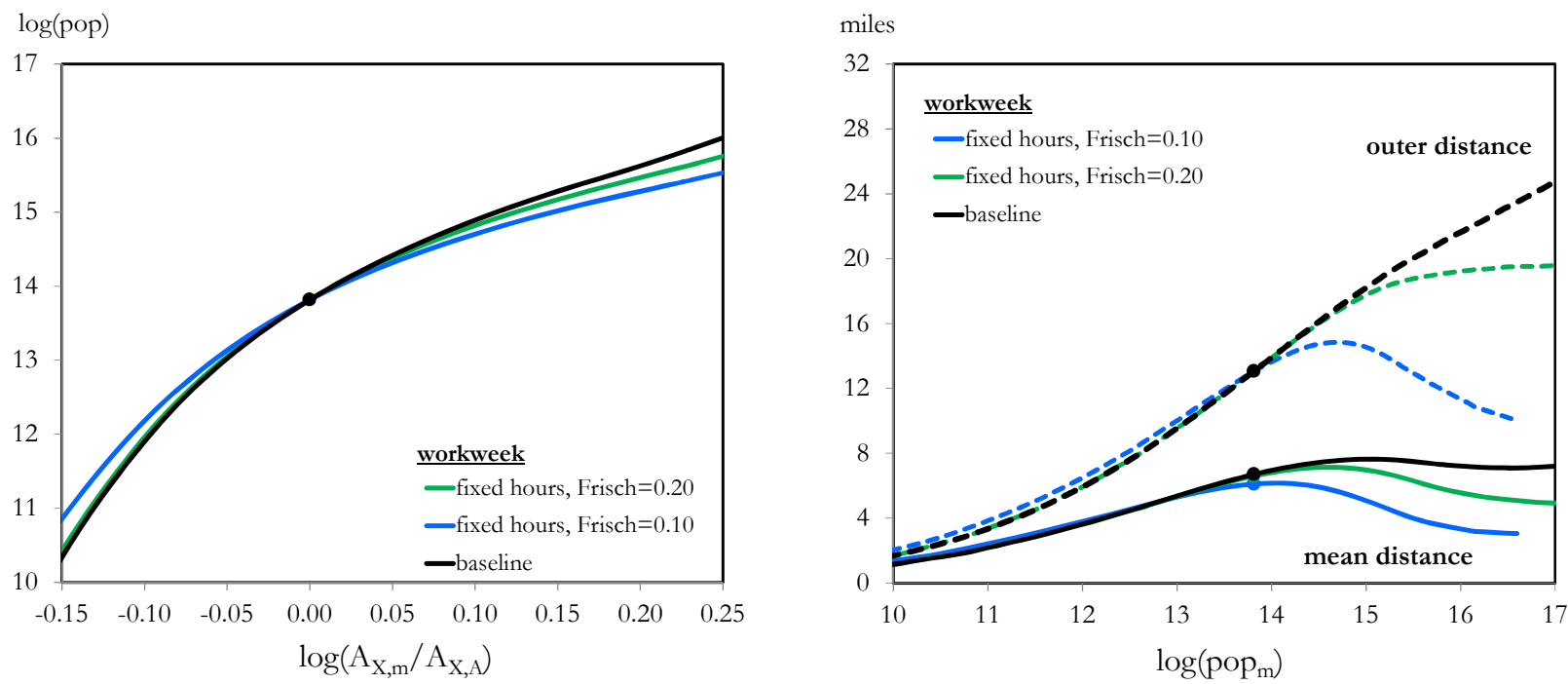

Figure 13: Fixed Weekly Workhours. Left panel shows correspondences of population with TFP when workers are required to work 40 hours per week. The Frisch elasticity is targeted to its baseline 0.20 (green line) and to 0.10 (blue line). Right panel shows associated correspondences of commute distance with population. Markers indicate outcomes in the anchor metro under each assumption.
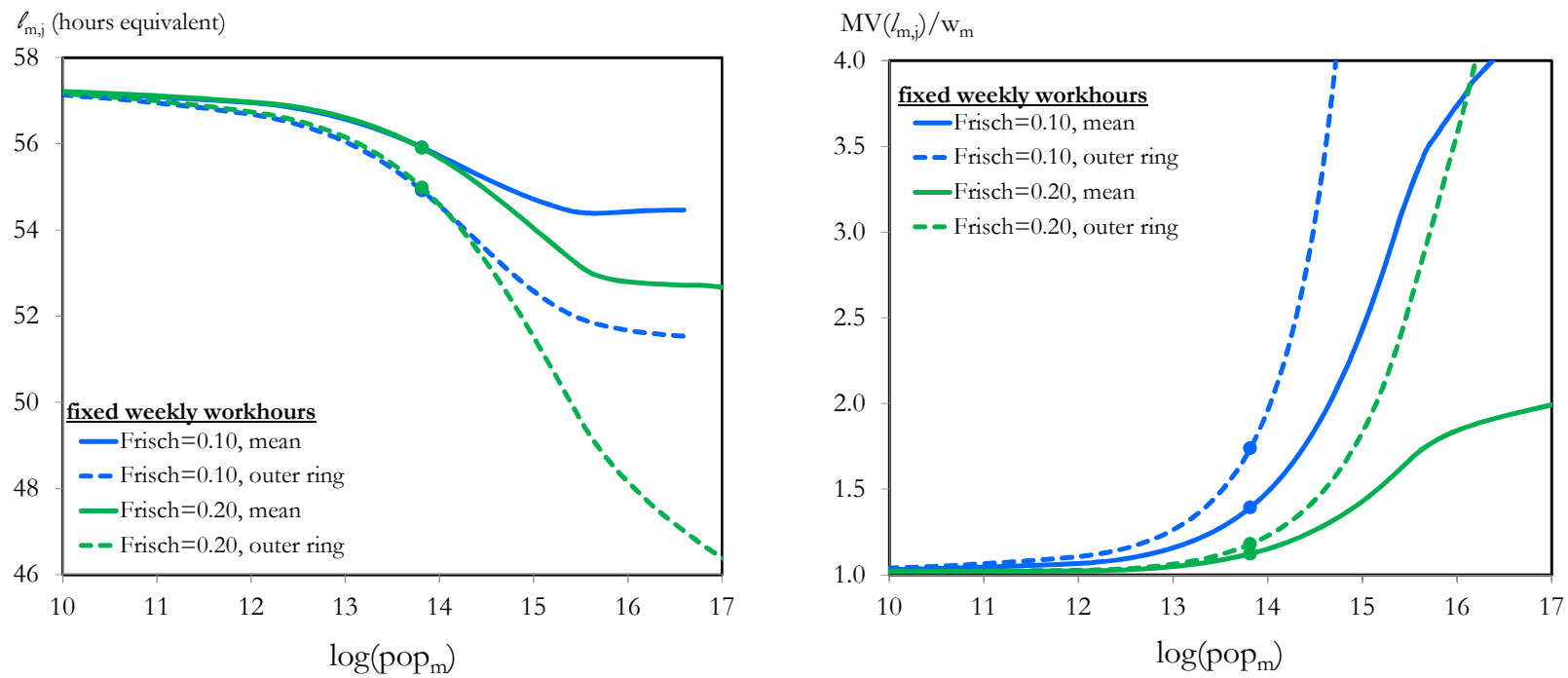

Figure 14: The Marginal Value of Leisure with Fixed Weekly Workhours. Left panel shows the correspondences of weekly leisure (explicit leisure hours plus leisure from commuting) with population. Right panel shows correspondences of the marginal valuation of leisure relative to the metro wage with population. Markers indicate outcomes for the anchor metro under each assumed Frisch elasticity.

2005). Wages, the denominator in these ratios, also increase with population, and so individuals' willingness to pay for services that free up time for leisure, measured by numeraire, increases by even more than depicted.

A second baseline assumption is that individuals receive only wage income. Equivalently, all payments to land and capital used in the production of housing and numeraire are paid to absentee 
owners, who either live outside the system of metros or who have measure zero. Capital income importantly affects the correspondence between TFP and population by decreasing the marginal utility return to working.

Suppose instead that individuals in all metros receive a lump sum transfer equal to per capita payments in the anchor metro to land and capital used in producing housing services there. The transfer, which equals 19 percent of mean wage income in the anchor metro, depends neither on where an individual lives (metro and location within it) nor on the quantity of housing services they consume. Such housing income moderately dampens responsiveness: as relative TFP increases from 0.90 to 1.15 , population increases from 20 percent above its baseline to 10 percent below it. A larger transfer of all per capita payments to land and capital in the anchor metro, which equals 82 percent of mean wage income there, dampens responsiveness more strongly. As relative TFP increases from 0.90 to 1.15, population increases from almost twice its baseline level to 20 percent below it. ${ }^{18}$

A third baseline assumption is that the radius of the CBD is the same, 2.4 miles, in all metros. In contrast, the inferred CBD radiuses for the seven metros summarized in Table 2 range from 1.9 to 3.4 miles. As an alternative, I endogenize the CBD radius by requiring the ratio of the price of land in the CBD to the price of land in the innermost residential ring to remain the same as in the anchor metro. ${ }^{19}$ Doing so intuitively increases the responsiveness of population at low relative TFP. For example, at relative TFP 0.90, the endogenous CBD radius is 1.6 miles (versus 2.4 miles in the anchor), implying CBD land area that is less than half that in the anchor metro. In consequence, metro population is more than a third below its baseline value.

Paradoxically, endogenizing the CBD in this way dampens population responsiveness at high relative TFP. With a constant CBD radius, the price of land in the inner residential ring increases faster than does the price of land in the CBD as population increases above some intermediate threshold. Maintaining the anchor metro ratio of prices requires the CBD to contract. At relative TFP 1.15, for example, the endogenous CBD radius is 1.9 miles and metro population is one tenth below baseline.

\footnotetext{
${ }^{18}$ The per mile numeraire cost, $\delta$, in these scenarios continues to be calibrated such that the mean commute cost in the anchor metro is 5 percent of total income. Hence the per mile distance cost relative to wage income is lower than under the baseline.

${ }^{19}$ The baseline ratio of the price of land in the anchor CBD to the price of land in the anchor inner ring is 3.6. A more natural assumption would be to require the land price in the CBD and in the inner residential ring to equal each other. However, doing so implies CBD radiuses that are implausibly large. For any CBD radius within the empirically inferred range, land's aggregate factor income from numeraire production per square mile of CBD land considerably exceeds land's aggregate factor income from housing production per square mile in the inner residential ring. In consequence, residential and commercial land use are likely to especially mix near the CBD, as documented by Brinkman (2013).
} 


\subsection{Alternative Metros: No Congestion, More Highway Capacity, and Telecom- muting}

The alternative parameterizations and assumptions described above are "system" scenarios in the sense that differences from the baseline apply to all metros including the anchor metro. This subsection instead describes alternative processes that generate outcomes in only one or a few open metros. This limitation on the number of alternative metros reflects that their combined aggregate population must remain sufficiently low to not affect the shared reservation level of utility that must be attained in all metros.

As already stated, commuting congestion proves the critical force constraining metro population. Figure 15 shows alternative open metros with assumed constant speed equal to its 27 mph minimum in the anchor metro (blue lines), equal to its $33 \mathrm{mph}$ mean in the anchor metro (green lines), and equal to its $50 \mathrm{mph}$ maximum (purple lines). Even under the slowest of these, the responsiveness of population to productivity increases by an order of magnitude relative to responsiveness with baseline congestion.

With baseline congestion, relative TFP levels of 1.15 and 1.25 respectively correspond to metros with population of 4.0 and 7.2 million. For an open metro with a constant commute speed of $27 \mathrm{mph}$, the same TFP levels correspond to population 6.9 and 19 million. For an open metro with constant $50 \mathrm{mph}$ speed, they correspond to population 13 and 38 million. Unsurprisingly, eliminating congestion also considerably increases metro commute distances (right panel). ${ }^{20}$
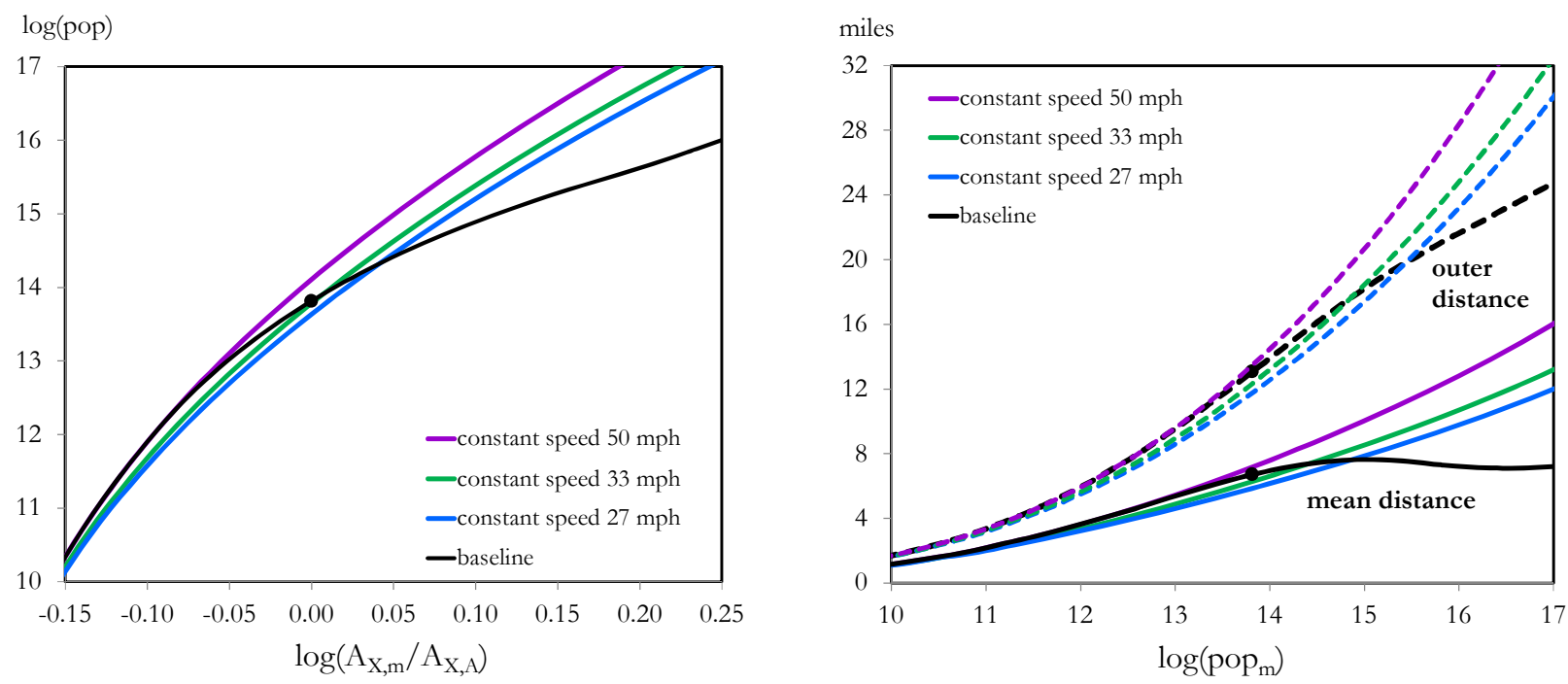

Figure 15: No Congestion. Left panel shows correspondences of population with TFP when commute speed remains constant at $27 \mathrm{mph}$ (blue line), $33 \mathrm{mph}$ (green line), and $50 \mathrm{mph}$ (purple line). Right panel shows associated correspondences of commute distance with population. The anchor metro continues to be driven by the baseline data generating process. Markers indicate outcomes for the anchor metro.

\footnotetext{
${ }^{20}$ Conversely, modifying the baseline by removing the $10 \mathrm{mph}$ floor on commute speed significantly dampens the responsiveness of population as TFP increases above 1.25. Doing so also causes outer commute distance to plateau at 24 miles and eventually to begin contracting.
} 
Other alternative processes that significantly boost the responsiveness of population ultimately do so by less than eliminating congestion. For example, highway provision in one or a handful of metros might increase more aggressively to increases in commute volume, say, with elasticity 0.94 rather than 0.92 (Figure 16, green lines). Or individuals might telecommute from home one day a week, thereby reducing their weekly one-way trips from 10 to 8 and highway volume by 20 percent for a given population (blue lines). Both of these considerably shift up the correspondence between population and TFP (left panel). But the slopes of the correspondences, which give the non-causal elasticity of population with respect to TFP, remain about the same as under the baseline. As relative TFP increases above 1.15, these alternatives attain population considerably below that attained with uncongested commuting. ${ }^{21}$
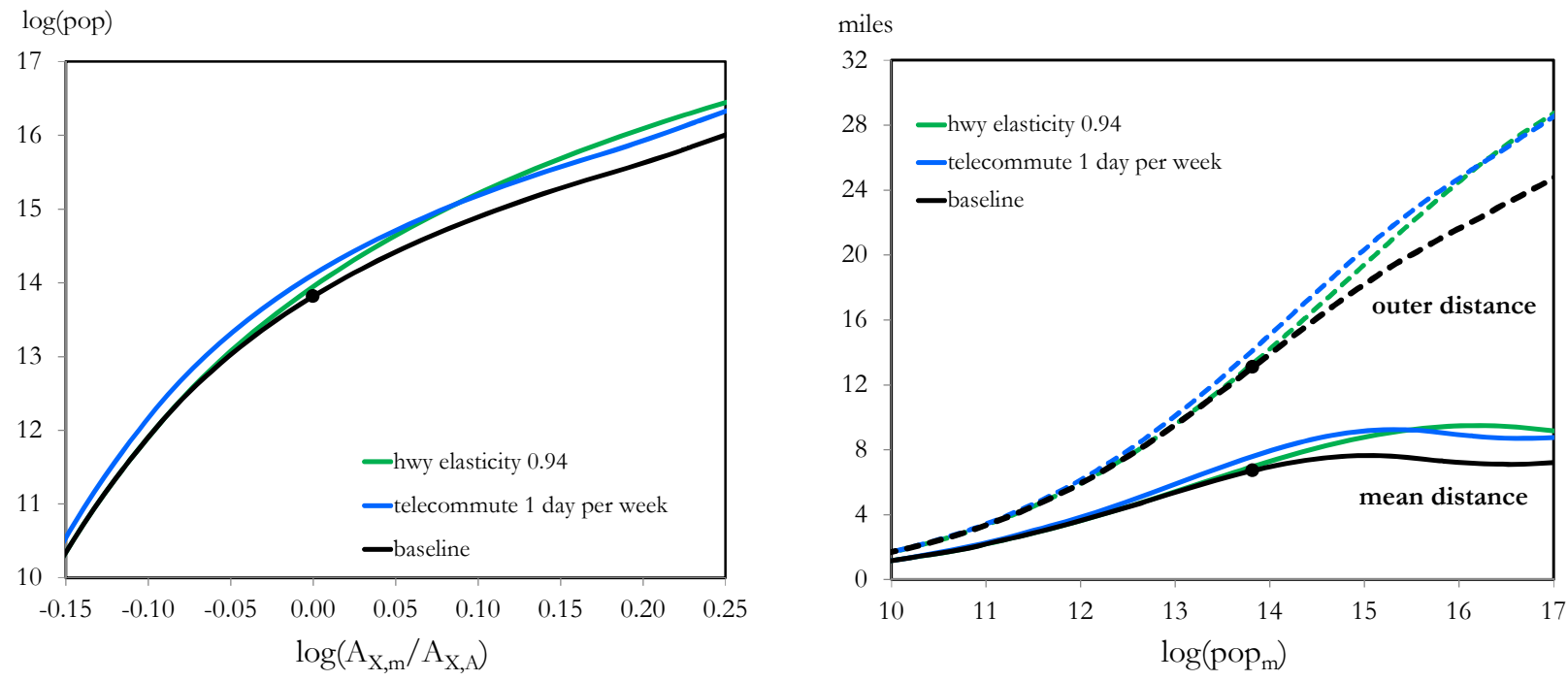

Figure 16: Telecommuting and More Elastic Highway Provision. Left panel shows correspondences of population with TFP when the elasticity of highway provision is 0.94 (green line) and when workers telecommute one day out of five (blue line). Right panel shows associated correspondences of commute distance with population. The anchor metro continues to be driven by the baseline data generating process (with elasticity of highway provision 0.92 ). Markers indicate outcomes for the anchor metro.

In addition, the telecommuting alternative worsens commuting congestion because the endogenous increase in population and commute volume dominates the one-fifth cut in volume for a given population. Thus part of the compensation for making eight rather than ten one-way commutes is that from any given distance, the eight take longer and are less pleasant.

Appendix B.2 includes detailed summaries for the above alternative metros as well as for

\footnotetext{
${ }^{21}$ The more elastic highway provision and telecommuting alternatives bestow less relative advantage if they apply to all metros, including the anchor, and so increase responsiveness by less. This is also true for the uncongested alternatives, although responsiveness remains extremely high even when all metros are uncongested. Separately, the upward shift in the population correspondence from increasing the elasticity of highway provision only partly crowds out faster highway speeds. A metro with $\sigma_{V}$ of 0.94 and relative TFP 1.15 has mean and inner-ring speeds of 22 and $19 \mathrm{mph}$, compared to 15 and $12 \mathrm{mph}$ under the baseline (Appendix Table B.12). The faster speeds are consistent with the empirical estimate that a discrete increase in highway capacity is completely crowded out by increased highway volume, leaving speed approximately unchanged (Duranton and Turner, 2011).
} 
alternatives with a 4-day workweek (the same 4 days), a higher distance cost, and an urban growth boundary.

\subsection{Unanchored Systems: Self-Driving Cars and Multifamily Construction}

Each of the scenarios above is anchored in the sense that the metro establishing the reservation utility level and perimeter land price is calibrated to match observed outcomes. This section instead models two pairs of alternatives for which no observed outcomes exist. Self-driving car technology is rapidly developing but has yet to be deployed beyond limited testing. And tall apartment buildings make up a small share of the occupied housing stock in most metros, partly due to land use regulation and partly due to perceived negative consumption amenities, at least until recently, of living near urban cores. The inability to calibrate these alternatives to observed outcomes implies that quantitative results should be interpreted strictly as building qualitative intuition on the direction and magnitude of differences from baseline outcomes.

Henry Ford debuted his Model $\mathrm{T}$ in 1908. The ensuing dramatic decrease in the cost of owning an automobile unleased seven decades of suburbanization beginning in the 1930s (Rappaport 2005). Self-driving cars may reignite such residential decentralization by lowering foregone leisure from commuting. Conversely, the increased ride sharing complemented by self-driving cars will contribute to greater residential centralization by lowering parking demand. Both of these impetuses increase the responsiveness of metro size to TFP and so may put significant upward pressure on the size of already large U.S. metros and significant downward pressure on the size of already small U.S. metros. ${ }^{22}$

I first consider two self-driving scenarios, both of which increase the leisure content of commuting while leaving the forces determining congestion the same as under the baseline. In the first scenario, commute leisure content linearly declines from 1 at $50 \mathrm{mph}$ to 0.5 at $10 \mathrm{mph}$ (Figure 17, green lines). The unitary content at maximum speed means that commute time is equally leisurely as explicit leisure time. For example, people might catch up on sleep or surf the internet. But they still find traffic stressful. The magnitude of the increase in responsiveness is larger in the second scenario, in which individuals enjoy a constant 0.75 leisure content while commuting (blue lines). For comparison, the baseline assumes that leisure content linearly declines from 0.5 at $50 \mathrm{mph}$ to 0 at $10 \mathrm{mph}$.

The declining leisure self-driving scenario moderately increases the responsiveness of metro population to productivity. As relative TFP increases from 0.90 to 1.15 , metro population increases from a level about one fifth below the baseline to a level one quarter above it (left panel green line). The scenario with constant 0.75 leisure content more dramatically increases responsiveness. As relative TFP increases from 0.90 to 1.15 , metro population increases from about one fifth below to

\footnotetext{
${ }^{22}$ The long life of existing homes and other structures, adjustment costs to rapidly building new ones, and frictions slowing labor mobility would cause the possible far-reaching geographic reorganization of population and employment to play out over many decades (Glaeser and Gyourko, 2005; Rappaport, 2004).
} 

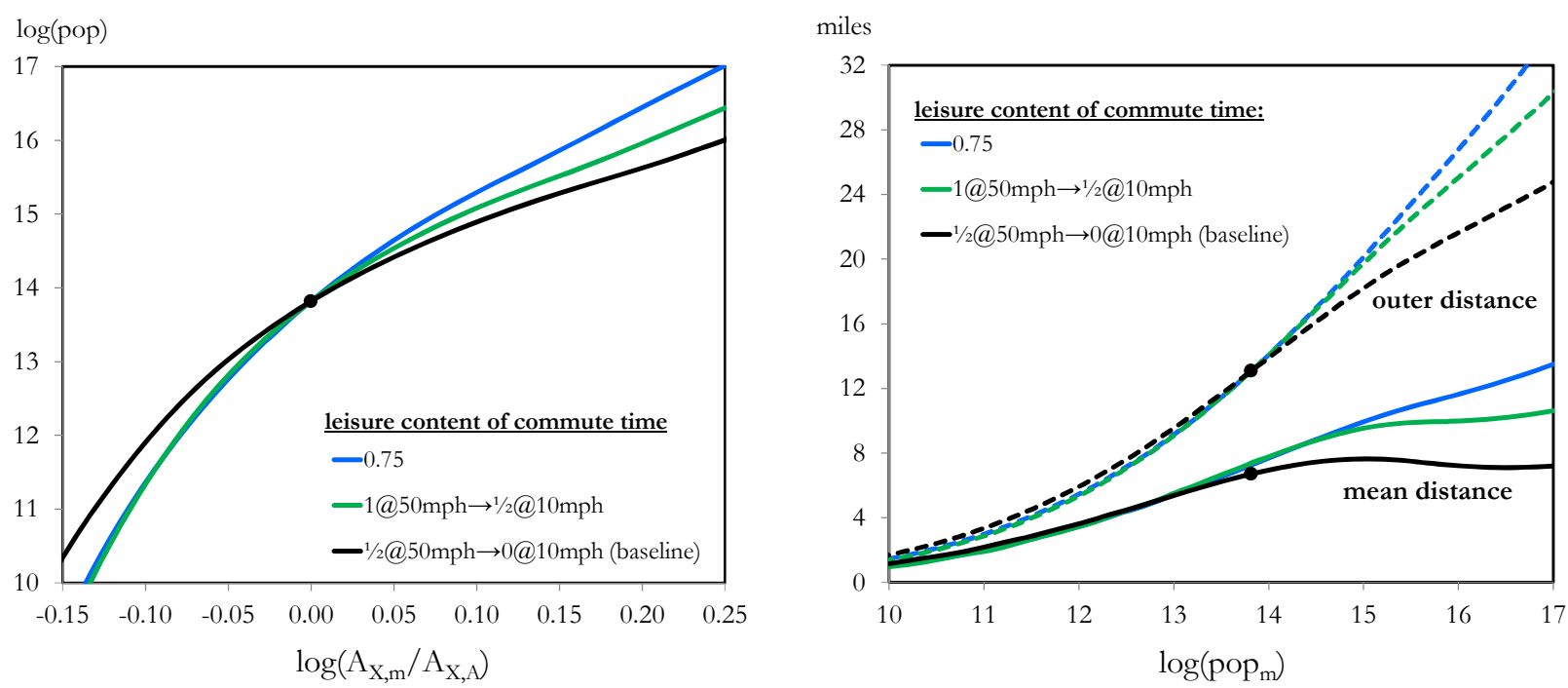

Figure 17: Self-Driving Cars. Left panel shows correspondences of population with TFP when the leisure content of commute time linearly decreases from 1 at $50 \mathrm{mph}$ to 0.50 at $10 \mathrm{mph}$ (green line) and when it remains constant at 0.75 (blue line). Right panel shows associated correspondences of commute distance with population. Markers indicate outcomes for a metro with the baseline leisure content, population 1 million, and normalized TFP of 1.

almost three quarters above baseline (blue line).

Both scenarios also drive greater residential decentralization, reflected by longer commute distances (right panel) and flatter population density gradients. Greater residential decentralization in turn worsens commuting congestion. For a metro area with fixed population, commute times from any distance beyond the innermost lengthen because workers begin their inward commutes from further away and so commute volumes at any distance other than the innermost increase.

Once widely adopted, self-driving cars may additionally improve commuting efficiency in the sense of increasing the speed at which a given volume of cars can pass through given physical highway stock (i.e., lowering $a$ or $b$ in equation 12a). The implied alleviation of congestion would considerably amplify the increased responsiveness of population to TFP as well as drive further residential decentralization.

On the other hand, self-driving cars are likely to also serve as an impetus toward residential centralization by lowering demand for parking space. Self-driving cars complement ridesharing services such as Uber and Lyft by cutting labor costs. Improved ridesharing lowers the benefits of car ownership, especially for individuals living in densely-settled neighborhoods, where parking is expensive and hard to find. The flexibility to substitute away from car ownership to ridesharing thus ameliorates the cost of residential density, analogous to easing the ability to substitute away from land to structure in producing housing services. As described below, such easing can cause metros to become extremely compact while significantly increasing the responsiveness of population to TFP. Complementing this, less drivers searching for a parking spot can significantly relieve neighborhood 
traffic congestion and so lower commute times (Brueckner and Franco, 2015).

Self-driving cars and ridesharing may similarly increase population responsiveness by decreasing the parking needs of workers. Driving remains the overwhelmingly main mode of commuting in the U.S., including to the CBD of most U.S. metros, and so requires significant investment in parking land area and structure adjacent to dense places of work. Greater take up of ridesharing would effectively decrease the land share of numeraire factor income, $\alpha_{L}$, and so increase responsiveness (as described in Section 6.1 and summarized in Appendix B.1). ${ }^{23}$

A second pair of unanchored alternative scenarios allow for a higher ability to substitute away from land in the production of housing. The baseline elasticity of substitution between land and structure, $\sigma_{L}=0.90$, is based on estimates that use single-family homes as observations, many of which are likely to have been subject to land use regulation. Land use regulation limits increasing structure intensity and so pushes down the estimated elasticity for constructing single-family homes relative to what is technologically feasible.

More important quanitatively, multifamily construction can more easily substitute from land to structure. For example, housing services surely increase proportionally more by stacking, say, five five-room apartments on top of each other compared to stacking five rooms of a single-family home on top of each other. Indeed, multifamily housing services increase approximately linearly with structure investment over broad ranges. ${ }^{24}$

An alternative parameterization, setting $\sigma_{L}$ to 1.05 rather than 0.90 , briefly described above and summarized in Appendix B.1, moderately increases the sensitivity of population to TFP. For example, population at relative TFP 1.15 is 4.8 million, one fifth above the baseline 4.0 million. The boost to population is significantly larger at higher TFP levels. For example, population at relative TFP 1.25 is 12.5 million, three quarters above the baseline 7.2 million.

Modestly increasing the elasticity further hugely boosts the responsiveness of population to TFP. At relative TFP 1.15, population soars to 10 million with $\sigma_{L}$ equal to 1.25 , and further to 18 million with $\sigma_{L}$ equal to 1.33 (Figure 18, left panel, blue and green lines). At a relative TFP of just 1.20, the respective populations are 29 million and 95 million! Removing the assumed floor on commute speed only modestly dampens this hyper sensitivity (purple line).

The higher substitutability also hugely strengthens residential centralization, causing metros to become extremely compact (right panel). Under both of the higher elasticities, mean commute

\footnotetext{
${ }^{23}$ The decrease in required parking space adjacent to workplaces is also likely to spur greater employment centralization. In a richer modeling framework that includes diffuse and polycentric employment, a decrease in parking requirements lowers the cost to firms of tightly clustering with each other, in turn allowing firms to benefit from agglomerative spillovers that attenuate over short distances (Fujita and Ogawa, 1982; Lucas and Rossi-Hansberg, 2002; Rosenthal and Strange, 2008). As described in Section 7, this strengthening of agglomerative forces would increase the amplification of exogenous productivity differences and so increase the equilibrium population of metros with non-agglomerative sources of high TFP.

${ }^{24}$ For example, the estimated construction cost per square foot of residential space is approximately the same for apartment buildings ranging from 8 to 24 stories height with the same land footprint (RSMeans, 2007). And housing services for an otherwise identical apartment typically increase with the floor it is on as evidenced by increasing rents (Liu, Rosenthal, and Strange, 2015).
} 

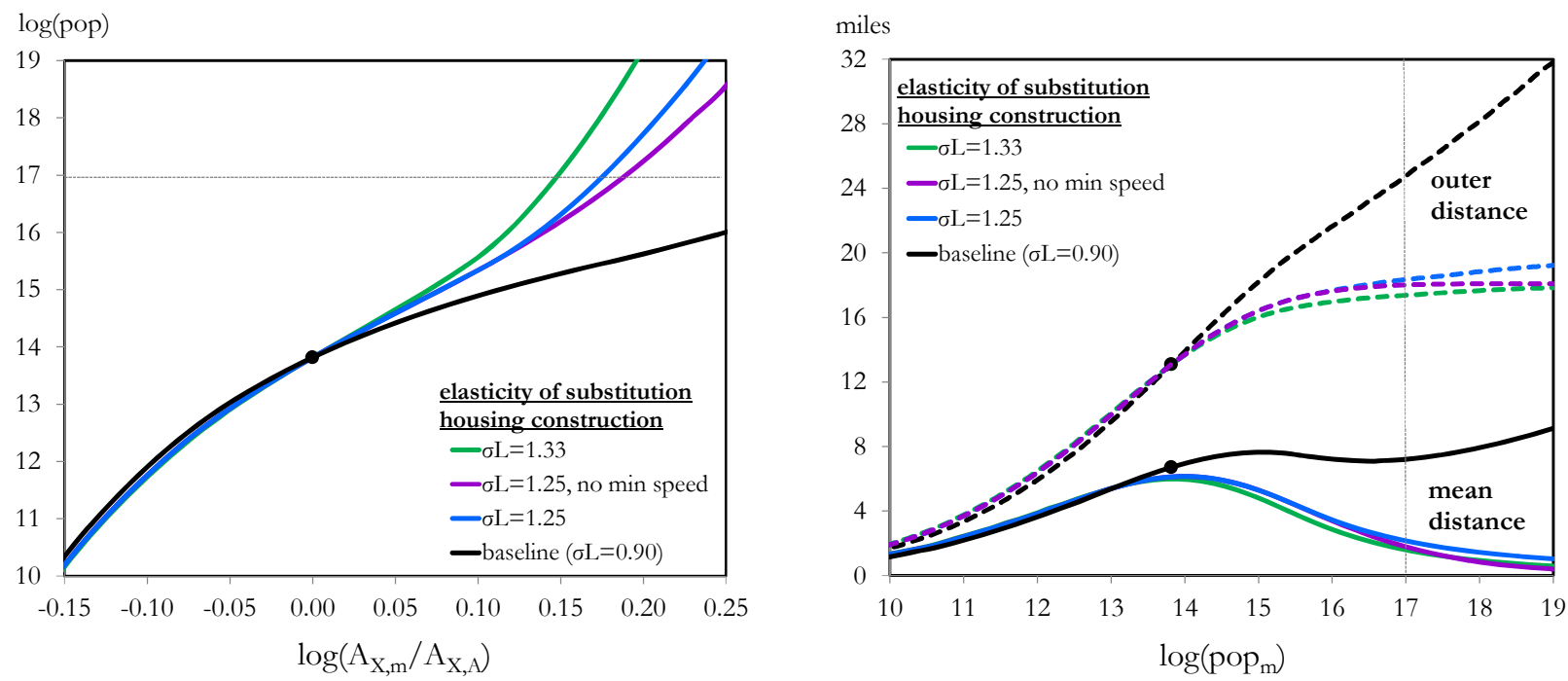

Figure 18: Multifamily Construction Technology. Left panel shows correspondences of population with TFP for elasticities of substitution between land and structure higher than under the baseline. The scenario depicted by the purple line additionally removes the baseline floor on commute speed. Right panel shows associated correspondences of commute distance with population. Gray lines denote the upper bound of the population axes in Figures 11-17. Markers indicate outcomes under the baseline elasticity for a metro with population 1 million and normalized TFP of 1 .

distance peaks at just over 6 miles when population is approximately 1 million (solid lines). As TFP drives population increasingly above this, mean commute distance falls, eventually asymptoting at about 1 mile. Outer commute distance approximately plateaus at 19 miles as population rises above 10 million.

Some of the associated quantitative results further illustrate the unanchored nature of the exercise. Consider, for example, a system of metros characterized by a $\sigma_{L}$ of 1.33 . For a semicircular metro with population 10 million (corresponding to relative TFP 1.13), population density plunges from 1.7 million per square mile in the inner ring - more than seven times the highest tract density in New York City in 2000 - to 900 per square mile at the outer ring, just 17 miles away. Even so, the price of housing services in the inner ring is less than three times the mean price in a metro with population 1 million, allowing residents in the innermost ring to live in moderate size apartments rather than tiny ones. ${ }^{25}$ Lastly, the land share of housing factor income increases from less than 10 percent in the innermost ring to 45 percent in the outermost ring, where the low price of land services drives extremely land-intensive construction.

But these unanchored results also give insight. First, single-family and multifamily production are surely characterized by different technologies. For single-family construction, a feasible elasticity to substitute between land and structure much above Cobb-Douglas implies implausibly high land intensity in outer suburbs. For multifamily construction, the feasible elasticity may be

\footnotetext{
${ }^{25}$ The co-existence of moderate housing prices and extreme crowdedness emphasizes the role of land regulation in driving soaring rents in places such as New York City (Glaeser, Gyourko, and Saks, 2005).
} 
extremely high over certain ranges of capital intensity (e.g, by increasing height by a few stories) but considerably lower over the entire range (e.g., due to engineering considerations for building above threshold heights). Second, the ease of substituting from land to structure in multifamily construction exerts huge leverage in determining the population and land area of the very largest metros. Third, the many considerations from which the model abstracts on net significantly constrain metro size above some threshold. In other words, at very high population, the excluded forces that decrease the responsiveness of population to productivity must collectively outweigh the excluded forces, including polycentricity, that increase the responsiveness of population to productivity. Otherwise, a relatively modest change to the model's parameterization would not cause metro population to explode as TFP increases to moderately high levels.

\section{Equilibrium Metro Size}

A fundamental goal of urban economics is to understand the endogenous benefits of metro size. The present model complements this by focusing on the associated costs of size. Equilibrium population occurs where benefits equal costs.

Figure 19 inverts the axes used in many of the figures above to show the baseline correspondence of log relative TFP against log population (left panel, black line). This depiction emphasizes interpreting the correspondence as capturing the productivity required to support a given population. For illustrative purposes, I have dropped the baseline assumption that speed is subject to a $10 \mathrm{mph}$ floor. Required log productivity increases convexly with log population. This convexity mirrors the robust concave correspondence of $\log$ population with respect to log productivity illustrated in Sections 5 and 6.

The correspondence of log required wages with log population (blue line) can be interpreted as the numeraire cost of population - the compensation required to offset higher housing prices and longer, more congested commutes. Under the baseline parameterization, the wage correspondence for small and medium metros approximately matches the productivity correspondence. But for larger metros, the wage correspondence lies increasingly above the productivity one. This reflects capital deepening dominating declining land intensity, made possible by the low baseline land share of numeraire production, $\alpha_{L}=0.016$. At a moderately higher land share, $\alpha_{L}=0.032$, capital deepening and declining land intensity approximately offset each other for large metros as well, aligning the productivity and wage correspondences. At a still higher land share, $\alpha_{L}=0.064$, declining land intensity dominates and so the the wage correspondence lies below the productivity correspondence.

The convex productivity and wage correspondences immediately imply that the non-causal elasticities of required productivity to population and required wages to population, $\epsilon_{A_{X}, p o p}$ and $\epsilon_{w, p o p}$, rise as population increases (right panel). At the anchor population, the required wage elasticity is 0.085 . As population rises above the anchor, the required wage elasticity increases steeply to 0.16 at $\log$ population 15 (population 3.3 million) and further to 0.32 at log population 

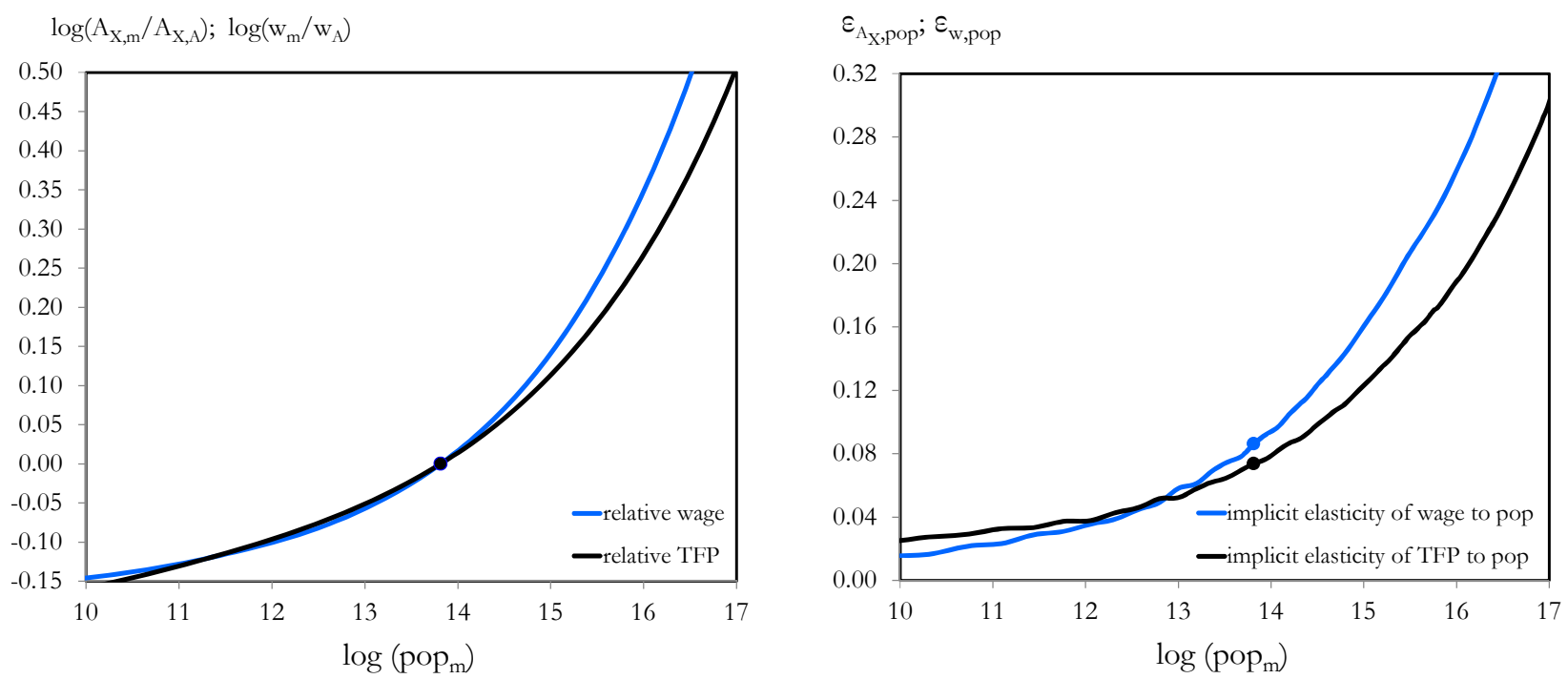

Figure 19: Population, Productivity, and Wages. Left panel shows the correspondences of metro TFP and wages with metro population when there is no minimum commute speed. Right panel shows the implied elasticity of required TFP and required wages with respect to population. Markers indicate outcomes in the anchor metro.

16 (population 8.9 million). As population falls below the anchor, the required wage elasticity deceases to 0.058 at $\log$ population 13 (population 440 thousand) and further to 0.035 at $\log$ population 12 (population 163 thousand). ${ }^{26}$

Estimates suggest that the long-run causal elasticity of wages with respect to population, $\sigma_{w, p o p}$, which encompasses both static agglomerative changes in labor productivity from metro size and the dynamic benefits from faster learning in large metros, lies between 0.02 and 0.06 (Combes and Gobillion, 2015). Agglomerative wage elasticity in the upper half of this likely range exceeds the baseline required wage elasticity to support increases in the population of small metros, leaving scope for agglomeration to generate multiple equilibria. In contrast, the baseline required wage elasticity to support increases in the population of medium and large metros considerably exceeds the likely agglomerative range, implying that differences in size among these metros must arise from some other source such as high exogenous TFP and high exogenous and agglomerative consumption amenities.

Figure 20 illustrates the equilibrium determination of metro population at the intersection of productivity costs and benefits using a 0.04 agglomerative TFP elasticity, the midpoint of the likely empirical range. ${ }^{27}$ The solid black line depicts the TFP cost of metro population, which is just the

\footnotetext{
${ }^{26}$ The elasticities are simply the slopes of the two correspondences in the left panel. The wobbles reflect numerical imprecision. With the baseline $10 \mathrm{mph}$ floor on speed, the elasticities peak when the speed floor first binds (at log population 15.5, population 5.4 million). They discretely fall off by several percentage points, remain flat, and then begin rising again at log population 17 (population 24 million).

${ }^{27}$ Equilibrium size based on matching TFP rather than wage costs and benefits emphasizes structural forces over
} 
inverted baseline correspondence shown in Sections 5 and 6. Consider the stylization that realized productivity combines exogenous and agglomerative components, $A_{X, m}($ pop $)=\widehat{A}_{X, m} \exp \left(\sigma_{A_{X}, p o p}\right.$. pop). The black dashed line represents levels of realized TFP endogenously attainable for a location with exogenous TFP equal to that of the anchor metro. Alternative levels of exogenous TFP vertically shift the attainable set. The green and purple lines respectively represent combinations for locations with exogenous TFP 2 and 6 percent above that of the anchor metro. The blue line represents combinations for locations with exogenous TFP 2 percent below that of the anchor metro.

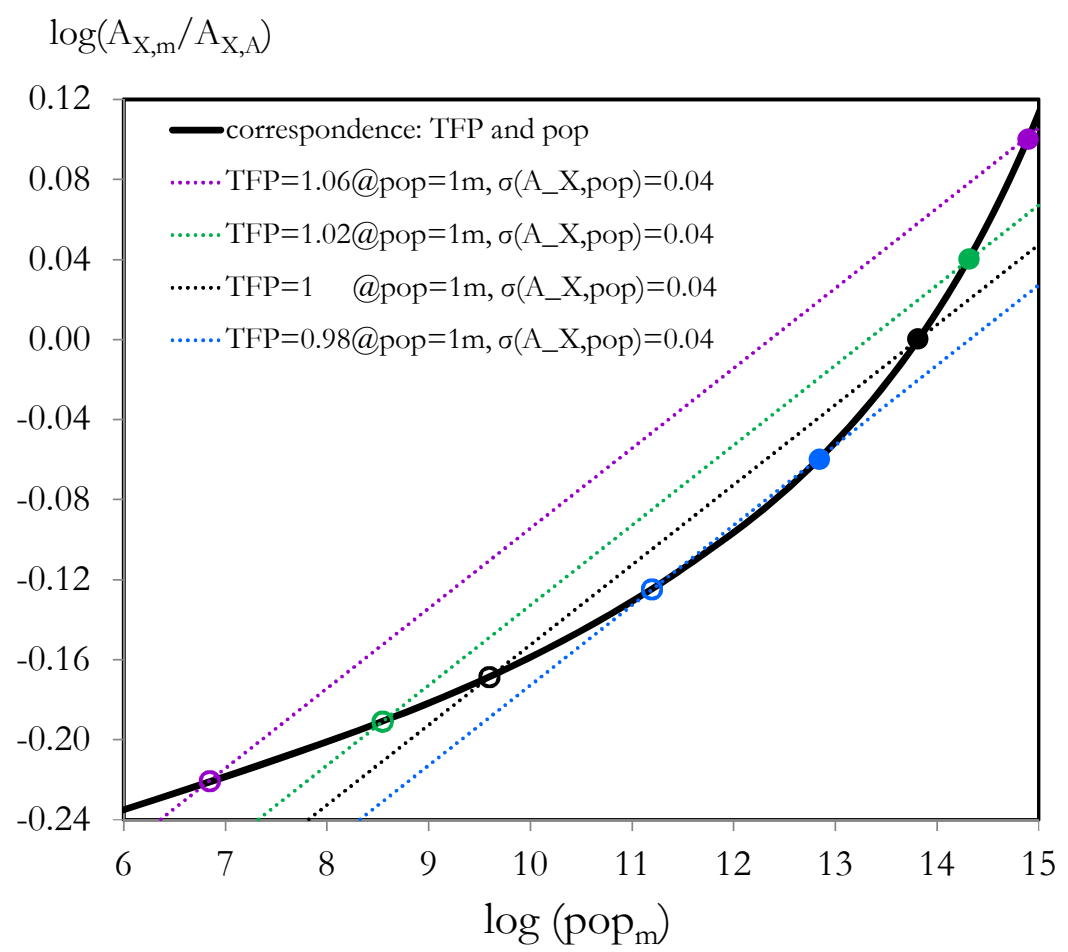

Figure 20: Equilibrium Metro Population. The solid black line shows the baseline correspondence of required TFP with metro population. The dashed lines show combinations of population and TFP attainable with agglomerative elasticity 0.04 from four alternative levels of exogenous TFP. Solid markers represent stable equilibria. Open markers represent unstable equilibria. A stable third set of equilibria exists at zero population for realized relative TFP corresponding to exogenous relative TFP up to 0.975 . The black solid marker indicates the stable equilibrium of the anchor metro.

Each of the agglomerative loci intersect the required correspondence twice, implying two equilibrium levels of population, one with higher population that is stable (solid marker) and one with

outcomes. However, the more persuasive estimates of agglomerative elasticity, which take account of unobserved heterogeneity, are based on wages. Agglomerative wage elasticity will be an upward-biased proxy of agglomerative TFP elasticity if the increased capital intensity that accompanies increasing population dominates increasing land scarcity, which is the case under the baseline scenario. It will be an downward-biased proxy if increasing land scarcity dominates. Agglomerative estimates are typically interpreted as equivalently describing TFP and wages, regardless of the source data (Combes and Gobillion, 2015). 
lower population that is unstable (open marker). For example, a location with exogenous TFP equal to that of the anchor has a high, stable equilibrium at log population 13.8 (population 1 million, solid black marker) and a low, unstable equilibrium at log population 9.6 (population 15 thousand, open black marker). For log "initial" population between these two levels, realized TFP exceeds required and so the location will "grow" toward the high-population equilibrium. ${ }^{28}$ For $\log$ initial population above the high equilibrium, realized TFP is below required and so the location will contract toward the high equilibrium. But if initial population is below the low equilibrium, the location will contract towards a third (stable) equilibrium at zero population, which can be interpreted as using land for agriculture or some other non-metro purpose. ${ }^{29}$

Importantly, the population spread between the the low and high equilibria increases with exogenous TFP. Thus as exogenous TFP increases, the initial population required to attain the high equilibria falls, diminishing the role of chance in determining outcomes. The location with exogenous TFP 6 percent above that of the anchor (purple line) requires an initial log population of only 6.9 (population 1 thousand) to lie within the range of attraction to the stable equilibrium at $\log$ population 14.9 (population 3 million).

In contrast, an exogenous level of TFP that can support only a small metro area requires initial population above some relatively high threshold to lie within the stable range of attraction. The location with exogenous TFP 2 percent below that of the anchor (blue line) requires an initial $\log$ population of at least 11.2 (population 73 thousand) to attain its stable equilibrium at log population 12.9 (population 380 thousand). Chance, such as the chronological order of settlement, thus plays an important role in determining which locations with sufficient exogenous TFP actually develop into small metros.

Figure 20 also illustrates that there exists a minimum equilibrium metro population, where the elasticities of required TFP and agglomerative TFP exactly equal each other. This minimum population thus decreases with the elasticity of required TFP and increases with the elasticity of agglomerative TFP. For the baseline required and agglomerative elasticities in the figure, it occurs approximately midway between the two blue markers, at log population 12.1 (population 180 thousand) and realized log relative TFP of -0.09 . The corresponding minimum exogenous TFP is just 2.5 percent below that of the anchor metro, generating an attainable set of realized TFP a tad below the blue dashed line. Any location with lower exogenous TFP can never attain realized TFP sufficient to support the metro use of land and so eventually end up agricultural or unoccupied.

More generally, agglomerative TFP asymmetrically amplifies variations in exogenous TFP,

\footnotetext{
${ }^{28}$ The model is static and so language that connotes otherwise can be misleading. However, interpreting equilibrium as a long-run steady state leaves space for interpreting tatonement as arising from long run dynamics.

${ }^{29}$ With heterogenous worker types, such as in Eeckhout, Pinheiro, Schmidheiny (2014) and Behrens, Duranton, and Robert-Nicoud (2014), the number of multiple equilibria will increase by an order of magnitude. For example, with two types of workers, the cost and benefit loci will each be two dimensional and equilibria will lie along one dimensional curves where they intersect.
} 
reflecting the convexity of the required correspondence. For example, exogenous TFP 2 percent above that of the anchor increases realized TFP by 4 percentage points and equilibrium population by $0.5 \log$ points (solid green versus solid black marker). Exogenous TFP 2 percent below that of the anchor decreases realized TFP by 6 percentage points and equilibrium population by $1 \log$ point (solid blue versus solid black marker).

\section{Conclusion}

I develop a framework that embeds the monocentric city model in a system of metros, across which utility and perimeter land price are equalized. The core monocentric model is generalized to a fully structural form with leisure in utility and congested commuting. Differences in total factor productivity across metros drive variations in metro population, radius, commute times, house and land prices, and a number of other outcomes.

Commuting congestion proves the critical force constraining metro size, causing population to become increasingly less responsive to increases in TFP as metros grow larger. Self-driving cars are likely to considerably increase the sensitivity of metro population to TFP, both by increasing the leisure content of commute time and by alleviating parking needs. They will increase sensitivity considerably more if they also alleviate congestion.

The concave correspondence of population with TFP implies that the non-causal elasticity of required TFP to population increases with metro size. Benchmark estimates and baseline quantitative results suggest that agglomerative TFP suffices to support increases in metro population from low levels, allowing chance to play a significant role in determining which locations develop into small metros. But agglomerative TFP falls considerably short of supporting increases in population from high levels, suggesting that large metros depend on strong "fundamentals" such as high exogenous TFP.

The quantitative results approximate a number of observed empirical relationships. They closely match the commute times and geographic distribution of workers who drive to the CBD of four benchmark metros - Omaha, Des Moines, Portland, and Denver. They match the flattening of mean commute distance as population increases above an intermediate threshold. Plausible variations in metro TFP generate population, population density, and commute times that span those of U.S. metros except for the very largest. And the range of land prices, house prices, and the elasticity of housing supply are consistent with empirical estimates.

As the model abstracts from many first-order considerations affecting metro size, the approximation of many observed outcomes likely reflects excluded determinants that offset each other or are implicitly embedded in external estimates of structural parameters. Explicitly modeling such determinants gives considerable scope for followup research. One priority is introducing consumption amenities that vary within and across metros. Albouy (2015) finds that net consumption amenities are uncorrelated with metro size, suggesting that positive amenities correlated with size 
offset the negative amenity arising from longer, more congested commutes. Such positive amenities, either exogenous or agglomerative, would lessen the dependence of metro size on productivity. A second, more challenging priority is introducing heterogeneity among residents and workers, which will multiply the number of equilibria.

Finally, the monocentricity of employment stands out as the model's most glaring contrast with observed outcomes. As is self-evident, assumed monocentric land use differs considerably from the process generating actual metros. Nevertheless, the quantitative approximations validate the model's empirical relevance, suggesting that it can help us understand many of the factors determining metro size. Indeed, the implausibly high productivity required to support monocentric metros with population of the very largest U.S. metros, all of which are highly polycentric, further validates the model's empirical relevance for small and medium metros. Like all good economic modeling, the monocentric stylization abstracts and simplifies to give insight.

\section{Bibliography}

Aguiar, Mark and Erik Hurst (2007). "Measuring Trends in Leisure: The Allocation of Time over Five Decades." Quarterly Journal of Economics 122, 969-1006.

Ahlfeldt, Gabriel M. and Daniel P. McMillen (2014). "New Estimates of the Elasticity of Substitution between Land and Capital." Lincoln Institute of Land Policy Working Paper.

Albouy, David (2015). "What Are Cities Worth? Land Rents, Local Productivity, and the Total Value of Amenities." Review of Economics and Statistics, forthcoming.

Albouy, David, Gabriel Ehrlich, and Yingyi Liu (2014). "Housing Demand and Expenditures: How Rising Rent Levels Affect Behavior and Cost-of-Living over Space and Time." University of Illinois working paper.

Albuoy, David and Bert Lue (2014). "Driving to Opportunity: Local Rents, Wages, Commuting Costs and Sub-Metropolitan Quality Of Life." NBER Working Paper 19922.

Alonso, William (1964) Location and Land Use. Cambridge: Harvard University Press.

Anas, Alex, Richard J. Arnott, and Kenneth A. Small (2000). "The Panexponential Monocentric Model." Journal of Urban Economics 47, 165-179.

Arnott, Richard J., and James G. MacKinnon (1977). "The Effects of Urban Transportation Changes: A General Equilibrium Simulation. Journal of Public Economics 8, 19-36.

Becker, Gary S. (1965). "A Theory of the Allocation of Time." The Economic Journal 75, 493-517.

Behrens, Kristian, Gilles Duranton, and Frederic Robert-Nicoud (2014). "Productive Cities: Sorting, Selection, and Agglomeration." Journal of Political Economy 122, 507-553.

Bleakley, Hoyt and Jeffrey Lin (2010). "Portage and Path Dependence." Quarterly Journal of Economics 172, 587-644.

Brinkman, Jeffrey C. (2013). "Congestion, Agglomeration, and the Structure of Cities." Federal Reserve Bank of Philadelphia Working Paper 13-25. 
Brueckner, Jan K. and Sofia F. Franco (2015). "Parking and Urban Form." University of California Irvine, working paper.

Ciccone, Antonio (2002). "Agglomeration Effects in Europe." European Economic Review 46, 213-227.

Combes, Pierre-Philippe and Laurent Gobillon (2015). "The Empirics of Agglomeration Economies." In: Gilles Duranton, Vernon Henderson, and William Strange (Eds.), Handbook of Regional and Urban Economics, Vol 5A. Amsterdam: Elsevier North-Holland, 247-348.

Combes, Pierre-Philippe, Gilles Duranton, and Laurent Gobillon (2016). "The Production Function for Housing: Evidence from France." Working paper.

Davis, Morris and Jonathan Heathcote (2007). "The Price and Quantity of Residential Land in the United States." Journal of Monetary Economics 54, 2595-2620.

Davis, Morris and François Ortalo-Magné (2011). "Household Expenditures, Wages, Rents." Review of Economic Dynamics 14, 248-261.

Duranton, Gilles and Diego Puga (2015). "Urban Land Use." In: Gilles Duranton, Vernon Henderson, and William Strange (Eds.), Handbook of Regional and Urban Economics, Vol 5A. Amsterdam: Elsevier North-Holland, 467-560.

Duranton, Gilles and Matthew A. Turner (2011). "The Fundamental Law of Road Congestion: Evidence from U.S. Cities." American Economic Review 101, 2616-2652.

Eeckhout, Jan, Roberto Pinheiro, and Kurt Schmidheiny (2014). "Spatial Sorting." Journal of Political Economy 122, 554-620.

Fujita, Masahisa (1989). Urban Economic Thoery. Cambridge: Cambridge University Press.

Fujita, Masahisa and Hideaki Ogawa (1982). "Multiple Equilibria and Structural Transition of Non-Monocentric Urban Configurations." Regional Science and Urban Economics 12, 161-196.

Glaeser, Edward L. and Matthew E. Kahn (2001). "Decentralized Employment and the Transformation of the American City." Brookings Wharton Papers on Urban Affairs, 147

Glaeser, Edward L. and Matthew E. Kahn (2004). "Sprawl and Urban Growth." In: Henderson, J. Vernon, Thisse, Jacques Francoise (Eds.), Handbook of Regional and Urban Economics, Vol. 4. Amsterdam: Elsevier North-Holland, 24812527.

Glaeser, Edward, and Joseph Gyourko (2005), "Urban Decline and Durable Housing." Journal of Political Economy 113, 345-375.

Glaeser, Edward, Josehph Gyourko, and Raven Saks (2005). "Why is Manhattan So Expensive." Journal of Law and Economics 48, 331-369

Gollin, Douglas (2002). "Getting Income Shares Right.” Journal of Political Economy 110, 458-474.

Holian, Matthew J., and Matthew E. Kahn (2012). The Impact of Center City Economic and Cultural Vibrancy on Greenhouse Gas Emissions from Transportation. San Jose, CA: MTI Publications. Dataset available from http://mattholian.blogspot.com/2013/05/central-business-districtgeocodes.html

Jackson, Jerry R., Ruth C. Johnson, and David L. Kaserman (1984). "The Measurement of Land Prices and the Elasticity of Substitution in Housing Production." Journal of Urban Economics 16, 
$1-12$.

Jorgenson, Dale W., Mun S. Ho, and Kevin J. Stiroh (2005). "Growth of U.S. Industries and Investments in Information Technology and Higher Education." In Measuring Capital in the New Economy, eds. Carol Corrado, John Haltiwanger, and Daniel Sichel. Chicago IL: University of Chicago Press.

Krueger, Alan B., Daniel Kahneman, David Schkade, Nobert Schwarz, and Arthur A. Stone (2009). "National Time Accounting: The Currency of Life." In Alan B. Krueger, ed., Measuring the Subjective Well-Being of Nations: National Accounts of Time Use and Well-Being. Chicago: NBER and University of Chicago Press.

Larson, William (2015). "New Estimates of Value of Land of the United Sates." Working Paper, U.S. Bureau of Economic Analysis.

Larson, William and Anthony Yezer (2015). "The Energy Implications of City Size and Density." Journal of Urban Economics 90, 35-49.

Li, Wenli, Haiyong Liu, Fang Yang, and Rui Yao (2016). "Housing over Time and over the Life Cycle: A Structural Estimation." International Economic Review (in press).

Liu, Cocker H., Stuart S. Rosenthal, and William C. Strange (2015). "The Vertical City: Rent Gradients and Spatial Structure." Working Paper.

Lucas, Robert E. Jr. and Esteban Rossi-Hansberg (2002). "On the Internal Structure of Cities." Econometrica 70, 1445-1476.

McGrattan, Ellen R, Richard Rogerson, and Randall Wright (1997). "An Equilibrium Model of the Business Cycle with Household Production and Fiscal Policy." International Economic Review $38,267-290$.

McMillen, Daniel P. and Stefani C. Smith (2003). "The Number of Subcenters in Large Urban Areas." Journal of Urban Economics 53, 321-338.

Mills, Edwin S. (1967). "An Aggregative Model of Resource Allocation in a Metropolitan Area." American Economic Review 57, 197-210.

Muth, Richard F. (1969). Cities and Housing. Chicago: University of Chicago Press.

Muth, Richard F. (1975). "Numerical Solution of Urban Residential Land-Use Models." Journal of Urban Economics 2, 307-332.

Rappaport, Jordan (2004). "Why Are Population Flows So Persistent?" Journal of Urban Economics 56, 554-580.

Rappaport, Jordan (2005). "The Shared Fortunes of Cities and Suburbs." Federal Reserve Bank of Kansas City Economic Review, Third Quarter.

Rappaport, Jordan (2008a). "A Productivity Model of City Crowdedness." Journal of Urban Economics 63, 715-722.

Rappaport, Jordan (2008b). "Consumption Amenities and City Population Density." Regional Science and Urban Economics 38, 533-552.

Rappaport, Jordan (2014). "Monocentric City Redux." Federal Reserve Bank of Kansas City Research Working Paper 14-09. 
Rappaport, Jordan and Jeffrey D. Sachs (2003). "The United States as a Coastal Nation." Journal of Economic Growth 8, 5-46

Reichling, Felix and Charles Whalen (2012). "Review of Estimates of the Frisch Elasticity of Labor Supply." Congressional Budget Office Working Paper 2012-13.

Rizzi, Luis L., Juan Pablo Limonado, and Seiji S.C. Steimetz (2012). "The Impact of Traffic Images on Travel Time Valuation in Stated Preference Choice Experiments." Transportmetrica 8, 427-442.

Roback, Jennifer (1982). "Wages, Rents, and the Quality of Life." Journal of Political Economy 90, 1257-1278.

Robinson, John and Geoffrey Godbey (1999). Time for Life: The Surprising Ways Americans Use Their Time. University Park PA: Penn State University Press.

Rosen, Sherwin (1979). "Wage-Based Indexes of Urban Quality of Life." In Miezkowski and Straszheim, Eds., Current Issues in Urban Economics. Baltimore: Johns Hopkins University Press.

Rosenthal, Stuart S. and William C. Strange (2008). "The Attenuation of Human Capital Spillovers." Journal of Urban Economics 64, 373-389.

RSMeans (2007), Square Foot Costs, 2008. Barbara Balboni senior editor. Kingston, MA: Reed Construction Data.

Saiz, Albert (2010). "The Geographic Determinants of Housing Supply." Quarterly Journal of Economics 125, 1253-1296.

Small, Kenneth A. and Erik T. Verhoef (2007). The Economics of Urban Transportation. New York City: Routledge

Small, Kennth A, Clifford Winston and Jia Yan (2005). "Uncovering the Distribution of Motorists' Preferences for Travel Time and Reliability." Econometrica 73, 1367-1382.

Sullivan, Arthur M. (1983). "A General Equilibrium Model with External Scale Economies in Production." Journal of Urban Economics 13, 235-255.

Sullivan, Arthur M. (1986). "A General Equilibrium Model with Agglomerative Economies and Decentralized Employment." Journal of Urban Economics 20, 55-74.

Thorsnes, Paul (1997). "Consistent Estimates of the Elasticity of Substitution between Land and Non-Land Inputs in the Production of Housing." Journal of Urban Economics 42, 98-108.

Wardman, Mark and J. Nicolás Ibáñez (2012). "The Congestion Multiplier: Variations in Motorists' Valuations of Travel Time with Traffic Congestion." Transportation Research Part A 46, 213-225. 


\section{A Summary Tables of Baseline Results}

\begin{tabular}{|c|c|c|c|c|c|c|}
\hline baseline & $\begin{array}{r}\text { (atfp } \\
0.90\end{array}$ & $\begin{array}{r}\text { (atfp } \\
0.95\end{array}$ & $\begin{array}{r}\text { @ tfp } \\
1.00\end{array}$ & $\begin{array}{r}\text { (atfp } \\
1.05\end{array}$ & $\begin{array}{r}\text { (a) } \mathrm{tfp} \\
1.10\end{array}$ & $\begin{array}{r}(0 \mathrm{tfp} \\
1.15\end{array}$ \\
\hline \multicolumn{7}{|l|}{ Size } \\
\hline population & 130,000 & 440,000 & $1,000,000$ & $1,800,000$ & $2,820,000$ & $4,020,000$ \\
\hline land area & 90 sq.mi & 230 sq.mi & 380 sq.mi & 520 sq.mi & 630 sq.mi & 720 sq.m \\
\hline \multicolumn{7}{|c|}{ Commute Distance } \\
\hline mean & $3.3 \mathrm{mi}$ & $5.4 \mathrm{mi}$ & $6.7 \mathrm{mi}$ & $7.4 \mathrm{mi}$ & $7.6 \mathrm{mi}$ & $7.6 \mathrm{~m}$ \\
\hline inner & $0.1 \mathrm{mi}$ & $0.1 \mathrm{mi}$ & $0.1 \mathrm{mi}$ & $0.1 \mathrm{mi}$ & $0.1 \mathrm{mi}$ & $0.1 \mathrm{~m}$ \\
\hline outer & $5.2 \mathrm{mi}$ & $9.5 \mathrm{mi}$ & $13.1 \mathrm{mi}$ & $15.7 \mathrm{mi}$ & $17.6 \mathrm{mi}$ & $19.0 \mathrm{~m}$ \\
\hline \multicolumn{7}{|c|}{ Population Density (ths prs per sqmi) } \\
\hline mean & 1.7 & 2.5 & 4.0 & 6.2 & 9.6 & 14.3 \\
\hline inner & 2.7 & 5.1 & 9.7 & 17.0 & 28.0 & 43.2 \\
\hline outer & 1.1 & 1.1 & 1.1 & 1.1 & 1.1 & 1.1 \\
\hline \multicolumn{7}{|c|}{ Commute Time } \\
\hline mean & $12 \mathrm{~min}$ & $15 \mathrm{~min}$ & $20 \mathrm{~min}$ & $25 \mathrm{~min}$ & $31 \mathrm{~min}$ & $36 \mathrm{~min}$ \\
\hline inner & $8 \mathrm{~min}$ & $8 \mathrm{~min}$ & $8 \mathrm{~min}$ & $8 \mathrm{~min}$ & $8 \mathrm{~min}$ & $8 \mathrm{~min}$ \\
\hline outer & $14 \min$ & $21 \mathrm{~min}$ & $29 \mathrm{~min}$ & $39 \mathrm{~min}$ & $50 \mathrm{~min}$ & $60 \mathrm{~min}$ \\
\hline \multicolumn{7}{|c|}{ Commute Speed } \\
\hline mean & $50 \mathrm{mph}$ & $43 \mathrm{mph}$ & $33 \mathrm{mph}$ & $25 \mathrm{mph}$ & $20 \mathrm{mph}$ & $17 \mathrm{mph}$ \\
\hline inner & $50 \mathrm{mph}$ & $39 \mathrm{mph}$ & $27 \mathrm{mph}$ & $20 \mathrm{mph}$ & $15 \mathrm{mph}$ & $12 \mathrm{mph}$ \\
\hline outer & $50 \mathrm{mph}$ & $50 \mathrm{mph}$ & $50 \mathrm{mph}$ & $50 \mathrm{mph}$ & $50 \mathrm{mph}$ & $50 \mathrm{mph}$ \\
\hline
\end{tabular}

Table A.1: TFP, Metro Size, and Commuting. Table shows size and commuting outcomes when numeraire TFP varies across metros. Population and land area are normalized to a span of $180^{\circ}$. 


\begin{tabular}{|c|c|c|c|c|c|c|}
\hline baseline & $\begin{array}{r}@ \text { tfp } \\
0.90\end{array}$ & $\begin{array}{r}\text { @ tfp } \\
0.95\end{array}$ & $\begin{array}{r}\text { @ tfp } \\
1.00\end{array}$ & $\begin{array}{r}\text { @ tfp } \\
1.05\end{array}$ & $\begin{array}{r}\text { (a)tfp } \\
1.10\end{array}$ & $\begin{array}{r}@ \text { tfp } \\
1.15\end{array}$ \\
\hline Population & 130,000 & 440,000 & $1,000,000$ & $1,800,000$ & $2,820,000$ & $4,020,000$ \\
\hline \multicolumn{7}{|c|}{ Housing Price (index) } \\
\hline mean & 0.70 & 0.83 & 1.00 & 1.22 & 1.50 & 1.82 \\
\hline inner & 0.86 & 1.16 & 1.58 & 2.11 & 2.77 & 3.55 \\
\hline outer & 0.61 & 0.61 & 0.61 & 0.61 & 0.61 & 0.61 \\
\hline \multicolumn{7}{|c|}{ Housing Expenditure (index) } \\
\hline mean & 0.85 & 0.92 & 1.00 & 1.09 & 1.20 & 1.31 \\
\hline inner & 0.93 & 1.06 & 1.22 & 1.39 & 1.59 & 1.79 \\
\hline outer & 0.81 & 0.81 & 0.82 & 0.83 & 0.84 & 0.86 \\
\hline \multicolumn{7}{|c|}{ Land Price (index) } \\
\hline mean & 0.31 & 0.54 & 1.00 & 1.86 & 3.34 & 5.75 \\
\hline inner & 0.56 & 1.30 & 2.95 & 6.23 & 12.11 & 21.84 \\
\hline outer & 0.19 & 0.19 & 0.19 & 0.19 & 0.19 & 0.19 \\
\hline
\end{tabular}

Table A.2: House and Land Prices. Table shows residential prices when TFP varies across metros. Population is normalized to a span of $180^{\circ}$. Indexes are normalized to equal 1 at the mean value in the anchor metro. 


\begin{tabular}{|c|c|c|c|c|c|c|}
\hline baseline & $\begin{array}{r}\text { (a)tfp } \\
0.90\end{array}$ & $\begin{array}{r}@ \text { tfp } \\
0.95\end{array}$ & $\begin{array}{r}@ \text { tfp } \\
1.00\end{array}$ & $\begin{array}{r}@ \text { tfp } \\
1.05\end{array}$ & $\begin{array}{r}\text { @tfp } \\
1.10\end{array}$ & $\begin{array}{r}\text { (a)tfp } \\
1.15\end{array}$ \\
\hline Population & 130,000 & 440,000 & $1,000,000$ & $1,800,000$ & $2,820,000$ & $4,020,000$ \\
\hline \multicolumn{6}{|c|}{ Numeraire Consumption (index) } & 1.09 \\
\hline inner & 0.97 & 1.00 & 1.04 & 1.08 & 1.13 & 1.17 \\
\hline outer & 0.94 & 0.95 & 0.97 & 0.98 & 0.99 & 1.00 \\
\hline \multicolumn{7}{|c|}{ Housing Consumption (index) } \\
\hline mean & 1.17 & 1.09 & 1.00 & 0.92 & 0.85 & 0.78 \\
\hline inner & 1.03 & 0.87 & 0.74 & 0.63 & 0.55 & 0.48 \\
\hline outer & 1.27 & 1.28 & 1.30 & 1.32 & 1.33 & 1.35 \\
\hline \multicolumn{7}{|c|}{ Leisure (includes from commuting) } \\
\hline mean & $57.0 \mathrm{hrs}$ & $56.8 \mathrm{hrs}$ & $56.6 \mathrm{hrs}$ & $56.4 \mathrm{hrs}$ & $56.2 \mathrm{hrs}$ & $56.1 \mathrm{hrs}$ \\
\hline inner & $57.3 \mathrm{hrs}$ & $57.3 \mathrm{hrs}$ & $57.3 \mathrm{hrs}$ & $57.3 \mathrm{hrs}$ & $57.3 \mathrm{hrs}$ & $57.3 \mathrm{hrs}$ \\
\hline outer & $56.9 \mathrm{hrs}$ & $56.5 \mathrm{hrs}$ & $56.1 \mathrm{hrs}$ & $55.6 \mathrm{hrs}$ & $55.2 \mathrm{hrs}$ & $54.8 \mathrm{hrs}$ \\
\hline \multicolumn{7}{|c|}{ Housing Expend Share } \\
\hline mean & 0.155 & 0.162 & 0.170 & 0.179 & 0.188 & 0.197 \\
\hline inner & 0.165 & 0.178 & 0.194 & 0.209 & 0.224 & 0.239 \\
\hline outer & 0.149 & 0.149 & 0.149 & 0.149 & 0.149 & 0.149 \\
\hline
\end{tabular}

Table A.3: Consumption and Leisure. Table shows consumption and leisure when TFP varies across metros. Population is normalized to a span of $180^{\circ}$. Indexes are normalized to equal 1 at the mean value in the anchor metro. Leisure includes both explicit leisure time and leisure derived from commuting. 


\begin{tabular}{|c|c|c|c|c|c|c|}
\hline baseline & $\begin{array}{r}\text { @ tfp } \\
0.90\end{array}$ & $\begin{array}{r}\text { a } \mathrm{tfp} \\
0.95\end{array}$ & $\begin{array}{r}\text { @.tfp } \\
1.00\end{array}$ & $\begin{array}{r}\text { @ tfp } \\
1.05\end{array}$ & $\begin{array}{r}\text { (a)tp } \\
1.10\end{array}$ & $\begin{array}{r}\text { @ tfp } \\
1.15\end{array}$ \\
\hline Population & 130,000 & 440,000 & $1,000,000$ & $1,800,000$ & $2,820,000$ & $4,020,000$ \\
\hline \multicolumn{7}{|c|}{ Housing Structure Density (index) } \\
\hline mean & 0.36 & 0.58 & 1.00 & 1.73 & 2.92 & 4.74 \\
\hline inner & 0.61 & 1.29 & 2.71 & 5.31 & 9.65 & 16.41 \\
\hline outer & 0.23 & 0.23 & 0.23 & 0.23 & 0.23 & 0.23 \\
\hline \multicolumn{7}{|c|}{ Housing Services Density (index) } \\
\hline mean & 0.53 & 0.72 & 1.00 & 1.39 & 1.88 & 2.49 \\
\hline inner & 0.76 & 1.25 & 1.98 & 2.99 & 4.26 & 5.79 \\
\hline outer & 0.40 & 0.40 & 0.40 & 0.40 & 0.40 & 0.40 \\
\hline \multicolumn{7}{|c|}{ Land Factor Share of Housing } \\
\hline mean & 0.329 & 0.339 & 0.350 & 0.361 & 0.372 & 0.383 \\
\hline inner & 0.343 & 0.362 & 0.381 & 0.399 & 0.415 & 0.430 \\
\hline outer & 0.319 & 0.319 & 0.319 & 0.319 & 0.319 & 0.319 \\
\hline \multicolumn{7}{|c|}{ Housing Supply Elasticity } \\
\hline mean & 1.84 & 1.76 & 1.68 & 1.60 & 1.53 & 1.46 \\
\hline inner & 1.72 & 1.58 & 1.46 & 1.35 & 1.27 & 1.19 \\
\hline outer & 1.92 & 1.92 & 1.92 & 1.92 & 1.92 & 1.92 \\
\hline
\end{tabular}

Table A.4: Housing Supply. Table shows measures of housing supply when TFP varies across metros. Population is normalized to a span of $180^{\circ}$. Indexes are normalized to equal 1 at the mean value in the anchor metro. Housing structure and housing services density are the respective ratios of housing capital and housing services to land area. 


\section{B Summary Tables of Alternative Scenarios}

\section{B.1 alternative parameterizations}

\begin{tabular}{|c|c|c|c|c|c|c|}
\hline \multirow{2}{*}{$\begin{array}{l}\text { Alternative } \\
\text { Parameterizations }\end{array}$} & \multicolumn{6}{|c|}{ population } \\
\hline & $\begin{array}{r}@ \mathrm{tfp} \\
0.90\end{array}$ & $\begin{array}{r}0 \mathrm{tfp} \\
0.95\end{array}$ & $\begin{array}{r}@ \mathrm{tfp} \\
1.00\end{array}$ & $\begin{array}{r}@ \mathrm{tfp} \\
1.05\end{array}$ & $\begin{array}{r}\text { @.tfp } \\
1.10\end{array}$ & $\begin{array}{r}\text { atfp } \\
1.15\end{array}$ \\
\hline Baseline & 130,000 & 440,000 & $1,000,000$ & $1,800,000$ & $2,820,000$ & $4,020,000$ \\
\hline \multicolumn{7}{|l|}{ Production } \\
\hline$\alpha_{\mathrm{L}}=0.004(0.016 ; \mathrm{X}$, land factor share $)$ & 40,000 & 340,000 & $1,000,000$ & $1,960,000$ & $3,170,000$ & $4,590,000$ \\
\hline$\alpha_{\mathrm{L}}=0.064(0.016 ; \mathrm{X}$, land factor share $)$ & 380,000 & 640,000 & $1,000,000$ & $1,470,000$ & $2,040,000$ & $2,720,000$ \\
\hline$\sigma_{\mathrm{L}}=0.75(0.90 ; \mathrm{H}, \mathrm{CES} \mathrm{K}$ and $\mathrm{L})$ & 130,000 & 450,000 & $1,000,000$ & $1,740,000$ & $2,610,000$ & $3,580,000$ \\
\hline$\sigma_{\mathrm{L}}=1.05(0.90 ; \mathrm{H}, \mathrm{CES} \mathrm{K}$ and $\mathrm{L})$ & 130,000 & 430,000 & $1,000,000$ & $1,890,000$ & $3,160,000$ & $4,880,000$ \\
\hline $\bar{\mu}_{L, A}=0.25(0.35 ; \mathrm{H}, \mathrm{L}$ mean fctr shr in anchor $)$ & 120,000 & 400,000 & $1,000,000$ & $2,010,000$ & $3,470,000$ & $5,730,000$ \\
\hline $\bar{\mu}_{\mathrm{L}, \mathrm{A}}=0.50(0.35 ; \mathrm{H}, \mathrm{L}$ mean fctr shr in anchor $)$ & 130,000 & 460,000 & $1,000,000$ & $1,700,000$ & $2,500,000$ & $3,390,000$ \\
\hline \multicolumn{7}{|l|}{$\underline{\text { Utility }}$} \\
\hline$\sigma_{\mathrm{h}}=0.50(0.67 ; \mathrm{CES} \mathrm{h}$ and $\mathrm{x})$ & 130,000 & 450,000 & $1,000,000$ & $1,760,000$ & $2,680,000$ & $3,730,000$ \\
\hline$\sigma_{\mathrm{h}}=0.90(0.67 ; \mathrm{CES} \mathrm{h}$ and $\mathrm{x})$ & 120,000 & 430,000 & $1,000,000$ & $1,870,000$ & $3,050,000$ & $4,560,000$ \\
\hline $\bar{\mu}_{\mathrm{h}, \mathrm{A}}=0.14(0.17 ; \mathrm{h}$ mean expnd shr in anchor $)$ & 130,000 & 430,000 & $1,000,000$ & $1,880,000$ & $3,050,000$ & $4,490,000$ \\
\hline $\bar{\mu}_{\mathrm{h}, \mathrm{A}}=0.22(0.17 ; \mathrm{h}$ mean expnd shr in anchor $)$ & 130,000 & 460,000 & $1,000,000$ & $1,730,000$ & $2,600,000$ & $3,600,000$ \\
\hline Frisch $_{\mathrm{A}, 1}=0.10 / \sigma_{l}=0.17 \quad(0.20 / 0.34)$ & 130,000 & 440,000 & $1,000,000$ & $1,800,000$ & $2,810,000$ & $4,010,000$ \\
\hline Frisch $_{\mathrm{A}, 1}=0.40 / \sigma_{l}=0.68(0.20 / 0.34)$ & 130,000 & 440,000 & $1,000,000$ & $1,810,000$ & $2,830,000$ & $4,050,000$ \\
\hline \multicolumn{7}{|l|}{ Commuting } \\
\hline no foregone leisure cost ( $\infty \operatorname{spd}$ or $\lambda=1)$ & 50,000 & 280,000 & $1,000,000$ & $2,740,000$ & $6,330,000$ & $13,060,000$ \\
\hline$\delta=0$ (no distance cost) & 20,000 & 300,000 & $1,000,000$ & $1,850,000$ & $2,820,000$ & $3,920,000$ \\
\hline$\lambda=0$ (no leisure content) & 160,000 & 460,000 & $1,000,000$ & $1,800,000$ & $2,850,000$ & $4,140,000$ \\
\hline$\lambda=1 / 2 \quad$ (constant leisure content $)$ & 90,000 & 380,000 & $1,000,000$ & $2,040,000$ & $3,500,000$ & $5,350,000$ \\
\hline$\sigma_{\mathrm{V}}=0.90($ elas hwy cpcty, base $=0.92)$ & 130,000 & 450,000 & $1,000,000$ & $1,730,000$ & $2,600,000$ & $3,570,000$ \\
\hline$\sigma_{\mathrm{V}}=0.94($ elas hwy cpcty, base $=0.92)$ & 130,000 & 430,000 & $1,000,000$ & $1,880,000$ & $3,090,000$ & $4,630,000$ \\
\hline
\end{tabular}

Table B.1: Alternative Parameterizations: Population versus TFP. Table shows metro population for alternative parameterizations of the process generating outcomes in all metros. Numbers in parentheses give baseline values. Population is normalized to a span of $180^{\circ}$. 


\begin{tabular}{|c|c|c|c|c|c|c|c|c|c|c|c|c|}
\hline \multirow{2}{*}{$\begin{array}{l}\text { Alternative } \\
\text { Parameterizations }\end{array}$} & \multicolumn{6}{|c|}{ mean commute distance (miles) } & \multicolumn{6}{|c|}{ outer commute distance (miles) } \\
\hline & $\begin{array}{r}\text { a } \mathrm{tfp} \\
0.90\end{array}$ & $\begin{array}{r}@ \mathrm{tfp} \\
0.95\end{array}$ & $\begin{array}{r}\text { (a) } \mathrm{tfp} \\
1.00\end{array}$ & $\begin{array}{r}\text { (a) } \mathrm{tfp} \\
1.05\end{array}$ & $\begin{array}{r}\text { (a)tfp } \\
1.10\end{array}$ & $\begin{array}{r}@ \mathrm{tfp} \\
1.15\end{array}$ & $\begin{array}{r}@ \text { tfp } \\
0.90\end{array}$ & $\begin{array}{r}\text { @ tfp } \\
0.95\end{array}$ & $\begin{array}{r}@ \text { tfp } \\
1.00\end{array}$ & $\begin{array}{r}@ \text { tfp } \\
1.05\end{array}$ & $\begin{array}{r}@ \text { tfp } \\
1.10\end{array}$ & $\begin{array}{r}\text { @ tfp } \\
1.15\end{array}$ \\
\hline Baseline & 3.3 & 5.4 & 6.7 & 7.4 & 7.6 & 7.6 & 5.2 & 9.5 & 13.1 & 15.7 & 17.6 & 19.0 \\
\hline \multicolumn{13}{|l|}{ Production } \\
\hline$\alpha_{\mathrm{L}}=0.004(0.016)$ & 1.6 & 4.9 & 6.7 & 7.4 & 7.6 & 7.6 & 2.4 & 8.5 & 13.1 & 16.1 & 18.1 & 19.5 \\
\hline$\alpha_{\mathrm{L}}=0.064(0.016)$ & 5.1 & 6.0 & 6.7 & 7.2 & 7.5 & 7.6 & 9.0 & 11.1 & 13.1 & 14.8 & 16.2 & 17.5 \\
\hline$\sigma_{\mathrm{L}}=0.75(0.90)$ & 3.1 & 5.5 & 7.1 & 8.1 & 8.6 & 9.0 & 4.9 & 9.4 & 13.1 & 15.9 & 18.0 & 19.6 \\
\hline$\sigma_{\mathrm{L}}=1.05(0.90)$ & 3.4 & 5.3 & 6.3 & 6.6 & 6.4 & 5.9 & 5.6 & 9.7 & 13.1 & 15.5 & 17.1 & 18.3 \\
\hline $\bar{\mu}_{\mathrm{L}, \mathrm{A}}=0.25(0.35)$ & 3.2 & 4.0 & 4.4 & 4.4 & 4.3 & 4.1 & 7.4 & 10.5 & 13.1 & 14.9 & 16.2 & 17.2 \\
\hline $\bar{\mu}_{\mathrm{L}, \mathrm{A}}=0.50(0.35)$ & 2.9 & 5.7 & 7.7 & 8.9 & 9.7 & 10.1 & 4.4 & 9.1 & 13.1 & 16.1 & 18.5 & 20.3 \\
\hline \multicolumn{13}{|l|}{$\underline{\text { Utility }}$} \\
\hline$\sigma_{\mathrm{h}}=0.50(0.67)$ & 3.3 & 5.4 & 6.8 & 7.6 & 8.0 & 8.2 & 5.2 & 9.5 & 13.1 & 15.7 & 17.7 & 19.2 \\
\hline$\sigma_{\mathrm{h}}=0.90(0.67)$ & 3.3 & 5.3 & 6.5 & 7.0 & 7.0 & 6.7 & 5.2 & 9.6 & 13.1 & 15.6 & 17.4 & 18.7 \\
\hline $\bar{\mu}_{h, A}=0.14(0.17)$ & 3.4 & 4.9 & 5.8 & 6.1 & 6.2 & 6.0 & 6.1 & 9.9 & 13.1 & 15.3 & 17.0 & 18.1 \\
\hline $\bar{\mu}_{\mathrm{h}, \mathrm{A}}=0.22(0.17)$ & 3.0 & 5.6 & 7.4 & 8.4 & 9.0 & 9.2 & 4.6 & 9.2 & 13.1 & 16.0 & 18.2 & 19.8 \\
\hline Frisch $_{\mathrm{A}, 1}=0.10 / \sigma_{l}=0.17$ & 3.3 & 5.4 & 6.7 & 7.4 & 7.6 & 7.6 & 5.3 & 9.6 & 13.1 & 15.6 & 17.5 & 18.8 \\
\hline Frisch $_{\mathrm{A}, 1}=0.40 / \sigma_{l}=0.68$ & 3.2 & 5.3 & 6.7 & 7.4 & 7.7 & 7.7 & 5.1 & 9.5 & 13.1 & 15.8 & 17.9 & 19.4 \\
\hline \multicolumn{13}{|l|}{ Commuting } \\
\hline no foregone leisure cost & 1.6 & 4.4 & 7.6 & 10.8 & 13.9 & 16.9 & 2.3 & 7.0 & 13.1 & 19.9 & 27.2 & 34.9 \\
\hline$\delta=0($ no distance cost $)$ & 0.8 & 4.7 & 8.2 & 9.5 & 9.9 & 9.8 & 1.1 & 7.0 & 13.1 & 16.6 & 18.9 & 20.4 \\
\hline$\lambda=0$ (no leisure) & 3.7 & 5.1 & 5.9 & 6.4 & 6.6 & 6.6 & 6.7 & 10.2 & 13.1 & 15.3 & 17.0 & 18.3 \\
\hline$\lambda=1 / 2 \quad($ constant leisure $)$ & 2.7 & 5.1 & 7.0 & 8.3 & 9.0 & 9.4 & 4.2 & 8.7 & 13.1 & 16.8 & 19.7 & 21.9 \\
\hline$\sigma_{\mathrm{V}}=0.90($ base $=0.92)$ & 3.2 & 5.4 & 6.8 & 7.3 & 7.4 & 7.3 & 5.1 & 9.5 & 13.1 & 15.5 & 17.2 & 18.3 \\
\hline$\sigma_{\mathrm{V}}=0.94($ base $=0.92)$ & 3.4 & 5.3 & 6.6 & 7.4 & 7.8 & 8.0 & 5.4 & 9.5 & 13.1 & 15.9 & 18.1 & 19.9 \\
\hline
\end{tabular}

Table B.2: Alternative Parameterizations: Commute Distance versus TFP. Table shows commute distances for alternative parameterizations of the process generating outcomes in all metros. Numbers in parentheses give baseline values. 


\begin{tabular}{|c|c|c|c|c|c|c|c|c|c|c|c|c|}
\hline \multirow{2}{*}{$\begin{array}{l}\text { Alternative } \\
\text { Parameterizations }\end{array}$} & \multicolumn{6}{|c|}{ mean pop density (ths prs per sq mi) } & \multicolumn{6}{|c|}{ inner pop density (ths prs per sq mi) } \\
\hline & $\begin{array}{r}@ \text { tfp } \\
0.90\end{array}$ & $\begin{array}{r}@ \text { tfp } \\
0.95\end{array}$ & $\begin{array}{r}@ \text { tfp } \\
1.00\end{array}$ & $\begin{array}{r}@ \text { tfp } \\
1.05\end{array}$ & $\begin{array}{r}@ \text { tfp } \\
1.10\end{array}$ & $\begin{array}{r}@ \text { tfp } \\
1.15\end{array}$ & $\begin{array}{r}@ \text { tfp } \\
0.90\end{array}$ & $\begin{array}{r}@ \text { tfp } \\
0.95\end{array}$ & $\begin{array}{r}@ \text { tfp } \\
1.00\end{array}$ & $\begin{array}{r}\text { @tfp } \\
1.05\end{array}$ & $\begin{array}{r}\text { @ tfp } \\
1.10\end{array}$ & $\begin{array}{r}\text { @ tfp } \\
1.15\end{array}$ \\
\hline Baseline & 1.7 & 2.5 & 4.0 & 6.2 & 9.6 & 14.3 & 2.7 & 5.1 & 9.7 & 17.0 & 28.0 & 43.2 \\
\hline \multicolumn{13}{|l|}{ Production } \\
\hline$\alpha_{\mathrm{L}}=0.004(0.016)$ & 1.3 & 2.2 & 4.0 & 6.7 & 10.9 & 16.7 & 1.7 & 4.4 & 9.7 & 18.6 & 32.1 & 51.1 \\
\hline$\alpha_{\mathrm{L}}=0.064(0.016)$ & 2.3 & 3.0 & 4.0 & 5.3 & 7.0 & 9.3 & 4.7 & 6.7 & 9.7 & 13.8 & 19.5 & 26.9 \\
\hline$\sigma_{\mathrm{L}}=0.75(0.90)$ & 1.8 & 2.5 & 3.5 & 4.9 & 6.7 & 8.7 & 2.7 & 4.7 & 7.8 & 11.9 & 17.1 & 23.3 \\
\hline$\sigma_{\mathrm{L}}=1.05(0.90)$ & 1.5 & 2.5 & 4.5 & 8.6 & 16.6 & 31.8 & 2.7 & 5.7 & 12.5 & 26.8 & 55.3 & 109.7 \\
\hline $\bar{\mu}_{\mathrm{L}, \mathrm{A}}=0.25(0.35)$ & 1.6 & 4.0 & 9.1 & 18.6 & 35.0 & 64.2 & 3.8 & 10.3 & 24.6 & 52.8 & 102.2 & 179.7 \\
\hline $\bar{\mu}_{L, A}=0.50(0.35)$ & 2.0 & 2.4 & 3.1 & 4.0 & 5.1 & 6.5 & 2.6 & 3.9 & 6.1 & 9.0 & 12.8 & 17.4 \\
\hline \multicolumn{13}{|l|}{ Utility } \\
\hline$\sigma_{\mathrm{h}}=0.50(0.67)$ & 1.7 & 2.5 & 3.8 & 5.6 & 8.0 & 11.1 & 2.7 & 5.0 & 8.8 & 14.4 & 21.9 & 31.4 \\
\hline$\sigma_{\mathrm{h}}=0.90(0.67)$ & 1.6 & 2.5 & 4.2 & 7.4 & 12.9 & 22.2 & 2.6 & 5.3 & 11.0 & 21.8 & 41.1 & 73.3 \\
\hline $\bar{\mu}_{\mathrm{h}, \mathrm{A}}=0.14$ & 1.5 & 2.8 & 5.3 & 9.5 & 15.9 & 25.2 & 3.0 & 6.7 & 14.1 & 26.9 & 46.9 & 75.9 \\
\hline $\bar{\mu}_{\mathrm{h}, \mathrm{A}}=0.22(0.17)$ & 1.9 & 2.4 & 3.3 & 4.5 & 6.3 & 8.5 & 2.6 & 4.2 & 7.0 & 11.2 & 17.0 & 24.7 \\
\hline Frisch $_{\mathrm{A}, 1}=0.10 / \sigma_{l}=0.17$ & 1.6 & 2.5 & 3.9 & 6.2 & 9.6 & 14.3 & 2.6 & 5.1 & 9.6 & 16.9 & 27.8 & 42.9 \\
\hline Frisch $_{\mathrm{A}, 1}=0.40 / \sigma_{l}=0.68$ & 1.7 & 2.5 & 4.0 & 6.2 & 9.6 & 14.2 & 2.7 & 5.2 & 9.8 & 17.3 & 28.3 & 43.8 \\
\hline \multicolumn{13}{|l|}{ Commuting } \\
\hline no foregone leisure cost & 1.8 & 2.3 & 3.1 & 4.6 & 6.7 & 9.6 & 2.1 & 3.5 & 6.0 & 10.0 & 15.9 & 24.0 \\
\hline$\delta=0($ no distance cost $)$ & 2.2 & 2.3 & 2.9 & 4.0 & 5.8 & 8.4 & 2.2 & 2.8 & 5.1 & 9.4 & 16.3 & 26.3 \\
\hline$\lambda=0$ (no leisure) & 1.7 & 2.9 & 5.0 & 8.2 & 12.7 & 18.9 & 3.4 & 6.9 & 12.8 & 22.3 & 36.1 & 55.1 \\
\hline$\lambda=1 / 2 \quad($ constant leisure $)$ & 1.6 & 2.4 & 3.6 & 5.6 & 8.5 & 12.5 & 2.4 & 4.5 & 8.2 & 14.3 & 23.4 & 36.2 \\
\hline$\sigma_{\mathrm{V}}=0.90$ (base $\left.=0.92\right)$ & 1.7 & 2.5 & 3.9 & 6.1 & 9.4 & 13.8 & 2.7 & 5.1 & 9.6 & 17.0 & 28.2 & 43.7 \\
\hline$\sigma_{\mathrm{V}}=0.94($ base $=0.92)$ & 1.6 & 2.5 & 4.0 & 6.4 & 9.9 & 14.8 & 2.7 & 5.2 & 9.8 & 17.1 & 27.8 & 42.7 \\
\hline
\end{tabular}

Table B.3: Alternative Parameterizations: Population Density versus TFP. Table shows population density for alternative parameterizations of the process generating outcomes in all metros. Numbers in parentheses give baseline values. Mean density is weighted by population. 


\begin{tabular}{|c|c|c|c|c|c|c|c|c|c|c|c|c|}
\hline \multirow{2}{*}{$\begin{array}{l}\text { Alternative } \\
\text { Parameterizations }\end{array}$} & \multicolumn{6}{|c|}{ mean commute time (minutes) } & \multicolumn{6}{|c|}{ outer commute time (minutes) } \\
\hline & $\begin{array}{r}0 \mathrm{tfp} \\
0.90\end{array}$ & $\begin{array}{r}@ \operatorname{tfp} \\
0.95\end{array}$ & $\begin{array}{r}@ \mathrm{tfp} \\
1.00\end{array}$ & $\begin{array}{r}@ \mathrm{tfp} \\
1.05\end{array}$ & $\begin{array}{r}\text { atfp } \\
1.10\end{array}$ & $\begin{array}{r}@ \mathrm{tfp} \\
1.15\end{array}$ & $\begin{array}{r}@ \mathrm{tfp} \\
0.90\end{array}$ & $\begin{array}{r}@ \mathrm{tfp} \\
0.95\end{array}$ & $\begin{array}{r}@ \mathrm{tfp} \\
1.00\end{array}$ & $\begin{array}{r}@ \mathrm{tfp} \\
1.05\end{array}$ & $\begin{array}{r}@ \mathrm{tfp} \\
1.10\end{array}$ & $\begin{array}{r}\text { atfp } \\
1.15\end{array}$ \\
\hline Baseline & 12 & 15 & 20 & 25 & 31 & 36 & 14 & 21 & 29 & 39 & 50 & 60 \\
\hline \multicolumn{13}{|l|}{$\underline{\text { Production }}$} \\
\hline$\alpha_{\mathrm{L}}=0.004(0.016)$ & 10 & 14 & 20 & 26 & 32 & 38 & 11 & 19 & 29 & 41 & 53 & 64 \\
\hline$\alpha_{L}=0.064(0.016)$ & 15 & 17 & 20 & 23 & 27 & 30 & 20 & 24 & 29 & 35 & 42 & 49 \\
\hline$\sigma_{\mathrm{L}}=0.75(0.90)$ & 12 & 16 & 21 & 27 & 32 & 38 & 14 & 20 & 29 & 39 & 50 & 60 \\
\hline$\sigma_{\mathrm{L}}=1.05(0.90)$ & 12 & 15 & 20 & 24 & 28 & 32 & 15 & 21 & 29 & 39 & 49 & 59 \\
\hline $\bar{\mu}_{L, A}=0.25(0.35)$ & 12 & 14 & 17 & 21 & 25 & 28 & 17 & 22 & 29 & 38 & 47 & 57 \\
\hline $\bar{\mu}_{L, A}=0.50(0.35)$ & 11 & 16 & 21 & 28 & 34 & 40 & 13 & 20 & 29 & 40 & 50 & 61 \\
\hline \multicolumn{13}{|l|}{ Utility } \\
\hline$\sigma_{\mathrm{h}}=0.50(0.67)$ & 12 & 16 & 21 & 26 & 32 & 37 & 14 & 21 & 30 & 39 & 50 & 60 \\
\hline$\sigma_{\mathrm{h}}=0.90(0.67)$ & 12 & 15 & 20 & 25 & 29 & 33 & 14 & 21 & 29 & 39 & 49 & 59 \\
\hline $\bar{\mu}_{\mathrm{h}, \mathrm{A}}=0.14 \quad(0.17)$ & 12 & 15 & 19 & 24 & 28 & 33 & 15 & 21 & 29 & 39 & 49 & 59 \\
\hline $\bar{\mu}_{h, A}=0.22(0.17)$ & 12 & 16 & 21 & 27 & 33 & 38 & 14 & 20 & 29 & 40 & 50 & 60 \\
\hline Frisch $_{\mathrm{A}, 1}=0.10 / \sigma_{l}=0.17$ & 12 & 16 & 20 & 25 & 31 & 35 & 14 & 21 & 29 & 39 & 49 & 59 \\
\hline Frisch $_{\mathrm{A}, 1}=0.40 / \sigma_{l}=0.68$ & 12 & 15 & 20 & 26 & 31 & 36 & 14 & 21 & 29 & 39 & 50 & 61 \\
\hline \multicolumn{13}{|l|}{ Commuting } \\
\hline$\lambda=1 \quad$ (no foregone leisure) & 10 & 14 & 22 & 41 & 78 & 105 & 11 & 17 & 30 & 60 & 118 & 176 \\
\hline$\delta=0$ (no distance cost) & 9 & 14 & 23 & 32 & 39 & 44 & 9 & 17 & 31 & 45 & 58 & 69 \\
\hline$\lambda=0$ (no leisure) & 12 & 15 & 19 & 24 & 29 & 34 & 16 & 22 & 29 & 38 & 48 & 58 \\
\hline$\lambda=1 / 2$ (constant leisure) & 11 & 15 & 21 & 29 & 38 & 48 & 13 & 19 & 29 & 43 & 60 & 79 \\
\hline$\sigma_{\mathrm{V}}=0.90($ base $=0.92)$ & 12 & 15 & 20 & 26 & 32 & 37 & 14 & 20 & 29 & 39 & 50 & 60 \\
\hline$\sigma_{\mathrm{V}}=0.94($ base $=0.92)$ & 12 & 16 & 20 & 25 & 30 & 34 & 14 & 21 & 30 & 39 & 49 & 59 \\
\hline
\end{tabular}

Table B.4: Alternative Parameterizations: Commute Time versus TFP. Table shows commute times for alternative parameterizations of the process generating outcomes in all metros. Numbers in parentheses give baseline values. 


\begin{tabular}{|c|c|c|c|c|c|c|c|c|c|c|c|c|}
\hline \multirow{2}{*}{$\begin{array}{l}\text { Alternative } \\
\text { Parameterizations }\end{array}$} & \multicolumn{6}{|c|}{ mean commute speed (mph) } & \multicolumn{6}{|c|}{ inner commute speed (mph) } \\
\hline & $\begin{array}{r}@ \text { tfp } \\
0.90\end{array}$ & $\begin{array}{r}@ \mathrm{tfp} \\
0.95\end{array}$ & $\begin{array}{r}@ \mathrm{tfp} \\
1.00\end{array}$ & $\begin{array}{r}@ \mathrm{tfp} \\
1.05\end{array}$ & $\begin{array}{r}0 \mathrm{tfp} \\
1.10\end{array}$ & $\begin{array}{r}@ \mathrm{tfp} \\
1.15\end{array}$ & $\begin{array}{r}\text { atfp } \\
0.90\end{array}$ & $\begin{array}{r}0 \mathrm{tfp} \\
0.95\end{array}$ & $\begin{array}{r}@ \mathrm{tfp} \\
1.00\end{array}$ & $\begin{array}{r}@ \mathrm{tfp} \\
1.05\end{array}$ & $\begin{array}{r}@ \mathrm{tfp} \\
1.10\end{array}$ & $\begin{array}{r}@ \mathrm{tfp} \\
1.15\end{array}$ \\
\hline Baseline & 50 & 42 & 31 & 24 & 19 & 15 & 50 & 39 & 27 & 20 & 15 & 12 \\
\hline \multicolumn{13}{|l|}{$\underline{\text { Production }}$} \\
\hline$\alpha_{\mathrm{L}}=0.004(0.016)$ & 50 & 45 & 31 & 23 & 18 & 14 & 50 & 42 & 27 & 19 & 14 & 11 \\
\hline$\alpha_{\mathrm{L}}=0.064(0.016)$ & 44 & 37 & 31 & 26 & 22 & 19 & 41 & 33 & 27 & 22 & 19 & 16 \\
\hline$\sigma_{\mathrm{L}}=0.75(0.90)$ & 50 & 43 & 32 & 25 & 20 & 17 & 50 & 39 & 28 & 21 & 17 & 14 \\
\hline$\sigma_{\mathrm{L}}=1.05(0.90)$ & 50 & 42 & 31 & 23 & 17 & 13 & 50 & 38 & 26 & 19 & 14 & 10 \\
\hline $\bar{\mu}_{L, A}=0.25(0.35)$ & 50 & 39 & 27 & 19 & 14 & 11 & 50 & 35 & 23 & 15 & 10 & 10 \\
\hline $\bar{\mu}_{L, A}=0.50(0.35)$ & 50 & 43 & 33 & 26 & 21 & 18 & 50 & 40 & 29 & 23 & 18 & 15 \\
\hline \multicolumn{13}{|l|}{ Utility } \\
\hline$\sigma_{\mathrm{h}}=0.50(0.67)$ & 50 & 42 & 31 & 24 & 19 & 16 & 50 & 38 & 27 & 20 & 16 & 13 \\
\hline$\sigma_{\mathrm{h}}=0.90(0.67)$ & 50 & 43 & 32 & 24 & 18 & 14 & 50 & 39 & 27 & 20 & 15 & 11 \\
\hline $\bar{\mu}_{\mathrm{h}, \mathrm{A}}=0.14$ & 50 & 41 & 30 & 22 & 17 & 13 & 50 & 37 & 25 & 18 & 13 & 10 \\
\hline $\bar{\mu}_{\mathrm{h}, \mathrm{A}}=0.22(0.17)$ & 50 & 43 & 33 & 25 & 21 & 17 & 50 & 40 & 29 & 22 & 17 & 14 \\
\hline Frisch $_{\mathrm{A}, 1}=0.10 / \sigma_{l}=0.17$ & 50 & 42 & 31 & 24 & 19 & 15 & 50 & 39 & 27 & 20 & 15 & 12 \\
\hline Frisch $_{\mathrm{A}, 1}=0.40 / \sigma_{l}=0.68$ & 50 & 42 & 31 & 24 & 19 & 15 & 50 & 39 & 27 & 20 & 15 & 12 \\
\hline \multicolumn{13}{|l|}{ Commuting } \\
\hline$\lambda=1 \quad$ (no foregone leisure) & 50 & 47 & 31 & 19 & 11 & 10 & 50 & 45 & 27 & 16 & 10 & 10 \\
\hline$\delta=0$ (no distance cost $)$ & 50 & 46 & 31 & 23 & 18 & 15 & 50 & 44 & 27 & 20 & 15 & 12 \\
\hline$\lambda=0$ (no leisure) & 50 & 41 & 30 & 23 & 18 & 14 & 50 & 37 & 26 & 19 & 14 & 11 \\
\hline$\lambda=1 / 2$ (constant leisure) & 50 & 44 & 32 & 23 & 17 & 13 & 50 & 41 & 28 & 19 & 14 & 10 \\
\hline$\sigma_{\mathrm{V}}=0.90($ base $=0.92)$ & 50 & 44 & 31 & 23 & 17 & 14 & 50 & 40 & 27 & 18 & 13 & 10 \\
\hline$\sigma_{\mathrm{V}}=0.94($ base $=0.92)$ & 50 & 40 & 31 & 25 & 21 & 17 & 49 & 37 & 28 & 22 & 18 & 15 \\
\hline
\end{tabular}

Table B.5: Alternative Parameterizations: Commute Speed versus TFP. Table shows mean commute speed (aggregate miles divided by aggregate drive time) and speed through the innermost ring for alternative parameterizations of the process generating outcomes in all metros. Numbers in parentheses give baseline values. 


\begin{tabular}{|c|c|c|c|c|c|c|c|c|c|c|c|c|}
\hline \multirow{2}{*}{$\begin{array}{l}\text { Alternative } \\
\text { Parameterizations }\end{array}$} & \multicolumn{6}{|c|}{ mean price of housing services } & \multicolumn{6}{|c|}{ inner price of housing services } \\
\hline & $\begin{array}{r}@ \mathrm{tfp} \\
0.90\end{array}$ & $\begin{array}{r}@ \mathrm{tfp} \\
0.95\end{array}$ & $\begin{array}{r}\infty \mathrm{tfp} \\
1.00\end{array}$ & $\begin{array}{r}@ \mathrm{tfp} \\
1.05\end{array}$ & $\begin{array}{r}a \mathrm{tfp} \\
1.10\end{array}$ & $\begin{array}{r}@ \mathrm{tfp} \\
1.15\end{array}$ & $\begin{array}{r}@ \mathrm{tfp} \\
0.90\end{array}$ & $\begin{array}{r}0 \mathrm{tfp} \\
0.95\end{array}$ & $\begin{array}{r}\infty \mathrm{tfp} \\
1.00\end{array}$ & $\begin{array}{r}@ \mathrm{tfp} \\
1.05\end{array}$ & $\begin{array}{r}@ \mathrm{tfp} \\
1.10\end{array}$ & $\begin{array}{r}\infty \mathrm{tfp} \\
1.15\end{array}$ \\
\hline Baseline & 0.70 & 0.83 & 1.00 & 1.22 & 1.50 & 1.82 & 0.86 & 1.16 & 1.58 & 2.11 & 2.77 & 3.55 \\
\hline \multicolumn{13}{|l|}{$\underline{\text { Production }}$} \\
\hline$\alpha_{\mathrm{L}}=0.004(0.016)$ & 0.64 & 0.79 & 1.00 & 1.27 & 1.59 & 1.97 & 0.72 & 1.08 & 1.58 & 2.21 & 2.99 & 3.92 \\
\hline$\alpha_{\mathrm{L}}=0.064(0.016)$ & 0.81 & 0.89 & 1.00 & 1.13 & 1.29 & 1.47 & 1.11 & 1.32 & 1.58 & 1.89 & 2.27 & 2.71 \\
\hline$\sigma_{\mathrm{L}}=0.75(0.90)$ & 0.72 & 0.84 & 1.00 & 1.20 & 1.44 & 1.73 & 0.87 & 1.17 & 1.59 & 2.14 & 2.81 & 3.62 \\
\hline$\sigma_{\mathrm{L}}=1.05(0.90)$ & 0.68 & 0.81 & 1.00 & 1.25 & 1.57 & 1.96 & 0.85 & 1.15 & 1.56 & 2.08 & 2.70 & 3.44 \\
\hline $\bar{\mu}_{L, A}=0.25(0.35)$ & 0.62 & 0.79 & 1.00 & 1.26 & 1.56 & 1.96 & 0.82 & 1.11 & 1.49 & 1.97 & 2.56 & 3.25 \\
\hline $\bar{\mu}_{L, A}=0.50(0.35)$ & 0.75 & 0.85 & 1.00 & 1.19 & 1.42 & 1.70 & 0.88 & 1.18 & 1.61 & 2.17 & 2.86 & 3.68 \\
\hline \multicolumn{13}{|l|}{ Utility } \\
\hline$\sigma_{\mathrm{h}}=0.50(0.67)$ & 0.70 & 0.83 & 1.00 & 1.21 & 1.44 & 1.72 & 0.87 & 1.17 & 1.58 & 2.07 & 2.65 & 3.31 \\
\hline$\sigma_{\mathrm{h}}=0.90(0.67)$ & 0.70 & 0.82 & 1.00 & 1.25 & 1.58 & 2.02 & 0.85 & 1.14 & 1.58 & 2.18 & 2.97 & 4.01 \\
\hline $\bar{\mu}_{\mathrm{h}, \mathrm{A}}=0.14 \quad(0.17)$ & 0.60 & 0.77 & 1.00 & 1.30 & 1.67 & 2.11 & 0.81 & 1.17 & 1.67 & 2.34 & 3.18 & 4.21 \\
\hline $\bar{\mu}_{\mathrm{h}, \mathrm{A}}=0.22(0.17)$ & 0.79 & 0.88 & 1.00 & 1.15 & 1.33 & 1.55 & 0.91 & 1.14 & 1.45 & 1.85 & 2.31 & 2.85 \\
\hline Frisch $_{\mathrm{A}, 1}=0.10 / \sigma_{l}=0.17$ & 0.70 & 0.82 & 1.00 & 1.22 & 1.50 & 1.82 & 0.86 & 1.16 & 1.58 & 2.11 & 2.77 & 3.55 \\
\hline Frisch $_{\mathrm{A}, 1}=0.40 / \sigma_{l}=0.68$ & 0.70 & 0.83 & 1.00 & 1.22 & 1.49 & 1.81 & 0.86 & 1.16 & 1.57 & 2.11 & 2.76 & 3.54 \\
\hline \multicolumn{13}{|l|}{ Commuting } \\
\hline no foregone leisure cost & 0.79 & 0.87 & 1.00 & 1.18 & 1.41 & 1.68 & 0.85 & 1.06 & 1.37 & 1.76 & 2.24 & 2.81 \\
\hline$\delta=0$ (no distance cost) & 0.88 & 0.91 & 1.00 & 1.15 & 1.35 & 1.60 & 0.89 & 0.99 & 1.30 & 1.77 & 2.36 & 3.07 \\
\hline$\lambda=0$ (no leisure) & 0.64 & 0.79 & 1.00 & 1.25 & 1.55 & 1.89 & 0.88 & 1.21 & 1.64 & 2.19 & 2.85 & 3.64 \\
\hline$\lambda=1 / 2 \quad$ (constant leisure $)$ & 0.72 & 0.84 & 1.00 & 1.21 & 1.47 & 1.77 & 0.85 & 1.12 & 1.50 & 1.99 & 2.60 & 3.32 \\
\hline$\sigma_{\mathrm{V}}=0.90($ base $=0.92)$ & 0.71 & 0.83 & 1.00 & 1.22 & 1.48 & 1.79 & 0.87 & 1.16 & 1.58 & 2.12 & 2.79 & 3.59 \\
\hline$\sigma_{\mathrm{V}}=0.94($ base $=0.92)$ & 0.69 & 0.82 & 1.00 & 1.23 & 1.51 & 1.84 & 0.86 & 1.16 & 1.57 & 2.10 & 2.74 & 3.50 \\
\hline
\end{tabular}

Table B.6: Alternative Parameterizations: Housing Price versus TFP. Table shows the price of housing services for alternative parameterizations of the process generating outcomes in all metros. Numbers in parentheses give baseline values. 


\begin{tabular}{|c|c|c|c|c|c|c|c|c|c|c|c|c|}
\hline \multirow{2}{*}{$\begin{array}{l}\text { Alternative } \\
\text { Parameterizations }\end{array}$} & \multicolumn{6}{|c|}{ mean price of land services } & \multicolumn{6}{|c|}{ inner price of land services } \\
\hline & $\begin{array}{r}0 \mathrm{tfp} \\
0.90\end{array}$ & $\begin{array}{r}@ \mathrm{tfp} \\
0.95\end{array}$ & $\begin{array}{r}\text { atfp } \\
1.00\end{array}$ & $\begin{array}{r}@ \mathrm{tfp} \\
1.05\end{array}$ & $\begin{array}{r}\text { @tfp } \\
1.10\end{array}$ & $\begin{array}{r}@ \mathrm{tfp} \\
1.15\end{array}$ & $\begin{array}{r}0 \mathrm{tfp} \\
0.90\end{array}$ & $\begin{array}{r}0 \mathrm{tfp} \\
0.95\end{array}$ & $\begin{array}{r}\text { atfp } \\
1.00\end{array}$ & $\begin{array}{r}@ \mathrm{tfp} \\
1.05\end{array}$ & $\begin{array}{r}(\mathrm{tfp} \\
1.10\end{array}$ & $\begin{array}{r}@ \mathrm{tfp} \\
1.15\end{array}$ \\
\hline Baseline & 0.31 & 0.54 & 1.00 & 1.86 & 3.34 & 5.75 & 0.56 & 1.30 & 2.95 & 6.23 & 12.11 & 21.84 \\
\hline \multicolumn{13}{|l|}{ Production } \\
\hline$\alpha_{\mathrm{L}}=0.004(0.016)$ & 0.23 & 0.47 & 1.00 & 2.06 & 3.97 & 7.13 & 0.32 & 1.05 & 2.95 & 7.02 & 14.62 & 27.49 \\
\hline$\alpha_{\mathrm{L}}=0.064(0.016)$ & 0.50 & 0.69 & 1.00 & 1.47 & 2.17 & 3.19 & 1.15 & 1.83 & 2.95 & 4.72 & 7.45 & 11.50 \\
\hline$\sigma_{\mathrm{L}}=0.75(0.90)$ & 0.34 & 0.57 & 1.00 & 1.70 & 2.77 & 4.28 & 0.60 & 1.35 & 2.90 & 5.60 & 9.86 & 16.06 \\
\hline$\sigma_{\mathrm{L}}=1.05(0.90)$ & 0.28 & 0.50 & 1.00 & 2.10 & 4.48 & 9.41 & 0.52 & 1.23 & 3.01 & 7.17 & 16.35 & 35.46 \\
\hline $\bar{\mu}_{L, A}=0.25(0.35)$ & 0.12 & 0.36 & 1.00 & 2.47 & 5.54 & 12.01 & 0.32 & 1.06 & 3.15 & 8.23 & 19.11 & 39.63 \\
\hline $\bar{\mu}_{L, A}=0.50(0.35)$ & 0.53 & 0.70 & 1.00 & 1.46 & 2.14 & 3.09 & 0.74 & 1.31 & 2.39 & 4.19 & 6.95 & 10.95 \\
\hline \multicolumn{13}{|l|}{ Utility } \\
\hline$\sigma_{\mathrm{h}}=0.50(0.67)$ & 0.32 & 0.55 & 1.00 & 1.78 & 3.02 & 4.89 & 0.58 & 1.34 & 2.95 & 5.93 & 10.89 & 18.49 \\
\hline$\sigma_{\mathrm{h}}=0.90(0.67)$ & 0.30 & 0.52 & 1.00 & 1.99 & 3.95 & 7.62 & 0.53 & 1.24 & 2.95 & 6.73 & 14.42 & 28.99 \\
\hline $\bar{\mu}_{\mathrm{h}, \mathrm{A}}=0.14 \quad(0.17)$ & 0.19 & 0.44 & 1.00 & 2.15 & 4.28 & 7.93 & 0.43 & 1.22 & 3.18 & 7.40 & 15.52 & 29.70 \\
\hline $\bar{\mu}_{\mathrm{h}, \mathrm{A}}=0.22(0.17)$ & 0.47 & 0.66 & 1.00 & 1.57 & 2.47 & 3.82 & 0.69 & 1.31 & 2.56 & 4.77 & 8.42 & 14.06 \\
\hline Frisch $_{\mathrm{A}, 1}=0.10 / \sigma_{l}=0.17$ & 0.31 & 0.54 & 1.00 & 1.86 & 3.35 & 5.77 & 0.56 & 1.30 & 2.96 & 6.24 & 12.14 & 21.90 \\
\hline Frisch $_{\mathrm{A}, 1}=0.40 / \sigma_{l}=0.68$ & 0.31 & 0.54 & 1.00 & 1.85 & 3.32 & 5.69 & 0.56 & 1.30 & 2.95 & 6.20 & 12.04 & 21.70 \\
\hline \multicolumn{13}{|l|}{ Commuting } \\
\hline no foregone leisure cost & 0.47 & 0.64 & 1.00 & 1.66 & 2.76 & 4.51 & 0.58 & 1.11 & 2.23 & 4.35 & 8.00 & 13.87 \\
\hline$\delta=0$ (no distance cost) & 0.68 & 0.75 & 1.00 & 1.57 & 2.64 & 4.49 & 0.70 & 0.94 & 2.02 & 4.55 & 9.43 & 17.92 \\
\hline$\lambda=0$ (no leisure) & 0.24 & 0.49 & 1.00 & 1.92 & 3.49 & 5.98 & 0.55 & 1.36 & 3.08 & 6.39 & 12.21 & 21.70 \\
\hline$\lambda=1 / 2$ (constant leisure) & 0.35 & 0.56 & 1.00 & 1.80 & 3.17 & 5.37 & 0.56 & 1.23 & 2.70 & 5.58 & 10.77 & 19.45 \\
\hline$\sigma_{\mathrm{V}}=0.90($ base $=0.92)$ & 0.32 & 0.55 & 1.00 & 1.84 & 3.30 & 5.66 & 0.57 & 1.30 & 2.97 & 6.34 & 12.43 & 22.56 \\
\hline$\sigma_{\mathrm{V}}=0.94($ base $=0.92)$ & 0.30 & 0.53 & 1.00 & 1.88 & 3.38 & 5.81 & 0.55 & 1.29 & 2.93 & 6.11 & 11.75 & 21.01 \\
\hline
\end{tabular}

Table B.7: Alternative Parameterizations: Land Price versus TFP. Table shows the price of land services for alternative parameterizations of the process generating outcomes in all metros. Numbers in parentheses give baseline values. 


\section{B.2 alternative assumptions, alternative metros, and unanchored systems}

\begin{tabular}{|c|c|c|c|c|c|c|}
\hline \multirow{3}{*}{$\begin{array}{l}\text { Alternative } \\
\text { Assumptions, Metros, and } \\
\text { Unanchored Systems }\end{array}$} & \multicolumn{6}{|c|}{ population } \\
\hline & (a)tfp & (a)tfp & @ tfp & (a)tfp & @ tfp & (atfp \\
\hline & 0.90 & 0.95 & 1.00 & 1.05 & 1.10 & \\
\hline Baseline & 130,000 & 440,000 & $1,000,000$ & $1,800,000$ & $2,820,000$ & $4,020,000$ \\
\hline \multicolumn{7}{|l|}{ Alternative Assumptions } \\
\hline fixed workhours, Frisch ${ }_{\mathrm{A}, 1}=0.20$ & 130,000 & 460,000 & $1,000,000$ & $1,740,000$ & $2,820,000$ & $3,630,000$ \\
\hline fixed workhours, Frisch ${ }_{\mathrm{A}, 1}=0.10$ & 170,000 & 500,000 & $1,000,000$ & $1,630,000$ & $2,350,000$ & $3,130,000$ \\
\hline rebate $\mathrm{H}$ (per capita $\mathrm{H}$ factor income in anchor) & 160,000 & 480,000 & $1,000,000$ & $1,720,000$ & $2,620,000$ & $3,670,000$ \\
\hline rebate $\mathrm{X}+\mathrm{H}$ (per capita $\mathrm{L}+\mathrm{K}$ income in anchor) & 250,000 & 560,000 & $1,000,000$ & $1,580,000$ & $2,280,000$ & $3,070,000$ \\
\hline endog CBD radius (constant land price ratio) & 80,000 & 430,000 & $1,000,000$ & $1,740,000$ & $2,620,000$ & $3,600,000$ \\
\hline TFP varies for $\mathrm{X}$ and $\mathrm{H}$ & 90,000 & 400,000 & $1,000,000$ & $1,930,000$ & $3,170,000$ & $4,720,000$ \\
\hline TFP varies for $\mathrm{H}$ only & 840,000 & 920,000 & $1,000,000$ & $1,080,000$ & $1,170,000$ & $1,260,000$ \\
\hline \multicolumn{7}{|l|}{ Alternative Metros } \\
\hline minimum speed $27 \mathrm{mph}$ (min in anchor) & 130,000 & 440,000 & $1,000,000$ & $2,020,000$ & $3,900,000$ & $7,060,000$ \\
\hline constant speed $27 \mathrm{mph}$ (min in anchor) & 90,000 & 320,000 & 830,000 & $1,870,000$ & $3,760,000$ & $6,920,000$ \\
\hline constant speed $33 \mathrm{mph}$ (mean in anchor) & 100,000 & 360,000 & 970,000 & $2,220,000$ & $4,500,000$ & $8,390,000$ \\
\hline constant speed $50 \mathrm{mph}$ (max in anchor) & 130,000 & 480,000 & $1,340,000$ & $3,170,000$ & $6,630,000$ & $12,700,000$ \\
\hline$\sigma_{\mathrm{V}}=0.94(0.92$ in anchor metro $)$ & 130,000 & 460,000 & $1,140,000$ & $2,240,000$ & $3,830,000$ & $5,910,000$ \\
\hline$\sigma_{\mathrm{V}}=0.90(0.92$ in anchor metro $)$ & 130,000 & 420,000 & 870,000 & $1,450,000$ & $2,110,000$ & $2,970,000$ \\
\hline 4-day workweek & 160,000 & 570,000 & $1,260,000$ & $2,240,000$ & $3,460,000$ & $4,900,000$ \\
\hline telecommute 1 day per week & 160,000 & 590,000 & $1,340,000$ & $2,420,000$ & $3,770,000$ & $5,380,000$ \\
\hline distance cost $50 \%$ above anchor (per mile) & 100,000 & 330,000 & 780,000 & $1,470,000$ & $2,400,000$ & $3,540,000$ \\
\hline growth boundary at anchor radius & - & - & $1,000,000$ & $1,730,000$ & $2,680,000$ & $3,830,000$ \\
\hline perimeter land price five times that of anchor & 30,000 & 220,000 & 750,000 & $1,570,000$ & $2,620,000$ & $3,860,000$ \\
\hline \multicolumn{7}{|l|}{ Unanchored Systems } \\
\hline$\lambda=3 / 4 \quad($ self-driving cars $I)$ & 70,000 & 340,000 & $1,000,000$ & $2,240,000$ & $4,150,000$ & $6,860,000$ \\
\hline$\lambda=1 @ 50 \rightarrow 1 / 2 @ 10 \mathrm{mph}$ (self-driving cars II) & 70,000 & 360,000 & $1,000,000$ & $2,020,000$ & $3,380,000$ & $5,030,000$ \\
\hline$\sigma_{\mathrm{L}}=1.25$ (multifamily housing I) & 110,000 & 400,000 & $1,000,000$ & $2,120,000$ & $4,270,000$ & $9,570,000$ \\
\hline$\sigma_{\mathrm{L}}=1.33$ (multifamily housing II) & 110,000 & 390,000 & $1,000,000$ & $2,250,000$ & $5,210,000$ & $17,670,000$ \\
\hline
\end{tabular}

Table B.8: Other Alternatives: Population versus TFP. Alternative assumptions apply to all metros, including the anchor. Alt metro scenarios apply only to one or a handful of metros. Unanchored scenarios lack observed outcomes to which to be calibrated. Population is normalized to a span of $180^{\circ}$. 


\begin{tabular}{|c|c|c|c|c|c|c|c|c|c|c|c|c|}
\hline \multirow{2}{*}{$\begin{array}{l}\text { Alt Assumptions, } \\
\text { Metros, and } \\
\text { Unanchored }\end{array}$} & \multicolumn{6}{|c|}{ mean commute distance (miles) } & \multicolumn{6}{|c|}{ outer commute distance (miles) } \\
\hline & $\begin{array}{r}@ \mathrm{tfp} \\
0.90\end{array}$ & $\begin{array}{r}@ \mathrm{tfp} \\
0.95\end{array}$ & $\begin{array}{r}@ \mathrm{tfp} \\
1.00\end{array}$ & $\begin{array}{r}@ \mathrm{tfp} \\
1.05\end{array}$ & $\begin{array}{r}\text { atfp } \\
1.10\end{array}$ & $\begin{array}{r}@ \mathrm{tfp} \\
1.15\end{array}$ & $\begin{array}{r}0 \mathrm{tfp} \\
0.90\end{array}$ & $\begin{array}{r}@ \mathrm{tfp} \\
0.95\end{array}$ & $\begin{array}{r}@ \mathrm{tfp} \\
1.00\end{array}$ & $\begin{array}{r}\text { @.tfp } \\
1.05\end{array}$ & $\begin{array}{r}@ \mathrm{tfp} \\
1.10\end{array}$ & $\begin{array}{r}@ \operatorname{tfp} \\
1.15\end{array}$ \\
\hline Baseline & 3.3 & 5.4 & 6.7 & 7.4 & 7.6 & 7.6 & 5.2 & 9.5 & 13.1 & 15.7 & 17.6 & 19.0 \\
\hline \multicolumn{13}{|l|}{ Alt Assumptions } \\
\hline fixed wrkhrs, Frisch ${ }_{\mathrm{A}, 1}=0.20$ & 3.3 & 5.4 & 6.6 & 7.1 & 7.1 & 6.9 & 5.4 & 9.7 & 13.1 & 15.5 & 17.3 & 18.0 \\
\hline fixed wrkhrs, Frisch ${ }_{\mathrm{A}, 1}=0.10$ & 3.9 & 5.5 & 6.1 & 6.1 & 5.7 & 5.2 & 6.7 & 10.5 & 13.1 & 14.4 & 14.8 & 14.6 \\
\hline rebate $\mathrm{H}$ factor incm & 3.6 & 5.6 & 6.9 & 7.6 & 8.0 & 8.1 & 5.8 & 9.8 & 13.1 & 15.6 & 17.6 & 19.0 \\
\hline rebate $\mathrm{X}+\mathrm{H}$ factor incm & 4.3 & 6.0 & 7.3 & 8.2 & 8.8 & 9.1 & 6.9 & 10.2 & 13.1 & 15.5 & 17.5 & 19.1 \\
\hline endog $\mathrm{CBD}$ radius & 2.9 & 5.4 & 6.7 & 7.4 & 7.8 & 7.9 & 4.4 & 9.5 & 13.1 & 15.7 & 17.6 & 19.0 \\
\hline TFP varies for $\mathrm{X} \& \mathrm{H}$ & 2.9 & 5.3 & 6.7 & 7.3 & 7.4 & 7.2 & 4.5 & 9.2 & 13.1 & 15.8 & 17.6 & 18.8 \\
\hline TFP varies for $\mathrm{H}$ only & 6.7 & 6.7 & 6.7 & 6.7 & 6.7 & 6.7 & 12.7 & 12.9 & 13.1 & 13.2 & 13.4 & 13.5 \\
\hline \multicolumn{13}{|l|}{$\underline{\text { Alternative Metros }}$} \\
\hline minimum speed $27 \mathrm{mph}$ & 3.3 & 5.4 & 6.7 & 7.6 & 8.6 & 9.6 & 5.2 & 9.5 & 13.1 & 16.3 & 19.7 & 23.1 \\
\hline constant speed $27 \mathrm{mph}$ & 2.5 & 4.1 & 5.6 & 6.9 & 8.1 & 9.3 & 4.1 & 7.5 & 11.0 & 14.6 & 18.1 & 21.6 \\
\hline constant speed $33 \mathrm{mph}$ & 2.7 & 4.6 & 6.2 & 7.8 & 9.2 & 10.6 & 4.4 & 8.2 & 12.2 & 16.3 & 20.3 & 24.4 \\
\hline constant speed $50 \mathrm{mph}$ & 3.3 & 5.6 & 7.8 & 9.9 & 12.0 & 13.9 & 5.2 & 9.9 & 15.1 & 20.4 & 25.9 & 31.5 \\
\hline$\sigma_{\mathrm{V}}=0.94$ (0.92 in anchor $)$ & 3.3 & 5.5 & 7.2 & 8.3 & 8.9 & 9.3 & 5.2 & 9.8 & 13.9 & 17.4 & 20.2 & 22.5 \\
\hline$\sigma_{\mathrm{V}}=0.90$ (0.92 in anchor $)$ & 3.3 & 5.2 & 6.2 & 6.6 & 6.6 & 6.4 & 5.2 & 9.3 & 12.2 & 14.2 & 15.5 & 16.5 \\
\hline 4-day workweek & 3.9 & 6.4 & 7.8 & 8.5 & 8.8 & 8.7 & 6.2 & 11.2 & 15.2 & 18.1 & 20.1 & 21.6 \\
\hline telecommute 1 day per wk & 3.9 & 6.5 & 8.1 & 8.9 & 9.2 & 9.2 & 6.2 & 11.4 & 15.7 & 18.8 & 21.1 & 22.7 \\
\hline dist cost $50 \%$ above base & 2.6 & 4.3 & 5.8 & 6.2 & 6.6 & 6.7 & 4.2 & 7.7 & 11.8 & 13.4 & 15.3 & 16.8 \\
\hline growth boundary & - & - & 6.7 & 6.7 & 6.6 & 6.5 & - & - & 13.1 & 13.1 & 13.1 & 13.1 \\
\hline perim $L$ price $5 x$ anchor & 0.5 & 2.4 & 4.4 & 5.6 & 6.3 & 6.6 & 0.7 & 3.6 & 7.1 & 9.9 & 12.0 & 13.5 \\
\hline \multicolumn{13}{|l|}{ Unanchored Systems } \\
\hline$\lambda=3 / 4$ (self-driving cars I) & 2.2 & 4.8 & 7.3 & 9.1 & 10.4 & 11.2 & 3.3 & 8.0 & 13.1 & 17.7 & 21.7 & 25.0 \\
\hline$\lambda=1 @ 50 \rightarrow 1 / 2 @ 10 \mathrm{mph}(\mathrm{II})$ & 2.1 & 5.0 & 7.4 & 8.8 & 9.6 & 9.9 & 3.2 & 8.1 & 13.1 & 17.0 & 19.9 & 22.1 \\
\hline$\sigma_{\mathrm{L}}=1.25$ (multifamily I) & 3.3 & 5.3 & 6.1 & 5.9 & 4.8 & 3.3 & 5.2 & 9.6 & 13.1 & 15.4 & 16.9 & 17.7 \\
\hline$\sigma_{\mathrm{L}}=1.33$ (multifamily II) & 3.3 & 5.2 & 6.0 & 5.4 & 3.9 & 1.9 & 5.2 & 9.6 & 13.1 & 15.3 & 16.6 & 17.3 \\
\hline
\end{tabular}

Table B.9: Other Alternatives: Commute Distance versus TFP. Alternative assumptions apply to all metros, including the anchor. Alt metro scenarios apply only to one or a handful of metros. Unanchored scenarios lack observed outcomes to which to be calibrated. 


\begin{tabular}{|c|c|c|c|c|c|c|c|c|c|c|c|c|}
\hline \multirow{2}{*}{$\begin{array}{l}\text { Alternative } \\
\text { Assumptions } \\
\text { and Metros }\end{array}$} & \multicolumn{6}{|c|}{ mean pop density (ths prs per sq mi) } & \multicolumn{6}{|c|}{ inner pop density (ths prs per sq mi) } \\
\hline & $\begin{array}{r}@ \mathrm{tfp} \\
0.90\end{array}$ & $\begin{array}{r}@ \text { tfp } \\
0.95\end{array}$ & $\begin{array}{r}@ \text { tfp } \\
1.00\end{array}$ & $\begin{array}{r}@ \text { tfp } \\
1.05\end{array}$ & $\begin{array}{r}@ \text { tfp } \\
1.10\end{array}$ & $\begin{array}{r}@ \text { tfp } \\
1.15\end{array}$ & $\begin{array}{r}@ \text { tfp } \\
0.90\end{array}$ & $\begin{array}{r}@ \text { tfp } \\
0.95\end{array}$ & $\begin{array}{r}@ \mathrm{tfp} \\
1.00\end{array}$ & $\begin{array}{r}@ \mathrm{tfp} \\
1.05\end{array}$ & $\begin{array}{r}@ \mathrm{tfp} \\
1.10\end{array}$ & $\begin{array}{r}@ \mathrm{tfp} \\
1.15\end{array}$ \\
\hline Baseline & 1.7 & 2.5 & 4.0 & 6.2 & 9.6 & 14.3 & 2.7 & 5.1 & 9.7 & 17.0 & 28.0 & 43.2 \\
\hline \multicolumn{13}{|l|}{$\underline{\text { Alt Assumptions }}$} \\
\hline fixed wrkhrs, Frisch ${ }_{A, 1}=0.20$ & 1.7 & 2.6 & 4.1 & 6.5 & 11.2 & 15.6 & 2.8 & 5.4 & 10.1 & 17.9 & 32.2 & 45.5 \\
\hline fixed wrkhrs, Frisch ${ }_{\mathrm{A}, 1}=0.10$ & 1.7 & 2.8 & 4.7 & 8.1 & 13.4 & 21.2 & 3.1 & 6.3 & 12.1 & 21.4 & 35.2 & 54.4 \\
\hline rebate $\mathrm{H}$ factor incm & 1.8 & 2.6 & 3.8 & 5.5 & 8.0 & 11.4 & 2.9 & 5.2 & 8.9 & 14.6 & 22.8 & 33.7 \\
\hline rebate $\mathrm{X}+\mathrm{H}$ factor incm & 2.1 & 2.6 & 3.4 & 4.4 & 5.7 & 7.3 & 3.4 & 5.0 & 7.4 & 10.5 & 14.7 & 19.9 \\
\hline endog $\mathrm{CBD}$ radius & 1.5 & 2.5 & 4.0 & 6.1 & 9.1 & 13.0 & 2.4 & 5.1 & 9.7 & 16.7 & 26.7 & 40.3 \\
\hline TFP varies for $\mathrm{X} \& \mathrm{H}$ & 1.5 & 2.3 & 4.0 & 6.8 & 11.5 & 18.7 & 2.2 & 4.6 & 9.7 & 18.8 & 33.9 & 56.9 \\
\hline TFP varies for $\mathrm{H}$ only & 3.3 & 3.6 & 4.0 & 4.3 & 4.7 & 5.0 & 7.8 & 8.7 & 9.7 & 10.7 & 11.7 & 12.9 \\
\hline \multicolumn{13}{|l|}{$\underline{\text { Alternative Metros }}$} \\
\hline minimum speed $27 \mathrm{mph}$ & 1.7 & 2.5 & 4.0 & 6.5 & 10.3 & 15.4 & 2.7 & 5.1 & 9.7 & 16.6 & 26.3 & 39.3 \\
\hline constant speed $27 \mathrm{mph}$ & 1.8 & 2.8 & 4.5 & 7.1 & 10.8 & 15.8 & 2.9 & 5.6 & 10.1 & 16.9 & 26.5 & 39.5 \\
\hline constant speed $33 \mathrm{mph}$ & 1.7 & 2.7 & 4.3 & 6.8 & 10.3 & 15.1 & 2.9 & 5.4 & 9.7 & 16.3 & 25.6 & 38.2 \\
\hline constant speed $50 \mathrm{mph}$ & 1.7 & 2.5 & 4.0 & 6.2 & 9.4 & 13.8 & 2.7 & 5.0 & 9.0 & 15.1 & 23.7 & 35.4 \\
\hline$\sigma_{\mathrm{V}}=0.94$ (0.92 in anchor) & 1.7 & 2.5 & 3.9 & 6.2 & 9.5 & 14.1 & 2.7 & 5.1 & 9.4 & 16.2 & 26.4 & 40.5 \\
\hline$\sigma_{\mathrm{V}}=0.90$ (0.92 in anchor) & 1.7 & 2.5 & 3.9 & 6.2 & 9.6 & 14.9 & 2.7 & 5.2 & 10.0 & 17.8 & 29.4 & 45.4 \\
\hline 4-day workweek & 1.6 & 2.4 & 3.8 & 6.0 & 9.3 & 13.8 & 2.6 & 5.0 & 9.5 & 16.8 & 27.7 & 42.9 \\
\hline telecommute 1 day per wk & 1.6 & 2.4 & 3.8 & 6.0 & 9.2 & 13.6 & 2.6 & 4.9 & 9.3 & 16.5 & 27.3 & 42.2 \\
\hline dist cost $50 \%$ above base & 1.7 & 2.7 & 5.1 & 6.8 & 10.4 & 15.3 & 2.9 & 5.6 & 12.6 & 17.7 & 28.7 & 43.9 \\
\hline growth boundary & - & - & 4.0 & 6.9 & 10.9 & 16.3 & - & - & 9.7 & 17.2 & 28.2 & 43.5 \\
\hline perim L price $5 \mathrm{x}$ anchor & 4.2 & 4.8 & 6.0 & 8.2 & 11.5 & 16.0 & 4.4 & 6.2 & 10.4 & 17.5 & 28.3 & 43.4 \\
\hline \multicolumn{13}{|l|}{ Unanchored Systems } \\
\hline$\lambda=3 / 4$ (self-driving cars I) & 1.7 & 2.3 & 3.4 & 5.1 & 7.6 & 11.3 & 2.3 & 4.0 & 7.2 & 12.4 & 20.2 & 31.2 \\
\hline$\lambda=1 @ 50 \rightarrow 1 / 2 @ 10 \mathrm{mph}$ (II) & 1.8 & 2.3 & 3.3 & 4.9 & 7.4 & 10.8 & 2.2 & 3.9 & 7.0 & 12.4 & 20.6 & 32.2 \\
\hline$\sigma_{\mathrm{L}}=1.25$ (multifamily $\mathrm{I}$ ) & 1.4 & 2.4 & 5.0 & 13.7 & 50 & 273 & 2.4 & 5.5 & 15.3 & 50.1 & 196 & 925 \\
\hline$\sigma_{\mathrm{L}}=1.33$ (multifamily II) & 1.4 & 2.3 & 5.3 & 18.5 & 116 & 1,510 & 2.3 & 5.5 & 17.2 & 72.0 & 458 & 4,284 \\
\hline
\end{tabular}

Table B.10: Other Alternatives: Population Density versus TFP. Alternative assumptions apply to all metros, including the anchor. Alt metro scenarios apply only to one or a handful of metros. Unanchored scenarios lack observed outcomes to which to be calibrated. Mean density is weighted by population. 


\begin{tabular}{|c|c|c|c|c|c|c|c|c|c|c|c|c|}
\hline \multirow{2}{*}{$\begin{array}{l}\text { Alternative } \\
\text { Assumptions } \\
\text { and Metros }\end{array}$} & \multicolumn{6}{|c|}{ mean commute time (minutes) } & \multicolumn{6}{|c|}{ outer commute time (minutes) } \\
\hline & $\begin{array}{r}@ \text { tfp } \\
0.90\end{array}$ & $\begin{array}{r}a \mathrm{tfp} \\
0.95\end{array}$ & $\begin{array}{r}@ \mathrm{tfp} \\
1.00\end{array}$ & $\begin{array}{r}@ \operatorname{tfp} \\
1.05\end{array}$ & $\begin{array}{r}@ \mathrm{tfp} \\
1.10\end{array}$ & $\begin{array}{r}@ \mathrm{tfp} \\
1.15\end{array}$ & $\begin{array}{r}@ \mathrm{tfp} \\
0.90\end{array}$ & $\begin{array}{r}@ \mathrm{tfp} \\
0.95\end{array}$ & $\begin{array}{r}@ \mathrm{tfp} \\
1.00\end{array}$ & $\begin{array}{r}@ \mathrm{tfp} \\
1.05\end{array}$ & $\begin{array}{r}0 \mathrm{tfp} \\
1.10\end{array}$ & $\begin{array}{r}@ \mathrm{tfp} \\
1.15\end{array}$ \\
\hline Baseline & 12 & 15 & 20 & 25 & 31 & 36 & 14 & 21 & 29 & 39 & 50 & 60 \\
\hline \multicolumn{13}{|l|}{ Alt Assumptions } \\
\hline 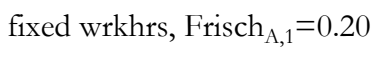 & 12 & 16 & 20 & 24 & 29 & 31 & 14 & 21 & 29 & 38 & 48 & 53 \\
\hline fixed wrkhrs, Frisch $_{\mathrm{A}, 1}=0.10$ & 13 & 16 & 20 & 22 & 24 & 25 & 16 & 22 & 30 & 36 & 40 & 43 \\
\hline rebate $\mathrm{H}$ factor incm & 12 & 16 & 21 & 26 & 31 & 36 & 15 & 21 & 30 & 39 & 49 & 59 \\
\hline rebate $\mathrm{X}+\mathrm{H}$ factor incm & 13 & 17 & 21 & 26 & 31 & 36 & 16 & 22 & 29 & 37 & 46 & 55 \\
\hline endog CBD radius & 11 & 15 & 20 & 25 & 30 & 35 & 13 & 21 & 29 & 39 & 48 & 58 \\
\hline TFP varies for $\mathrm{X} \& \mathrm{H}$ & 11 & 15 & 20 & 26 & 31 & 37 & 13 & 20 & 29 & 40 & 51 & 62 \\
\hline TFP varies for $\mathrm{H}$ only & 19 & 20 & 20 & 21 & 21 & 21 & 28 & 29 & 29 & 30 & 31 & 32 \\
\hline \multicolumn{13}{|l|}{$\underline{\text { Alternative Metros }}$} \\
\hline minimum speed $27 \mathrm{mph}$ & 12 & 15 & 20 & 24 & 26 & 29 & 14 & 21 & 29 & 38 & 46 & 54 \\
\hline constant speed $27 \mathrm{mph}$ & 14 & 17 & 20 & 23 & 26 & 28 & 17 & 24 & 32 & 40 & 48 & 55 \\
\hline constant speed $33 \mathrm{mph}$ & 13 & 16 & 19 & 22 & 25 & 27 & 16 & 23 & 30 & 38 & 45 & 53 \\
\hline constant speed $50 \mathrm{mph}$ & 12 & 15 & 17 & 20 & 22 & 25 & 14 & 20 & 26 & 33 & 39 & 46 \\
\hline$\sigma_{\mathrm{V}}=0.94$ (0.92 in anchor) & 12 & 15 & 19 & 23 & 28 & 32 & 14 & 20 & 28 & 37 & 46 & 56 \\
\hline$\sigma_{\mathrm{V}}=0.90$ (0.92 in anchor $)$ & 12 & 16 & 22 & 27 & 33 & 38 & 14 & 21 & 31 & 42 & 52 & 63 \\
\hline 4-day workweek & 13 & 18 & 24 & 31 & 37 & 44 & 15 & 24 & 35 & 48 & 61 & 74 \\
\hline telecommute 1 day per wk & 13 & 17 & 23 & 30 & 37 & 43 & 15 & 23 & 34 & 47 & 60 & 73 \\
\hline dist cost $50 \%$ above base & 11 & 13 & 19 & 21 & 26 & 31 & 13 & 18 & 27 & 32 & 41 & 51 \\
\hline growth boundary & - & - & 20 & 24 & 28 & 32 & - & - & 29 & 35 & 41 & 48 \\
\hline perim $L$ price $5 \mathrm{x}$ anchor & 9 & 11 & 15 & 21 & 27 & 32 & 9 & 12 & 19 & 28 & 38 & 49 \\
\hline \multicolumn{13}{|l|}{ Unanchored Systems } \\
\hline$\lambda=3 / 4$ (self-driving cars I) & 11 & 14 & 21 & 33 & 48 & 64 & 12 & 18 & 30 & 49 & 75 & 105 \\
\hline$\lambda=1 @ 50 \rightarrow 1 / 2 @ 10 \mathrm{mph}$ (II) & 11 & 15 & 22 & 31 & 40 & 50 & 12 & 19 & 30 & 46 & 63 & 81 \\
\hline$\sigma_{\mathrm{L}}=1.25$ (multifamily I) & 12 & 15 & 19 & 22 & 24 & 23 & 14 & 20 & 29 & 38 & 47 & 56 \\
\hline$\sigma_{\mathrm{L}}=1.33$ (multifamily II) & 12 & 15 & 19 & 21 & 21 & 17 & 14 & 20 & 29 & 38 & 47 & 53 \\
\hline
\end{tabular}

Table B.11: Other Alternatives: Commute Time versus TFP. Alternative assumptions apply to all metros, including the anchor. Alt metro scenarios apply only to one or a handful of metros. Unanchored scenarios lack observed outcomes to which to be calibrated. 


\begin{tabular}{|c|c|c|c|c|c|c|c|c|c|c|c|c|}
\hline \multirow{2}{*}{$\begin{array}{l}\text { Alternative } \\
\text { Assumptions } \\
\text { and Metros }\end{array}$} & \multicolumn{6}{|c|}{ mean commute speed (mph) } & \multicolumn{6}{|c|}{ inner commute speed (mph) } \\
\hline & @tfp & @tfp & @tfp & @tfp & @tfp & @tfp & @ tfp & @tfp & (a) tfp & (a)tfp & @tfp & $\begin{array}{r}@ \mathrm{tfp} \\
1.15\end{array}$ \\
\hline Baseline & 50 & 42 & 31 & 24 & 19 & 15 & 50 & 39 & 27 & 20 & 15 & 12 \\
\hline \multicolumn{13}{|l|}{ Alt Assumptions } \\
\hline fixed wrkhrs, Frisch ${ }_{\mathrm{A}, 1}=0.20$ & 50 & 42 & 31 & 24 & 19 & 16 & 50 & 38 & 27 & 20 & 15 & 13 \\
\hline fixed wrkhrs, Frisch ${ }_{\mathrm{A}, 1}=0.10$ & 50 & 39 & 30 & 24 & 20 & 17 & 49 & 35 & 26 & 20 & 16 & 13 \\
\hline rebate $\mathrm{H}$ factor incm & 50 & 41 & 31 & 24 & 20 & 16 & 50 & 38 & 27 & 21 & 16 & 13 \\
\hline rebate $\mathrm{X}+\mathrm{H}$ factor incm & 49 & 40 & 33 & 27 & 22 & 19 & 47 & 37 & 29 & 23 & 19 & 15 \\
\hline endog $\mathrm{CBD}$ radius & 50 & 42 & 31 & 24 & 20 & 16 & 50 & 39 & 27 & 20 & 16 & 13 \\
\hline TFP varies for $\mathrm{X} \& \mathrm{H}$ & 50 & 43 & 31 & 23 & 18 & 14 & 50 & 40 & 27 & 19 & 14 & 11 \\
\hline TFP varies for $\mathrm{H}$ only & 34 & 33 & 31 & 30 & 29 & 28 & 30 & 29 & 27 & 26 & 25 & 24 \\
\hline \multicolumn{13}{|l|}{ Alternative Metros } \\
\hline minimum speed $27 \mathrm{mph}$ & 50 & 42 & 31 & 28 & 28 & 28 & 50 & 39 & 27 & 27 & 27 & 27 \\
\hline constant speed $27 \mathrm{mph}$ & 27 & 27 & 27 & 27 & 27 & 27 & 27 & 27 & 27 & 27 & 27 & 27 \\
\hline constant speed $33 \mathrm{mph}$ & 33 & 33 & 33 & 33 & 33 & 33 & 33 & 33 & 33 & 33 & 33 & 33 \\
\hline constant speed $50 \mathrm{mph}$ & 50 & 50 & 50 & 50 & 50 & 50 & 50 & 50 & 50 & 50 & 50 & 50 \\
\hline$\sigma_{\mathrm{V}}=0.94$ (0.92 in anchor) & 50 & 46 & 38 & 31 & 26 & 22 & 50 & 44 & 35 & 28 & 23 & 19 \\
\hline$\sigma_{\mathrm{V}}=0.90$ (0.92 in anchor) & 50 & 38 & 26 & 19 & 14 & 12 & 50 & 34 & 21 & 15 & 11 & 10 \\
\hline 4-day workweek & 50 & 39 & 28 & 21 & 17 & 14 & 50 & 35 & 24 & 18 & 13 & 11 \\
\hline telecommute 1 day per wk & 50 & 41 & 30 & 23 & 18 & 15 & 50 & 38 & 26 & 19 & 15 & 12 \\
\hline dist cost $50 \%$ above base & 50 & 46 & 32 & 27 & 21 & 17 & 50 & 43 & 27 & 22 & 17 & 13 \\
\hline growth boundary & - & - & 31 & 24 & 19 & 15 & - & - & 27 & 21 & 16 & 13 \\
\hline perim $L$ price $5 \mathrm{x}$ anchor & 50 & 49 & 35 & 25 & 19 & 15 & 50 & 48 & 31 & 22 & 16 & 13 \\
\hline \multicolumn{13}{|l|}{ Unanchored Systems } \\
\hline$\lambda=3 / 4($ self-driving cars I) & 50 & 45 & 31 & 21 & 15 & 11 & 50 & 42 & 27 & 18 & 12 & 10 \\
\hline$\lambda=1 @ 50 \rightarrow 1 / 2 @ 10 \mathrm{mph}$ (II) & 50 & 45 & 31 & 22 & 17 & 13 & 50 & 42 & 27 & 19 & 14 & 11 \\
\hline$\sigma_{\mathrm{L}}=1.25$ (multifamily $\mathrm{I}$ ) & 50 & 43 & 32 & 23 & 16 & 12 & 50 & 40 & 27 & 18 & 12 & 10 \\
\hline$\sigma_{\mathrm{L}}=1.33$ (multifamily II) & 50 & 44 & 32 & 22 & 14 & 11 & 50 & 40 & 27 & 18 & 10 & 10 \\
\hline
\end{tabular}

Table B.12: Other Alternatives: Commute Speed versus TFP. Alternative assumptions apply to all metros, including the anchor. Alt metro scenarios apply only to one or a handful of metros. Unanchored scenarios lack observed outcomes to which to be calibrated. Mean commute speed is calculated as aggregate miles divided by aggregate drive time. 


\begin{tabular}{|c|c|c|c|c|c|c|c|c|c|c|c|c|}
\hline \multirow{2}{*}{$\begin{array}{l}\text { Alternative } \\
\text { Assumptions } \\
\text { and Metros }\end{array}$} & \multicolumn{6}{|c|}{ mean price of housing services } & \multicolumn{6}{|c|}{ inner price of housing services } \\
\hline & $\begin{array}{r}(1 \mathrm{tfp} \\
0.90\end{array}$ & $\begin{array}{r}@ \mathrm{tfp} \\
0.95\end{array}$ & $\begin{array}{r}@ \mathrm{tfp} \\
1.00\end{array}$ & $\begin{array}{r}@ \mathrm{tfp} \\
1.05\end{array}$ & $\begin{array}{r}@ \mathrm{tfp} \\
1.10\end{array}$ & $\begin{array}{r}@ \mathrm{tfp} \\
1.15\end{array}$ & $\begin{array}{r}@ \mathrm{tfp} \\
0.90\end{array}$ & $\begin{array}{r}@ \mathrm{tfp} \\
0.95\end{array}$ & $\begin{array}{r}@ \mathrm{tfp} \\
1.00\end{array}$ & $\begin{array}{r}\infty \mathrm{tfp} \\
1.05\end{array}$ & $\begin{array}{r}@ \mathrm{tfp} \\
1.10\end{array}$ & $\begin{array}{r}@ \mathrm{tfp} \\
1.15\end{array}$ \\
\hline Baseline & 0.70 & 0.83 & 1.00 & 1.22 & 1.50 & 1.82 & 0.86 & 1.16 & 1.58 & 2.11 & 2.77 & 3.55 \\
\hline \multicolumn{13}{|l|}{$\underline{\text { Alt Assumptions }}$} \\
\hline fixed wrkhrs, Frisch ${ }_{\mathrm{A}, 1}=0.20$ & 0.69 & 0.82 & 1.00 & 1.24 & 1.61 & 1.91 & 0.86 & 1.16 & 1.58 & 2.12 & 2.93 & 3.57 \\
\hline fixed wrkhrs, Frisch ${ }_{\mathrm{A}, 1}=0.10$ & 0.65 & 0.79 & 1.00 & 1.28 & 1.65 & 2.11 & 0.85 & 1.18 & 1.62 & 2.18 & 2.87 & 3.69 \\
\hline rebate $\mathrm{H}$ factor incm & 0.74 & 0.85 & 1.00 & 1.18 & 1.41 & 1.67 & 0.91 & 1.19 & 1.55 & 1.99 & 2.53 & 3.16 \\
\hline rebate $\mathrm{X}+\mathrm{H}$ factor incm & 0.82 & 0.90 & 1.00 & 1.12 & 1.25 & 1.41 & 1.01 & 1.22 & 1.47 & 1.76 & 2.09 & 2.47 \\
\hline endog CBD radius & 0.68 & 0.82 & 1.00 & 1.21 & 1.45 & 1.73 & 0.82 & 1.16 & 1.58 & 2.09 & 2.70 & 3.41 \\
\hline TFP varies for $\mathrm{X} \& \mathrm{H}$ & 0.76 & 0.85 & 1.00 & 1.20 & 1.45 & 1.76 & 0.90 & 1.18 & 1.58 & 2.09 & 2.73 & 3.49 \\
\hline TFP varies for $\mathrm{H}$ only & 1.05 & 1.02 & 1.00 & 0.98 & 0.96 & 0.94 & 1.61 & 1.59 & 1.58 & 1.56 & 1.55 & 1.53 \\
\hline \multicolumn{13}{|l|}{$\underline{\text { Alternative Metros }}$} \\
\hline minimum speed $27 \mathrm{mph}$ & 0.70 & 0.83 & 1.00 & 1.25 & 1.56 & 1.92 & 0.86 & 1.16 & 1.58 & 2.08 & 2.68 & 3.36 \\
\hline constant speed $27 \mathrm{mph}$ & 0.72 & 0.86 & 1.06 & 1.31 & 1.61 & 1.95 & 0.90 & 1.21 & 1.61 & 2.10 & 2.69 & 3.37 \\
\hline constant speed $33 \mathrm{mph}$ & 0.71 & 0.85 & 1.04 & 1.28 & 1.57 & 1.91 & 0.89 & 1.19 & 1.58 & 2.06 & 2.63 & 3.30 \\
\hline constant speed $50 \mathrm{mph}$ & 0.70 & 0.83 & 1.01 & 1.23 & 1.50 & 1.82 & 0.86 & 1.15 & 1.52 & 1.98 & 2.52 & 3.16 \\
\hline$\sigma_{\mathrm{V}}=0.94$ (0.92 in anchor $)$ & 0.70 & 0.83 & 1.00 & 1.23 & 1.50 & 1.82 & 0.86 & 1.15 & 1.55 & 2.06 & 2.68 & 3.42 \\
\hline$\sigma_{\mathrm{V}}=0.90$ (0.92 in anchor $)$ & 0.70 & 0.82 & 1.00 & 1.22 & 1.49 & 1.84 & 0.86 & 1.17 & 1.60 & 2.16 & 2.85 & 3.65 \\
\hline 4-day workweek & 0.70 & 0.81 & 0.98 & 1.20 & 1.47 & 1.78 & 0.85 & 1.15 & 1.56 & 2.09 & 2.75 & 3.53 \\
\hline telecommute 1 day per wk & 0.70 & 0.81 & 0.98 & 1.20 & 1.46 & 1.77 & 0.85 & 1.14 & 1.55 & 2.08 & 2.73 & 3.50 \\
\hline dist cost $50 \%$ above base & 0.72 & 0.85 & 1.04 & 1.28 & 1.56 & 1.89 & 0.90 & 1.20 & 1.62 & 2.15 & 2.81 & 3.58 \\
\hline growth boundary & - & - & 1.00 & 1.30 & 1.63 & 2.00 & - & - & 1.58 & 2.12 & 2.78 & 3.56 \\
\hline perim $L$ price $5 \mathrm{x}$ anchor & 1.06 & 1.12 & 1.25 & 1.44 & 1.68 & 1.98 & 1.08 & 1.27 & 1.63 & 2.14 & 2.79 & 3.56 \\
\hline \multicolumn{13}{|l|}{ Unanchored Systems } \\
\hline$\lambda=3 / 4$ (self-driving cars I) & 0.75 & 0.85 & 1.00 & 1.20 & 1.44 & 1.74 & 0.85 & 1.10 & 1.45 & 1.90 & 2.47 & 3.15 \\
\hline$\lambda=1 @ 50 \rightarrow 1 / 2 @ 10 \mathrm{mph}(\mathrm{II})$ & 0.77 & 0.86 & 1.00 & 1.19 & 1.43 & 1.71 & 0.85 & 1.09 & 1.45 & 1.92 & 2.52 & 3.25 \\
\hline$\sigma_{\mathrm{L}}=1.25$ (multifamily I) & 0.68 & 0.80 & 1.00 & 1.28 & 1.68 & 2.27 & 0.83 & 1.12 & 1.50 & 1.98 & 2.53 & 3.11 \\
\hline$\sigma_{\mathrm{L}}=1.33$ (multifamily II) & 0.67 & 0.80 & 1.00 & 1.31 & 1.76 & 2.41 & 0.83 & 1.11 & 1.49 & 1.95 & 2.45 & 2.89 \\
\hline
\end{tabular}

Table B.13: Other Alternatives: Housing Prices versus TFP. Alternative assumptions apply to all metros, including the anchor. Alt metro scenarios apply only to one or a handful of metros. Unanchored scenarios lack observed outcomes to which to be calibrated. For each scenario, the population-weighted mean price of housing in the anchor metro is normalized to 1. 


\begin{tabular}{|c|c|c|c|c|c|c|c|c|c|c|c|c|}
\hline \multirow{2}{*}{$\begin{array}{l}\text { Alternative } \\
\text { Assumptions } \\
\text { and Metros }\end{array}$} & \multicolumn{6}{|c|}{ mean price of land services } & \multicolumn{6}{|c|}{ inner price of land services } \\
\hline & $\begin{array}{r}@ \mathrm{tfp} \\
0.90\end{array}$ & $\begin{array}{r}@ \mathrm{tfp} \\
0.95\end{array}$ & $\begin{array}{r}@ \mathrm{tfp} \\
1.00\end{array}$ & $\begin{array}{r}@ \mathrm{tfp} \\
1.05\end{array}$ & $\begin{array}{r}@ \mathrm{tfp} \\
1.10\end{array}$ & $\begin{array}{r}@ \mathrm{tfp} \\
1.15\end{array}$ & $\begin{array}{r}@ \mathrm{tfp} \\
0.90\end{array}$ & $\begin{array}{r}@ \mathrm{tfp} \\
0.95\end{array}$ & $\begin{array}{r}@ \mathrm{tfp} \\
1.00\end{array}$ & $\begin{array}{r}@ \operatorname{tfp} \\
1.05\end{array}$ & $\begin{array}{r}@ \mathrm{tfp} \\
1.10\end{array}$ & $\begin{array}{r}@ \mathrm{tfp} \\
1.15\end{array}$ \\
\hline Baseline & 0.31 & 0.54 & 1.00 & 1.86 & 3.34 & 5.75 & 0.56 & 1.30 & 2.95 & 6.23 & 12.11 & 21.84 \\
\hline \multicolumn{13}{|l|}{ Alt Assumptions } \\
\hline fixed wrkhrs, Frisch ${ }_{\mathrm{A}, 1}=0.20$ & 0.30 & 0.53 & 1.00 & 1.91 & 4.03 & 6.38 & 0.55 & 1.29 & 2.95 & 6.25 & 13.80 & 22.03 \\
\hline fixed wrkhrs, Frisch ${ }_{\mathrm{A}, 1}=0.10$ & 0.24 & 0.48 & 1.00 & 2.06 & 4.09 & 7.64 & 0.52 & 1.29 & 3.01 & 6.43 & 12.56 & 22.69 \\
\hline rebate $\mathrm{H}$ factor incm & 0.37 & 0.59 & 1.00 & 1.69 & 2.82 & 4.56 & 0.67 & 1.40 & 2.86 & 5.49 & 9.92 & 16.92 \\
\hline rebate $\mathrm{X}+\mathrm{H}$ factor incm & 0.52 & 0.71 & 1.00 & 1.42 & 2.02 & 2.85 & 0.94 & 1.58 & 2.59 & 4.15 & 6.45 & 9.73 \\
\hline endog $\mathrm{CBD}$ radius & 0.28 & 0.53 & 1.00 & 1.80 & 3.09 & 5.05 & 0.48 & 1.28 & 2.95 & 6.07 & 11.40 & 19.89 \\
\hline TFP varies for $\mathrm{X} \& \mathrm{H}$ & 0.28 & 0.50 & 1.00 & 2.03 & 4.02 & 7.58 & 0.47 & 1.17 & 2.95 & 6.90 & 14.75 & 29.03 \\
\hline TFP varies for $\mathrm{H}$ only & 0.84 & 0.92 & 1.00 & 1.09 & 1.18 & 1.27 & 2.37 & 2.65 & 2.95 & 3.27 & 3.60 & 3.95 \\
\hline \multicolumn{13}{|l|}{ Alternative Metros } \\
\hline minimum speed $27 \mathrm{mph}$ & 0.31 & 0.54 & 1.00 & 1.95 & 3.58 & 6.12 & 0.56 & 1.30 & 2.95 & 6.04 & 11.18 & 19.23 \\
\hline constant speed $27 \mathrm{mph}$ & 0.34 & 0.62 & 1.17 & 2.15 & 3.77 & 6.30 & 0.63 & 1.46 & 3.14 & 6.18 & 11.28 & 19.32 \\
\hline constant speed $33 \mathrm{mph}$ & 0.33 & 0.59 & 1.11 & 2.03 & 3.56 & 5.94 & 0.61 & 1.39 & 2.98 & 5.89 & 10.76 & 18.44 \\
\hline constant speed $50 \mathrm{mph}$ & 0.31 & 0.54 & 1.00 & 1.81 & 3.15 & 5.25 & 0.56 & 1.26 & 2.69 & 5.30 & 9.70 & 16.65 \\
\hline$\sigma_{\mathrm{V}}=0.94$ (0.92 in anchor) & 0.31 & 0.54 & 0.99 & 1.84 & 3.27 & 5.58 & 0.56 & 1.27 & 2.83 & 5.86 & 11.21 & 20.02 \\
\hline$\sigma_{\mathrm{V}}=0.90$ (0.92 in anchor) & 0.31 & 0.54 & 1.00 & 1.87 & 3.39 & 6.14 & 0.56 & 1.32 & 3.08 & 6.61 & 12.96 & 23.38 \\
\hline 4-day workweek & 0.30 & 0.51 & 0.95 & 1.77 & 3.19 & 5.51 & 0.53 & 1.25 & 2.87 & 6.11 & 11.95 & 21.63 \\
\hline telecommute 1 day per wk & 0.30 & 0.51 & 0.94 & 1.74 & 3.14 & 5.40 & 0.53 & 1.23 & 2.82 & 5.98 & 11.69 & 21.17 \\
\hline dist cost $50 \%$ above base & 0.33 & 0.60 & 1.12 & 2.07 & 3.68 & 6.24 & 0.62 & 1.43 & 3.18 & 6.56 & 12.53 & 22.35 \\
\hline growth boundary & - & - & 1.00 & 2.05 & 3.83 & 6.60 & - & - & 2.95 & 6.30 & 12.25 & 22.05 \\
\hline perim L price $5 x$ anchor & 0.99 & 1.18 & 1.64 & 2.53 & 4.04 & 6.48 & 1.06 & 1.67 & 3.24 & 6.47 & 12.31 & 22.02 \\
\hline \multicolumn{13}{|l|}{ Unanchored Systems } \\
\hline$\lambda=3 / 4$ (self-driving cars I) & 0.39 & 0.59 & 1.00 & 1.74 & 3.01 & 5.12 & 0.56 & 1.17 & 2.51 & 5.11 & 9.80 & 17.60 \\
\hline$\lambda=1 @ 50 \rightarrow^{1 / 2} @ 10 \mathrm{mph}(\mathrm{II})$ & 0.43 & 0.61 & 1.00 & 1.73 & 2.99 & 5.06 & 0.57 & 1.16 & 2.52 & 5.31 & 10.44 & 19.14 \\
\hline$\sigma_{\mathrm{L}}=1.25$ (multifamily I) & 0.29 & 0.48 & 1.00 & 2.61 & 9 & 39 & 0.48 & 1.11 & 2.97 & 8.95 & 31 & 120 \\
\hline$\sigma_{\mathrm{L}}=1.33$ (multifamily II) & 0.28 & 0.47 & 1.00 & 2.98 & 14 & 112 & 0.46 & 1.06 & 2.97 & 10.23 & 47 & 280 \\
\hline
\end{tabular}

Table B.14: Other Alternatives: Land Prices versus TFP. Alternative assumptions apply to all metros, including the anchor. Alt metro scenarios apply only to one or a handful of metros. Unanchored scenarios lack observed outcomes to which to be calibrated. For each scenario, the population-weighted mean price of land in the anchor metro is normalized to 1. 